\title{
NOBLE METAL CHEMISTY AND HYDROGEN GENERATION DURING SIMULATED DWPF MELTER FEED PREPARATION
}

D. C. Koopman

June 2008

E\&CPT Research Programs

Savannah River National Laboratory Aiken, SC 29808

Prepared for the U.S. Department of Energy Under Contract Number DEAC09-96SR18500

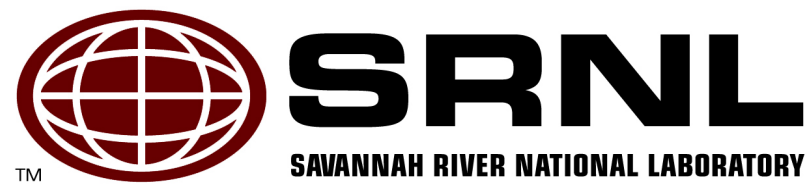




\section{DISCLAIMER}

This report was prepared by Washington Savannah River Company (WSRC) for the United States Department of Energy under Contract No. DE-AC09-96SR18500 and is an account of work performed under that contract. Neither the United States Department of Energy, nor WSRC, nor any of their employees makes any warranty, expressed or implied, or assumes any legal liability or responsibility for the accuracy, completeness, or usefulness, of any information, apparatus, or product or process disclosed herein or represents that its use will not infringe privately owned rights. Reference herein to any specific commercial product, process, or service by trademark, name, manufacturer or otherwise does not necessarily constitute or imply endorsement, recommendation, or favoring of same by WSRC or by the United States Government or any agency thereof. The views and opinions of the authors expressed herein do not necessarily state or reflect those of the United States Government or any agency thereof.

\section{Printed in the United States of America \\ Prepared For U.S. Department of Energy}


Key Words: DWPF, Hydrogen, Noble Metals, Catalysis, SRAT, SME

Retention: Permanent

\section{NOBLE METAL CHEMISTY AND HYDROGEN GENERATION DURING SIMULATED DWPF MELTER FEED PREPARATION}

D. C. Koopman

June 2008

E\&CPT Research Programs

Savannah River National Laboratory Aiken, SC 29808

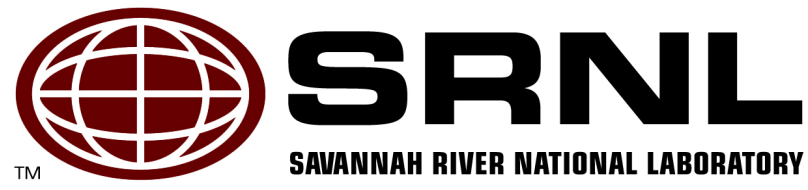




\section{REVIEWS AND APPROVALS}

\section{AUTHOR:}

D. C. Koopman, Process Engineering Technology

Date

\section{TECHNICAL REVIEWERS:}

J. D. Newell, Process Engineering Technology

Date

M. E. Stone, Process Engineering Technology

Date

\section{APPROVERS:}

J. C. Griffin, Research Programs Manager, E\&CPT

Date

C. C. Herman, Manager, Process Engineering Technology

Date

J. E. Occhipinti, Manager, Process Cognizant Engineering

Date

Waste Solidification Engineering 


\section{EXECUTIVE SUMMARY}

Simulations of the Defense Waste Processing Facility (DWPF) Chemical Processing Cell vessels were performed with the primary purpose of producing melter feeds for the beaded frit program plus obtaining samples of simulated slurries containing high concentrations of noble metals for off-site analytical studies for the hydrogen program. Eight pairs of 22-L simulations were performed of the Sludge Receipt and Adjustment Tank (SRAT) and Slurry Mix Evaporator (SME) cycles. These sixteen simulations did not contain mercury. Six pairs were trimmed with a single noble metal $(\mathrm{Ag}, \mathrm{Pd}, \mathrm{Rh}$, or $\mathrm{Ru})$. One pair had all four noble metals, and one pair had no noble metals. One supporting 4-L simulation was completed with $\mathrm{Ru}$ and $\mathrm{Hg}$. Several other 4-L supporting tests with mercury have not yet been performed.

This report covers the calculations performed on SRNL analytical and process data related to the noble metals and hydrogen generation. It was originally envisioned as a supporting document for the off-site analytical studies. Significant new findings were made, and many previous hypotheses and findings were given additional support as summarized below.

The timing of hydrogen generation events was reproduced very well within each of the eight pairs of runs, e.g. the onset of hydrogen, peak in hydrogen, etc. occurred at nearly identical times. Peak generation rates and total SRAT masses of $\mathrm{CO}_{2}$ and oxides of nitrogen were reproduced well. Comparable measures for hydrogen were reproduced with more variability, but still reasonably well. The extent of the reproducibility of the results validates the conclusions that were drawn from the data. Supported and confirmed hypotheses include:

- During single noble metal tests, rhodium at $0.2 \mathrm{wt} \%$ produced the maximum SRAT hydrogen generation rate, while ruthenium at $0.2 \mathrm{wt} \%$ drove the largest peak area in terms of total hydrogen mass. Palladium and silver made minimal amounts of hydrogen at $0.2 \mathrm{wt} \%$ noble metal.

- The peak hydrogen generation rate decreased when $\mathrm{Rh}$ concentration was doubled from 0.1 to $0.2 \mathrm{wt} \%$ in both the frit pair and the bead pair. This confirmed a single result from the 2005 form of noble metal testing.

- Increasing $\mathrm{Ru}$ by $87 \%$ increased the SRAT peak hydrogen generation rate about $100 \%$ and the total mass of hydrogen produced by $30-50 \%$. It was expected that more $\mathrm{Ru}$ would produce more $\mathrm{H}_{2}$ everything else being equal.

- Nitrite destruction was traditionally believed to be a prerequisite for all noble metal catalyzed hydrogen generation. In this testing, nitrite destruction appeared to be a prerequisite for the initiation of Ru-catalyzed hydrogen generation.

- Nitrite destruction and hydrogen data from testing with $\mathrm{Rh}$ suggested that sufficient nitrite remained for a nitro-Rh complex to be present at the time of the peak hydrogen generation rate, i.e. Rh appeared to activate while the nitrite concentration was still comparable to the $\mathrm{Rh}$ concentration. Nitro-Rh complexes were proposed as the most active catalyst for hydrogen generation in the 1991-2 University of Georgia study. Circumstantial data supporting this were obtained in the bead-frit tests. Supernate 
concentration data indicated that most of the $\mathrm{Rh}$ was no longer in the supernate, i.e. only a small fraction of the Rh may have been producing the hydrogen.

- The hydrogen generation rate following the peak declined nearly linearly with the supernate $\mathrm{Ru}$ concentration. The $\mathrm{Rh}$ peak and decline occurred too rapidly to obtain comparable data. Similar behavior was observed for both $\mathrm{Rh}$ and $\mathrm{Ru}$ in the 2005 form of noble metal testing.

- SME cycle hydrogen results depended greatly on SRAT cycle behavior. Generally, the initial SME cycle hydrogen generation rate was slightly higher than the final SRAT cycle hydrogen generation rate due to the formic acid added with the first frit addition.

Major new noble metal dissolution and hydrogen generation correlations and findings from these tests include:

- Insoluble Rh dissolved during SRAT acid addition and was precipitating about the time of the maximum hydrogen generation rate.

- Palladium dissolved before $\mathrm{Rh}$ and $\mathrm{Ru}$ during SRAT acid addition, and then began precipitating before significant hydrogen generation. Pd-induced hydrogen generation was about 20 times less than $\mathrm{Rh}$ or $\mathrm{Ru}$ at the same noble metal mass loading.

- $\mathrm{Ru}$ began dissolving about the same time as $\mathrm{Rh}$ and then also began precipitating. Data indicate that $\mathrm{Ru}$ underwent a second dissolution-precipitation sequence during the SRAT cycle. The second sequence generally corresponded with the onset, peak, and decline of hydrogen generation during Ru testing and occurred after nitrite destruction.

- Silver did not appear to dissolve. The Ag tests produced more hydrogen than the no noble metal tests indicating that Ag was a weak catalyst for hydrogen generation.

- Combining all four noble metals led to a smaller SRAT peak hydrogen generation rate than in the corresponding runs with matching concentrations of either $\mathrm{Rh}$ or $\mathrm{Ru}$ alone. The four noble metal combination, however, destroyed the most formate.

- Mercury, initially at $1.5 \mathrm{wt} \%$ in the total solids, did not inhibit hydrogen generation at 0.2 $\mathrm{wt} \% \mathrm{Ru}$. Hydrogen generation seemed to begin sooner when mercury was present, however, and nitrite appeared to be destroyed sooner as well.

The data indicate that it is likely that either a freshly precipitated form of $\mathrm{Rh}$ or a nitro-Rh complex was responsible for the maximum in the SRAT hydrogen generation rate profile. Both were potentially present at the time of the peak. A precipitated $\mathrm{Rh}$ species may include coprecipitated $\mathrm{Ru}$ in normal tests, since $\mathrm{Ru}$ was observed to be precipitating at the same time as Rh. A nitro-Rh complex may have been bound to the insoluble solids somehow, since most of the Rh was not in the supernate during the time of maximum hydrogen generation.

Available SRNL sample analytical methods do not give information on the form of insoluble noble metals. Samples were obtained for off-site analysis by X-ray Absorption spectroscopy (XAS). Ideally, these spectra will provide additional information about the oxidation state and presence of other transition metal atoms in the vicinity of the noble metals. 


\section{TABLE OF CONTENTS}

EXECUTIVE SUMMARY ..................................................................................................

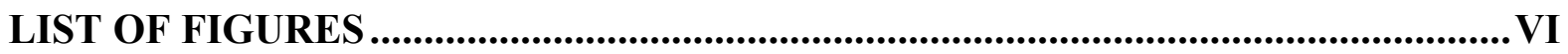

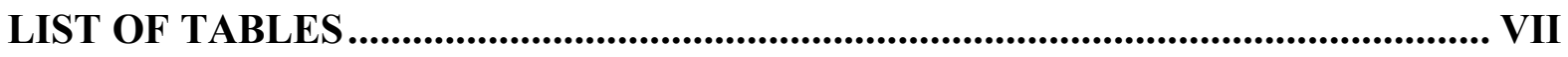

LIST OF ACRONYMS ............................................................................................

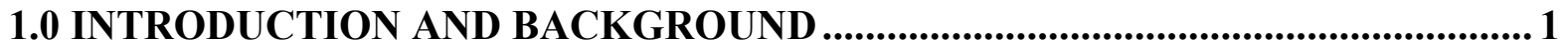

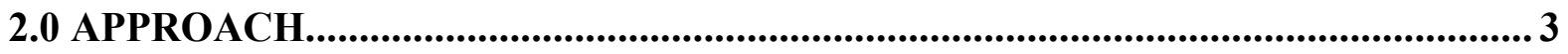

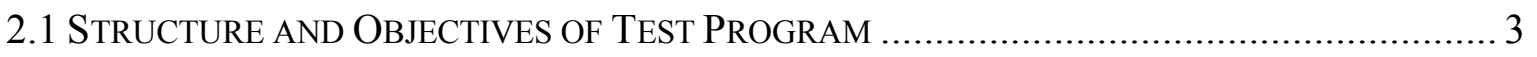

2.2 Chemical Process Cell Simulation Details................................................... 5

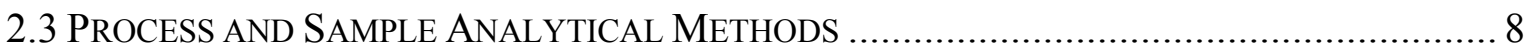

2.4 PROCESS MODELING AND CALCULATIONS …………......................................... 10

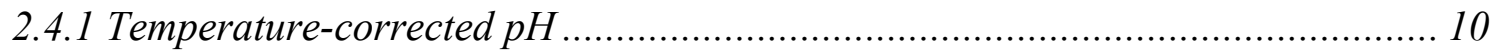

2.4.2 DWPF-scale Hydrogen Generation Rate ...................................................... 10

2.4.3 Extent of Dissolution of a Cation ................................................................. 10

2.4.4 Dissolution-Precipitation Model................................................................ 12

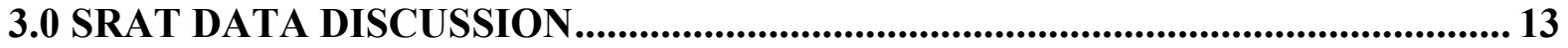

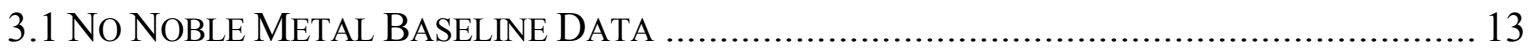

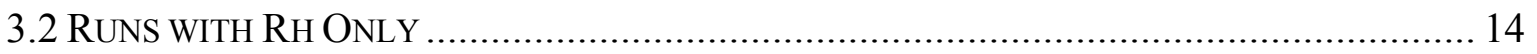

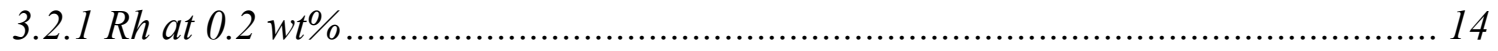

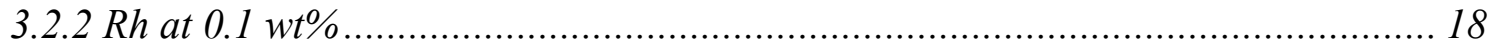

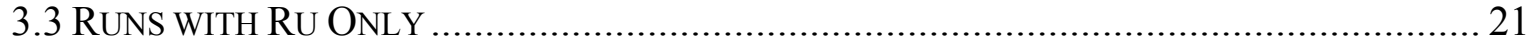

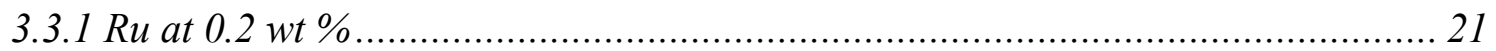

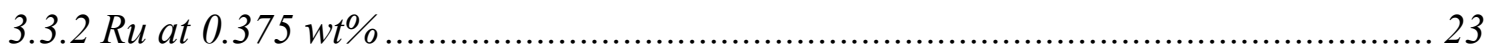

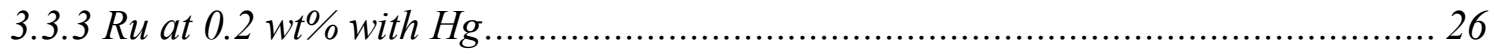

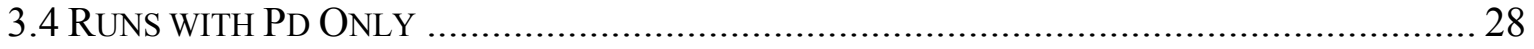

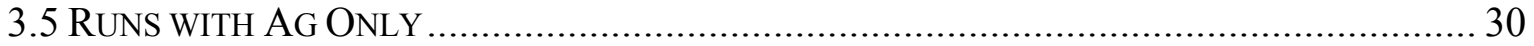

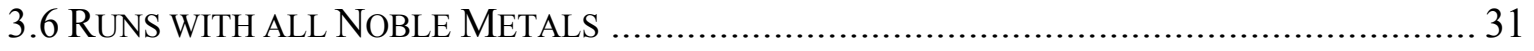

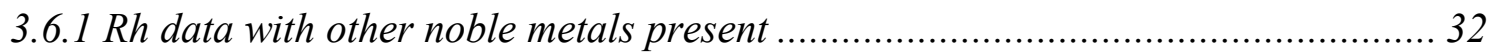

3.6.2 Ru data with other noble metals present ........................................................ 34

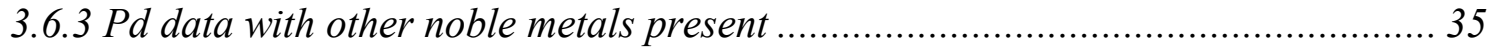

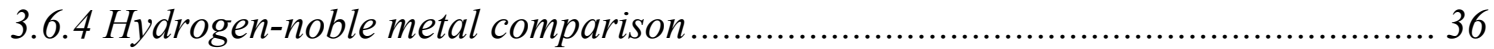

3.7 SUMMARY OF SRAT HYDROGEN - NOBLE METAL DATA ........................................... 37

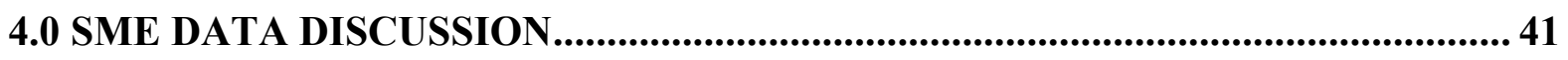

4.1 Ru ONLY RunS AND ALL Noble Metal RunS ...................................................... 41

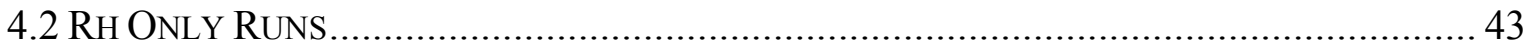

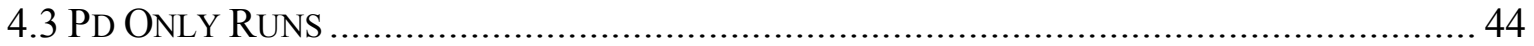

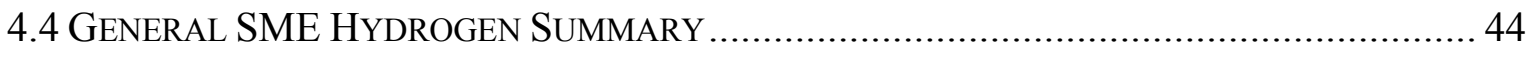

5.0 INSIGHTS FROM LITERATURE AND PAST REPORTS ...................................49

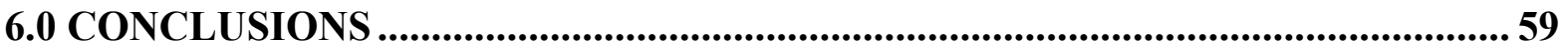




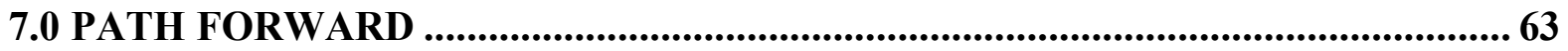

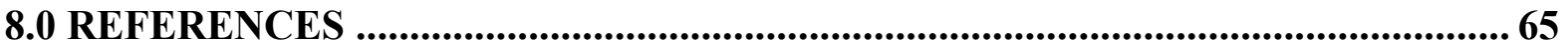

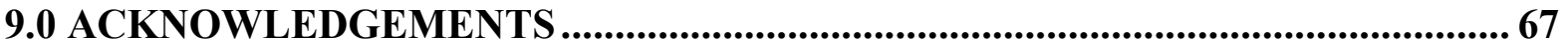

\section{LIST OF FIGURES}

Figure 1. Hydrogen generation in the absence of noble metals ......................................... 14

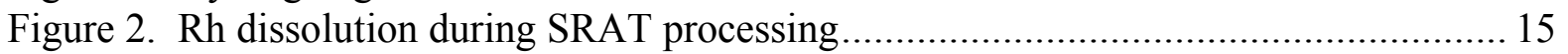

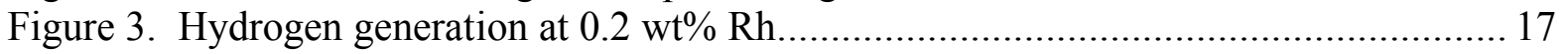

Figure 4. Hydrogen generation at $0.2 \mathrm{wt} \% \mathrm{Rh}$ after the SRAT peak .................................. 18

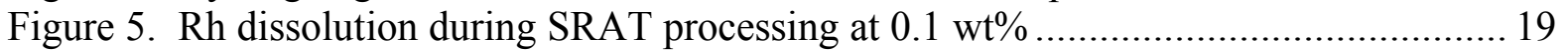

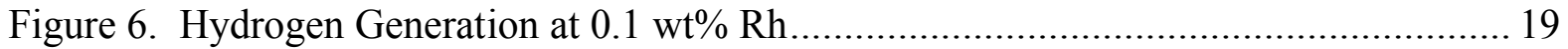

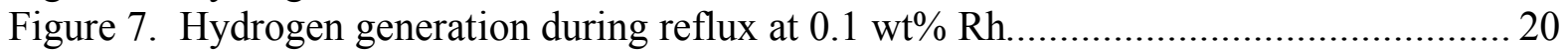

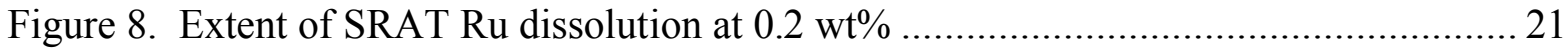

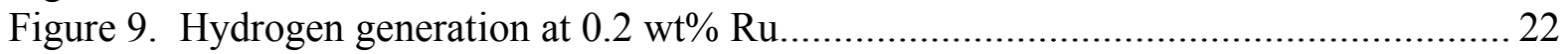

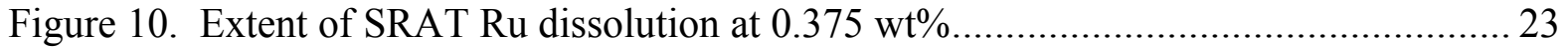

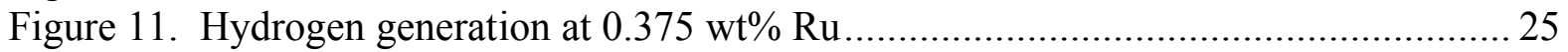

Figure 12. Hydrogen generation rate vs. Ru dissolution at $0.375 \mathrm{wt} \%$............................... 26

Figure 13. Extent of Ru dissolution with and without $\mathrm{Hg}$................................................. 27

Figure 14. Hydrogen generation at $0.2 \mathrm{wt} \% \mathrm{Ru}$ with and without $\mathrm{Hg}$................................ 27

Figure 15. Pd dissolution during SRAT processing ………................................................ 29

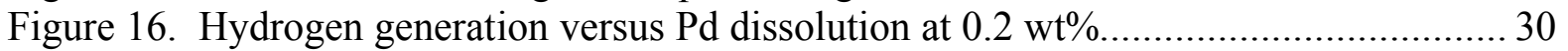

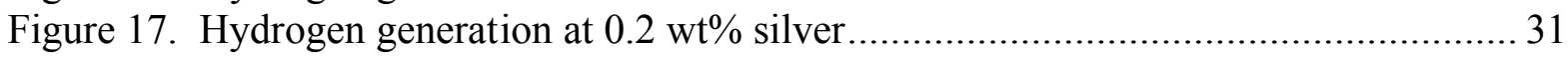

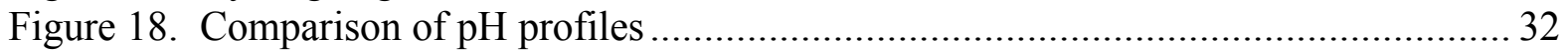

Figure 19. Rh dissolution during processing with all noble metals..................................... 32

Figure 20. Hydrogen generation from all noble metals with Rh data .................................. 33

Figure 21. Extent of SRAT Ru dissolution at $0.375 \mathrm{wt} \%$ with other noble metals................ 34

Figure 22. Hydrogen generation vs. Ru dissolution with other noble metals ....................... 35

Figure 23. Pd dissolution at $0.1 \mathrm{wt} \%$ in the presence of other noble metals ........................ 35

Figure 24. Comparison of $\mathrm{pH}$ profiles for $\mathrm{Pd}$ with/without other noble metals..................... 36

Figure 25. Hydrogen and noble metal supernate concentration.......................................... 37

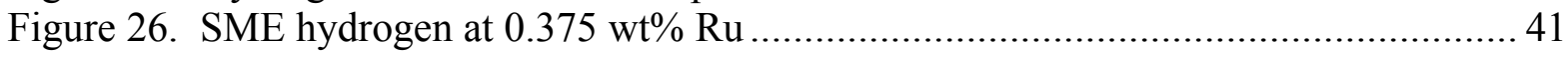

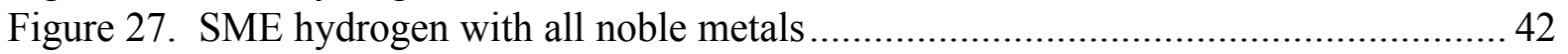

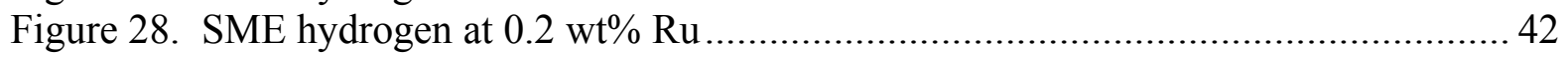

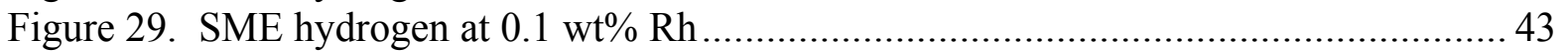

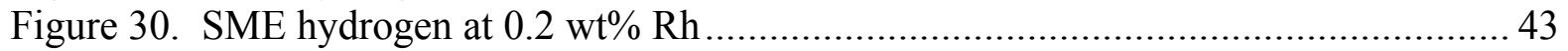

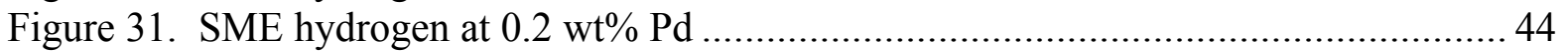

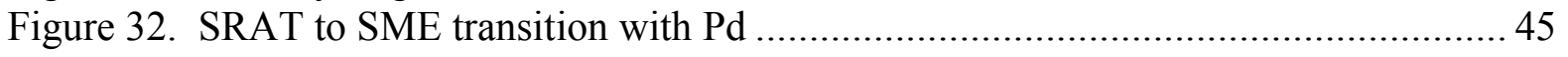

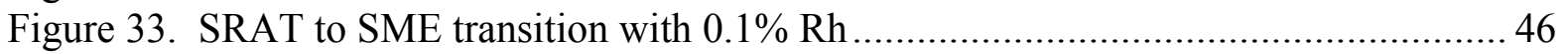

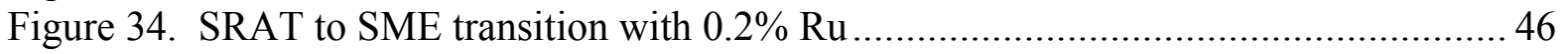

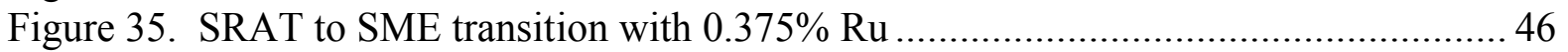

Figure 36. Reprint of Figure 5 from Hsu and Ritter ........................................................... 49

Figure 37. Bead run analog to Hsu and Ritter plot........................................................ 50

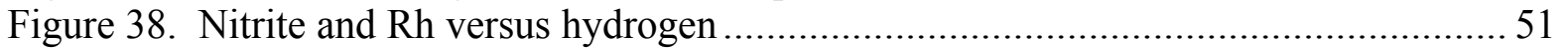




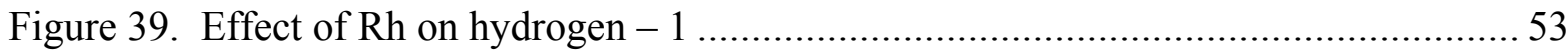

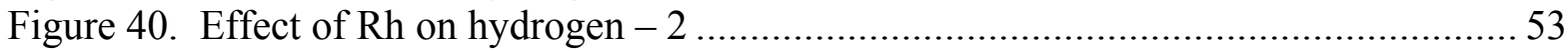

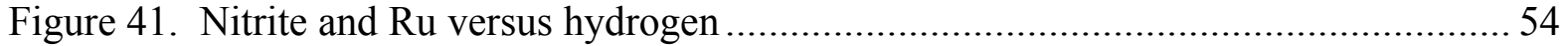

Figure 42. Hydrogen decline as Ru precipitates $(0.2 \mathrm{wt} \%)$......................................... 55

Figure 43. Hydrogen decline as Ru precipitates $(0.375 \mathrm{wt} \%)$........................................ 56

\section{LIST OF TABLES}

Table 1. Trim Chemical Ranges .............................................................................. 2

Table 2. Test Matrix for 22-L Simulations ............................................................... 4

Table 3. Wt\% Calcined Elemental Composition of Sludge ......................................... 5

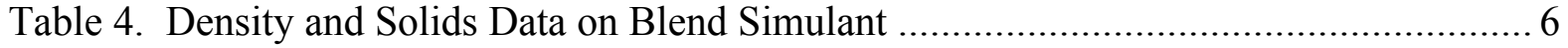

Table 5. Anion Data on Blend Simulant ....................................................................... 6

Table 6. Summary of Maximum Rate and Total Hydrogen Production............................... 38

Table 7. Summary of SME Maximum Rate and Total Hydrogen Production..................... 44 


\section{LIST OF ACRONYMS}

$\begin{array}{ll}\text { ACTL } & \text { Aiken County Technology Laboratory } \\ \text { AD } & \text { Analytical Development } \\ \text { ASP } & \text { Analytical Study Plan } \\ \text { BFMT } & \text { Bead-Frit Matching Test } \\ \text { CPC } & \text { Chemical Process Cell } \\ \text { DWPF } & \text { Defense Waste Processing Facility } \\ \text { E\&CPT } & \text { Environmental and Chemical Process Technology } \\ \text { EXAFS } & \text { Extended XAFS } \\ \text { FAVC } & \text { Formic Acid Vent Condenser } \\ \text { GC } & \text { Gas Chromatograph } \\ \text { HM } & \text { H-canyon Modified Purex process } \\ \text { H2Bead } & \text { Run prefix for a 22-L simulation with beaded frit 418 } \\ \text { H2Frit } & \text { Run prefix for a 22-L simulation with regular frit 418 } \\ \text { IC } & \text { Ion Chromatography } \\ \text { ICP-AES } & \text { Inductively Coupled Plasma-Atomic Emission Spectroscopy } \\ \text { ICP-MS } & \text { Inductively Coupled Plasma-Mass Spectroscopy } \\ \text { ISE } & \text { Ion Selective Electrode } \\ \text { LWO } & \text { Liquid Waste Operations } \\ \text { MWWT } & \text { Mercury Water Wash Tank } \\ \text { ORP } & \text { Oxidation-Reduction Probe } \\ \text { PSAL } & \text { Process Science Analytical Laboratory } \\ \text { ppm } & \text { parts per million } \\ \text { QA } & \text { Quality Assurance } \\ \text { SME } & \text { Slurry Mix Evaporator } \\ \text { SRAT } & \text { Sludge Receipt and Adjustment Tank } \\ \text { SRNL } & \text { Savannah River National Laboratory } \\ \text { TA } & \text { Technical Analyst } \\ \text { TIC } & \text { Total Inorganic Carbon } \\ \text { TR } & \text { Technical Report } \\ \text { TT\&QAP } & \text { Task Technical and Quality Assurance Plan } \\ \text { TTR } & \text { Task Technical Request } \\ \text { WSRC } & \text { Washington Savannah River Company } \\ \text { XAFS } & \text { X-ray Absorption Fine Structure spectroscopy } \\ \text { XANES } & \text { X-ray Absorption, Near-Edge Structure spectroscopy } \\ \text { XAS } & \text { X-ray Absorption Spectroscopy } \\ & \end{array}$




\subsection{INTRODUCTION AND BACKGROUND}

Due to the higher than expected hydrogen generation during the Tank 51-SB4 qualification run, DWPF engineering requested the Savannah River National Laboratory (SRNL) to expand the ongoing catalytic hydrogen generation program in order to increase process chemistry understanding in the DWPF Sludge Receipt and Adjustment Tank and Slurry Mix Evaporator (SRAT and SME respectively).

The work presented in this Technical Report was identified as part of SRNL/Liquid Waste Organization (LWO) meetings to define potential causes of catalytic hydrogen generation as well as from an external technical review panel commissioned to evaluate SRNL hydrogen related data and programs. ${ }^{1}$ The work scope was covered under the technical task request: HLWDWPF-TTR-2007-0016. A task technical and quality assurance plan (TT\&QAP) was drafted to address the needs of the TTR which included issues that were raised in meetings with LWO plus some of the recommendations made by the review panel. ${ }^{2}$ A supporting analytical study plan was issued. ${ }^{3}$

The testing discussed here partially addresses the determination of the chemistry of noble metal activation, hydrogen generation, and noble metal deactivation (form/speciation/morphology of noble metals in the SRAT as a function of time. This test phase included more time dependent sampling of the SRAT to determine whether or not the noble metals were with the insoluble solids or in the supernate. This testing phase also included advanced analytical measurements, such as XAS (x-ray absorption spectroscopy). XAS includes XAFS or X-ray Absorption FineStructure spectroscopy, EXAFS or extended XAFS, and XANES or X-ray Absorption, Nearedge Structure spectroscopy. XAS data are obtained off-site, e.g. at Argonne and Brookhaven National Laboratories. These measurements were intended to determine the oxidation states of, and the nearest neighbor elements to, the individual noble metals. This report summarizes the analysis of SRNL samples and processing data intended to provide context for the XAS work. Sample results from the off-site lab work will be presented in separate reports. The first XAS report will cover Ru samples. ${ }^{4}$

The majority of the results presented in this report come from samples and process data obtained during sixteen 22-L SRAT/SME simulations that were performed in the second half of 2007 to produce eight SME products with frit 418 and a matching set of eight SME products with spherically beaded frit 418 . The requirement to produce two 25 gallon batches of melter feed to compare beaded frit to regular frit fell under a separate task plan. ${ }^{5}$ One 4-L process simulation was performed solely for the catalytic hydrogen generation program to produce some XAS samples containing mercury with $\mathrm{Ru}$, since the 22-L simulations did not have mercury. Two additional 4-L runs are needed to produce XAS samples containing high concentrations of Rh with $\mathrm{Hg}$ and high concentrations of all noble metals with $\mathrm{Hg}$. A follow-up to this report will be issued to summarize processing data once those SRAT runs are completed.

A third report covers the information that was obtained on acid consumption and general SRAT chemistry. ${ }^{6}$ Additional reports are planned as XAS data become available for samples with Rh (with $\mathrm{Ru}$ and/or $\mathrm{Hg}$ and/or other noble metals). Each of these reports addresses one or more of 
the recommendations of the catalytic hydrogen review panel and the proposed tasks in the catalytic hydrogen generation program TT\&QAP. ${ }^{2}$ The results of the beaded-frit melter feed testing (rheology, settling, sampling characteristics, etc.) are discussed in a separate report.

Simulant preparation and preliminary flowsheet studies were performed prior to this task in order to produce a sufficient quantity of material for the planned testing and to define a suitable acid addition stoichiometry. This work has already been documented. ${ }^{7}$ The noble metal and mercury baseline in this work is summarized in Table 1 along with the ranges covered in the beaded frit melter feed preparation study.

Table 1. Trim Chemical Ranges

\begin{tabular}{|l|c|c|}
\hline $\begin{array}{l}\text { Trim } \\
\text { Element }\end{array}$ & $\begin{array}{c}\text { Baseline Runs } \\
\mathrm{wt} \%\end{array}$ & $\begin{array}{c}\text { This Study } \\
\mathrm{wt} \%\end{array}$ \\
\hline $\mathrm{Ag}$ & 0.0030 & $0-0.20$ \\
\hline $\mathrm{Pd}$ & 0.0010 & $0-0.20$ \\
\hline $\mathrm{Rh}$ & 0.0078 & $0-0.20$ \\
\hline $\mathrm{Ru}$ & 0.0300 & $0-0.375$ \\
\hline $\mathrm{Hg}$ & 1.5000 & $0-1.50$ \\
\hline
\end{tabular}

This study increased the noble metal concentrations to values more than an order of magnitude higher than in the baseline testing. The primary driver for this increase was to produce samples containing noble metals at concentrations above the XAS detection limits. It was recognized that this might produce some extreme catalytic chemistry compared to conventional flowsheet simulations. In particular, the testing with high levels of $\mathrm{Rh}$ and $\mathrm{Ru}$ were expected to produce significant quantities of hydrogen with maximum rates exceeding the scaled equivalent to 0.65 $\mathrm{lbs} / \mathrm{hr}$ in the DWPF SRAT and $0.223 \mathrm{lbs} / \mathrm{hr}$ in the DWPF SME. 


\subsection{APPROACH}

\subsection{Structure and Objectives of Test Program}

Sixteen SRAT/SME simulations were performed using the 22-L SRAT-scale equipment at ACTL. The primary purpose of these sixteen simulations was to prepare 25 gallons of melter feed containing frit 418 plus a matching 25 gallons of melter feed where the frit 418 was replaced with spherical glass beads of frit 418 composition (bead 418). The two 25 gallon batches of melter feed needed to have the same processing history in order to eliminate that as a source of variation in rheological and settling properties.

The eight individual SRAT/SME simulations needed to produce a single 25 gallon batch of melter feed did not need to be identical. The only requirement was that each SRAT/SME simulation with frit 418 had a matching SRAT/SME simulation with beads. A test structure consisting of eight pairs was proposed where the two runs within a given pair were identical in all respects except that one was given frit while the other was given beads during the SME cycle. In particular, SRAT cycles within a pair were as nearly identical as possible. SME cycles were nearly identical as well except for the substitution of bead 418 for frit 418 .

The task to improve understanding of catalytic hydrogen generation in the SRAT/SME needed to develop a program to characterize the behavior of the noble metals during processing. Existing methods to characterize the oxidation state and local environment around a specific atom such as $\mathrm{Rh}$ or $\mathrm{Ru}$ require techniques such as XAS. Detection limits of these methods require samples containing higher concentrations of the individual noble metals than are normally present in qualification simulations or sludge batch flowsheet simulations. In addition, some samples were needed that contained only individual noble metals rather than combinations of them.

The beaded-frit melter feed preparations were seen as an opportunity to make pairs of SRAT/SME simulations containing single noble metals at high concentrations. The 22-L scale of the simulations also meant that the required sample volumes would not be a potential issue (large sample volume is a bigger issue in the 4-L and smaller scale tests). Consequently, the sixteen 22-L simulations could be used to produce samples for XAS noble metal characterization studies as a second primary objective. The only constraint from the melter feed preparation program was that none of the 22-L runs could have mercury. Consequently, a few additional runs would be needed to produce samples that could assess interactions between noble metals and mercury. One such run has been completed containing $\mathrm{Ru}$ and $\mathrm{Hg}$.

The sixteen 22-L simulations were given the noble metal loadings and run identifiers listed in Table 2. 
Table 2. Test Matrix for 22-L Simulations

\begin{tabular}{|l|c|c|}
\hline Noble Metal Loading & Frit run with & Bead run with \\
\hline $0.2 \% \mathrm{Rh}$ & H2Frit1 & H2Bead10 \\
\hline $0.2 \% \mathrm{Ru}$ & H2Frit2 & H2Bead13 \\
\hline $0.2 \% \mathrm{Ag}$ & H2Frit3 & H2Bead9 \\
\hline $0.2 \% \mathrm{Pd}$ & H2Frit4 & H2Bead15 \\
\hline $0.375 \% \mathrm{Ru}$ & H2Frit5 & H2Bead 12 \\
\hline $0.1 \% \mathrm{Rh}$ & H2Frit6 & H2Bead16 \\
\hline No noble metals & H2Frit7 & H2Bead11 \\
\hline All noble metals & H2Frit8 & H2Bead14 \\
\hline
\end{tabular}

The first four pairs each had an identical mass loading of a single noble metal to permit direct comparisons of the relative effects. Molar loadings were nearly identical due to the narrow atomic weight range of $\mathrm{Ru}$ to $\mathrm{Ag}$ from 101-108. The all noble metals tests had $0.1 \mathrm{wt} \%$ each of $\mathrm{Ag}, \mathrm{Pd}$, and $\mathrm{Rh}$ along with $0.375 \mathrm{wt} \% \mathrm{Ru}$. This noble metal combination put the two key noble metals, $\mathrm{Rh}$ and $\mathrm{Ru}$, at their relative fission yields while having all noble metals at or above the minimum detection limits for the off-site lab methods. It also would permit direct comparisons of results with the pairs of runs at $0.1 \mathrm{wt} \% \mathrm{Rh}$ and at $0.375 \mathrm{wt} \% \mathrm{Ru}$. The no noble metals tests were performed to provide a baseline for the chemistry in the absence of noble metals. The need for baseline testing was confirmed after completing the initial Ag and Pd tests.

The sixteen simulations were successfully performed in pairs following the numerical sequence in Table 2. H2Frit1 and H2Frit2 were the first two simulations, and H2Bead15 and H2Bead16 were the last two simulations. Several months elapsed between the eight frit runs and the eight bead runs due to a delay in delivery of the beaded frit 418. The 4-L bead-frit matching test with $0.2 \mathrm{wt} \% \mathrm{Ru}$ and $1.5 \mathrm{wt} \% \mathrm{Hg}$ was performed during this interim period. The sequence of the bead runs was reordered relative to the frit runs for two reasons. The main reason was to have one high hydrogen producer and one low hydrogen producer in each of the last four pairs of runs. Equipment was modified in one hood (larger diameter off-gas line, increased air purge capacity, taller manometer) to better handle the high hydrogen generation rates during the second set of tests. Reordering the tests also tended to randomize some of the potential lab hood specific biases that might be present in the data.

The 22-L simulation scale, combined with the high noble metal concentrations, offered an opportunity to study SRAT-cycle noble metal dissolution behavior using the analytical methods available within SRNL. Scoping samples were taken during the eight frit runs. These samples developed the general characteristics of the dissolution behavior. Critical periods and significant gaps in the data were studied in the eight matching bead runs. This sampling met additional recommendations of the hydrogen review panel to study SRAT chemistry and to develop a timeline of the reactions that occur during processing. Obtaining these samples became a tertiary objective for the sixteen simulations.

There was a concern from the hydrogen review panel that the supernate samples might contain colloidal elemental noble metals rather than dissolved noble metals. The simulant used for the testing contained an $\mathrm{Al}(\mathrm{OH})_{3}$ with a nominal mean particle size of $250 \mathrm{~nm}$. Efficient removal of 
this species from the supernates indicates that any colloidal noble metals must be present as droplets less than $100 \mathrm{~nm}$ in size, since $\mathrm{Al}(\mathrm{OH})_{3}$ fines smaller than $250 \mathrm{~nm}$ were removed and the $\mathrm{Al}(\mathrm{OH})_{3}$ particles are less dense than elemental noble metals.

\subsection{Chemical Process Cell Simulation Details}

Simulated DWPF washed sludge was prepared for both the bead-frit melter feed comparison testing and the catalytic hydrogen generation program. ${ }^{7}$ The sludge was prepared by combining three generic simulants plus trim chemicals to produce a bulk composition intermediate between Purex and HM wastes with a supernate similar to recent sludge batches. The composition was determined using inductively coupled plasma-atomic emission spectroscopy (ICP-AES) and ion chromatography (IC). The nominal compositional data of the untrimmed simulant obtained from a sample of the blended simulant are summarized in the next three tables. This information gives a good overview as to the type of simulant that was used in this program without having to locate the referenced report. A few revisions and additions have been made to the original values as more data have become available. Also, general SRAT and SME product composition data are not included in this report, but are instead covered in the report on SRAT chemistry and acid consumption, so these tables provide the only internal documentation of the approximate simulant composition. ${ }^{6}$

The ABC blend simulant sample and eight SRAT receipt samples supporting the XAS work were analyzed in duplicate, and the results were averaged. The eight SRAT receipt sample averages were averaged to give the values in the SRAT receipt sample column.

Table 3. Wt\% Calcined Elemental Composition of Sludge

\begin{tabular}{|l|c|c|}
\hline & $\begin{array}{c}\text { ABC Blend Simulant } \\
\text { wt } \%\end{array}$ & $\begin{array}{c}\text { SRAT Receipt } \\
\text { wt\% (std. dev.) }\end{array}$ \\
\hline $\mathrm{Al}$ & 16.1 & $16.0(0.30)$ \\
\hline $\mathrm{Ba}$ & 0.221 & $0.207(0.006)$ \\
\hline $\mathrm{Ca}$ & 2.55 & $2.50(0.13)$ \\
\hline $\mathrm{Cr}$ & 0.163 & $0.148(0.006)$ \\
\hline $\mathrm{Cu}$ & 0.143 & $0.087(0.008)$ \\
\hline $\mathrm{Fe}$ & 21.8 & $21.4(0.76)$ \\
\hline $\mathrm{K}$ & 0.276 & $0.169(0.051)$ \\
\hline $\mathrm{Mg}$ & 1.76 & $1.45(0.077)$ \\
\hline $\mathrm{Mn}$ & 4.05 & $3.85(0.147)$ \\
\hline $\mathrm{Na}$ & 12.2 & $12.9(0.53)$ \\
\hline $\mathrm{Ni}$ & 0.998 & $0.847(0.023)$ \\
\hline $\mathrm{Pb}$ & 0.055 & $0.045(0.004)$ \\
\hline $\mathrm{Si}$ & 1.72 & $1.60(0.078)$ \\
\hline $\mathrm{Ti}$ & 0.018 & $0.019(0.001)$ \\
\hline $\mathrm{Zn}$ & 0.213 & $0.202(0.008)$ \\
\hline $\mathrm{Zr}$ & 0.628 & $0.426(0.019)$ \\
\hline
\end{tabular}


The standard deviations given in the SRAT receipt sample column were from averaging the averages of duplicate results for the eight different SRAT receipt samples. Results for the single sludge sample average were generally within two standard deviations from the corresponding average of averages for the SRAT receipt samples. Results for $\mathrm{Mg}$, Ni and $\mathrm{Zr}$ were exceptions. SRAT product compositions were checked to reduce uncertainties for these three elements (only). ICP-AES analyses of the SRAT products showed that $\mathrm{Ni}$ averaged $0.93 \%, \mathrm{Mg}$ averaged $1.69 \%$, and $\mathrm{Zr}$ averaged $0.46 \% .{ }^{6}$ The sludge $\mathrm{Zr}$ value is the only result that appears to be inconsistent with both SRAT receipt and SRAT product sample results. Table 4 gives the density and solids data.

Table 4. Density and Solids Data on Blend Simulant

\begin{tabular}{|l|c|}
\hline & ABC Blend Simulant \\
\hline Wt. \% total solids & 22.8 \\
\hline Wt. \% insoluble solids & 16.8 \\
\hline Wt. \% soluble solids & 6.0 \\
\hline Wt. \% calcined solids & 16.0 \\
\hline Slurry Density, g/mL & 1.175 \\
\hline Supernate Density, g/mL & 1.053 \\
\hline
\end{tabular}

Table 5 summarizes the available information on anions in the simulant. Values are per kg of the simulant slurry.

Table 5. Anion Data on Blend Simulant

\begin{tabular}{|l|r|}
\hline $\mathrm{ABC}$ Blend Simulant & $\mathrm{mg} / \mathrm{kg}$ \\
\hline $\mathrm{OH}^{-}$(by ion-mass balance) & 80,000 \\
\hline $\mathrm{NO}_{2}{ }^{-}$ & 17,950 \\
\hline $\mathrm{NO}_{3}{ }^{-}$ & 10,850 \\
\hline $\mathrm{O}^{2-}$ (by ion-mass balance) & 13,000 \\
\hline $\mathrm{C}_{2} \mathrm{O}_{4}{ }^{2-}$ (by recipe calculation) & 1,400 \\
\hline $\mathrm{PO}_{4}{ }^{3-}$ (by ICP P) & 160 \\
\hline $\mathrm{SO}_{4}{ }^{2-}$ (by IC) & 1,625 \\
\hline $\mathrm{SO}_{4}{ }^{2-}$ (by ICP S) & 1,350 \\
\hline $\mathrm{Total}^{-}$Inorganic Carbon & $849^{2}$ \\
\hline $\mathrm{Cl}^{-}$ & 390 \\
\hline $\mathrm{F}^{-}$(by recipe calculation) & 47 \\
\hline $\mathrm{HCO}_{2}{ }^{-}$ & 0 \\
\hline $1-$ revised to $13,790 \mathrm{mg} / \mathrm{kg}$ later & \\
$2-$ revised to $1,350 \mathrm{mg} / \mathrm{kg}$ later &
\end{tabular}

Fluoride was below the $100 \mathrm{mg} / \mathrm{kg}$ detection limit for IC, but was known to be present in the blend simulant from the recipe. A recipe calculation gave the value in Table 5. Oxalate was also reported at the calculated value from the recipe, since the weighted dilution preparation does not bring $100 \%$ of the oxalate ion into solution. Formate was shown at zero, since no formate species were added during recipe preparation. Phosphate was below the detection limit by IC, so 
it was calculated from the slurry ICP-AES value for phosphorous (a measure of total phosphate rather than soluble phosphate). Total sulfate calculated from ICP-AES sulfur was somewhat less than sulfate by IC but within reasonable expectations for analytical data. Subsequent sample data and analysis support a nitrate value of about $13,790 \mathrm{mg} / \mathrm{kg}$ and a total inorganic carbon value (TIC) of $1350 \mathrm{mg} / \mathrm{kg}$. TIC is assumed to be nearly $100 \%$ carbonate ion at the $\mathrm{pH}$ of the slurry. The measured anions account for less than $20 \%$ of the charge required to balance the cations. The balance of negative charge is present as insoluble oxide and soluble and/or insoluble hydroxide ion. A simultaneous mass and ion balance gives an approximate distribution of charge between the two from which the corresponding slurry concentrations can be calculated. The simulant was titrated using the ACTL auto-titrator to $\mathrm{pH}$ 7. The average result was $0.313 \mathrm{M}$ equivalent hydroxide.

About 14.4 L of untrimmed simulant was added to each SRAT vessel. The SRAT receipt volume was about $14.9 \mathrm{~L}$ with trim chemicals and flush water added. The nominal sludge composition was used to prepare an acid calculation for each of the eight pairs of 22-L simulations. Variations in nitrate due to the noble metal trim chemicals led to very minor differences in the ratio of nitric acid to formic acid. Formic acid made up about $91 \%$ of the total acid. A stoichiometric factor of $198 \%$ was chosen based on the preliminary acid window study. ${ }^{7}$ This factor led to an acid addition of 1.96 moles acid per liter of untrimmed simulant.

Nominal scaled DWPF SRAT/SME processing conditions were generally used; however, neither cycle had a heel from a prior batch.

- The air purge scaled to $230 \mathrm{scfm}$ in DWPF.

- A 200 ppm antifoam addition was made prior to nitric acid addition.

- Acid addition was at $93^{\circ} \mathrm{C}$.

- A 100 ppm antifoam addition was made prior to formic acid addition.

- Acid additions were at roughly two gallons per minute scaled from 6000 gallons to 14.9 L. Slurry volume reached a maximum of about $16.5 \mathrm{~L}$ following acid addition and antifoam additions (scaled gain of 645 gallons).

- A 500 ppm antifoam addition was made prior to going to boiling following acid addition. (No further antifoam additions were made until the SME cycle.)

- Boiling targeted the scaled equivalent to the DWPF maximum potential rate of 5000 $\mathrm{lbs} / \mathrm{hr}$, or about $29 \mathrm{~g} /$ minute. Dewatering was delayed by up to an hour in the three pairs of runs containing $\mathrm{Rh}$ due to the high hydrogen generation rates at the end of acid addition. Dewatering typically took about 50 minutes.

- Dewatering was followed by twelve hours of reflux. The end of reflux defined the end of the SRAT cycle.

- After SRAT product samples were pulled, the air purge was adjusted to the SME rate (equivalent to $74 \mathrm{scfm}$ in DWPF).

- A 100 ppm antifoam addition was made.

- This was followed by the first frit-water-formic acid slurry addition (or bead-waterformic acid). No canister decon dewatering periods were simulated in the SME cycle.

- After the first frit addition dewatering, the second frit-water-formic acid slurry addition was made, and the SME was concentrated to the target $\mathrm{wt} \%$ total solids. 
A complete SRAT/SME simulation took about 30-33 hours measured from the start of heating prior to acid addition in the SRAT until the time that the SME product had cooled to less than $50^{\circ} \mathrm{C}$. Simulations were run around the clock. The GC's were baked out between runs. The eight frit runs were performed the weeks of 7/9/07 and 7/16/07, while the eight bead runs were performed the weeks of 11/12/07 and 11/26/07.

\subsection{Process and Sample Analytical Methods}

The automated data acquisition system developed for the 4-L SRAT rigs was modified and used to collect electronic data from the sixteen 22-L SRAT/SME simulations on a PC. Data included SRAT temperature, bath temperatures for the cooling water to the SRAT condenser and Formic Acid Vent Condenser (FAVC), $\mathrm{pH}$, mixer speed and torque, air and helium purge flows (He is used as an internal standard and is set to $0.5 \%$ of the nominal SRAT or SME air purge flow), and raw gas chromatograph (GC) data. Acid addition data collected on the 4-L rigs from the automated dispensers was not collected from the MasterFlex pumps used on the 22-L rigs. Such data would have been approximate in any case since there are flow rate variations of $\pm 15 \%$ relative to the setpoint.

Agilent 3000A micro GC's were used on twelve of the sixteen runs. Four of the frit runs used an Agilent $200 \mathrm{H}$ micro GC. Both models have two columns. Column-A collects data related to He, $\mathrm{H}_{2}, \mathrm{O}_{2}, \mathrm{~N}_{2}$, NO, and $\mathrm{CO}$, while column-B collects data related to $\mathrm{CO}_{2}$ and $\mathrm{N}_{2} \mathrm{O}$. GC's were calibrated with a standard containing 0.499 vol $\% \mathrm{He}, 1.010 \mathrm{vol} \% \mathrm{H}_{2}, 20.00 \mathrm{vol} \% \mathrm{O}_{2}, 51.0 \mathrm{vol} \%$ $\mathrm{N}_{2}, 25.0 \mathrm{vol} \% \mathrm{CO}_{2}$ and $2.50 \mathrm{vol} \% \mathrm{~N}_{2} \mathrm{O}$. Air was also used to give a two point calibration for $\mathrm{N}_{2}$. $\mathrm{NO}$ vol\% data were obtained semi-quantitatively using the historical ratios of $\mathrm{He} / \mathrm{NO}$ area factors for the individual GC's, since no calibration gas with NO was available. No evidence for $\mathrm{CO}$ generation was obtained when examining the region of the chromatogram where it would elute.

The DWPF-scale hydrogen generation rate was calculated from the $\mathrm{H}_{2} / \mathrm{He}$ vol \% ratio, known He flow, and the scale factor for the test. He flow was controlled by an MKS mass flow controller. In several tests, step change testing of the He flow rate suggested that the MKS was improperly zeroed. Actual He flowrate was probably lower than indicated/targeted in all of these instances. This bias leads to calculated hydrogen generation rates that are higher than the actual rates. This issue has no impact on the timing of events, which was one of the primary observations being made.

The GC's were checked with calibration gas following the SRAT cycle and again following the SME cycle. GC operation was particularly problematic during the eight frit runs. GC data indicated that significant step changes in the sum of gases were occurring randomly during operation (as monitored during periods with little off-gas generation by adding $\mathrm{O}_{2}, \mathrm{~N}_{2}$ and $\mathrm{He}$ ). The sum could increase to the neighborhood of $125 \%$ or decline to the neighborhood of $80 \%$. The similarity of these two numbers (one is the inverse of the other) did not go unnoticed. It was suspected that something was temporarily impacting the column injection volumes, but sometimes it was removed during bake-out between runs. When these shifts were noticed during the runs, a period was allotted to collect additional data from the calibration gas cylinder at the expense of obtaining process data. Consequently, some GC data were lost, and some GC data 
received considerably post-run processing in an attempt to remove the effects of changing injection volumes. The post-processing was complicated by the fact that the two columns within the micro GC did not appear to be impacted equivalently by the shifts. The frequency of GC problems has been much higher in the past year or two than in the past, and a cause is being sought. Hydrogen data were apparently affected. The four tests labeled H2Frit1, 3, 5, and 7 appeared to be the most impacted by the GC issues. Data from the four matching tests, H2Bead10, H2Bead9, H2Bead12, and H2Bead11 respectively, were considered to be more reliable. Small sintered metal filters were obtained prior to the eight bead runs. These did not appear to have a large impact on the process data and seemed to mitigate some of the operational issues.

Most of the bead-frit tests had a $\mathrm{pH}$ probe in the SRAT slurry to monitor $\mathrm{pH}$ as hydrogen was evolved. Performance of this lot of $\mathrm{pH}$ probes was problematic, and it included many outright failures. Eight runs had a nitrate ion selective electrode (ISE) in the Mercury Water Wash Tank (MWWT) to monitor nitrate in the condensate, and six runs had on oxidation-reduction probe (ORP) in the SRAT up until boiling to monitor the reduction potential. One reason for the ORP was to determine whether an improved ORP should be purchased that could withstand boiling conditions and would monitor the oxidation-reduction potential during hydrogen generation.

Process samples were analyzed by various methods. Slurry and supernate elementals were determined by ICP-AES for bulk species and noble metals at PSAL. Slurry samples were calcined at $1100^{\circ} \mathrm{C}$, however, which adversely impacts recovery of noble metals, $\mathrm{Pb}$, and $\mathrm{Cr}$. Slurry anions were determined on weighted dilutions after filtering by IC. Supernate samples were submitted to Analytical Development (AD) for ICP-Mass Spectroscopy (ICP-MS) analysis for $\mathrm{Pd}, \mathrm{Rh}$, and $\mathrm{Ru}$. Soluble $\mathrm{Ba}$ and $\mathrm{Pb}$ concentrations were also obtained by ICP-MS. Supernate samples from the frit run with Ag were submitted to AD instead of PSAL, since PSAL reported issues with Ag determination. The supernate samples were obtained by immediately centrifuging slurry samples for about 15 minutes at $4000 \mathrm{rpm}$ to compact the insoluble solids. Fresh solids formed in some of the decanted supernates following cooling. Consequently, AD was asked to perform an aqua regia dissolution/preparation prior to ICP-MS to redissolve as many of the precipitated solids as possible.

Approximately 300 samples were generated to support XAS work (18-21 per SRAT simulation) with the intent to connect the hydrogen and supernate noble metal data in this report to additional data about the form, oxidation state, etc. of the noble metals. About 100 samples were of the SRAT slurry. Each of these samples was accompanied by a sample pulled into a centrifuge tube. These samples were centrifuged per the above protocol. The decanted supernates accounted for a second 100 samples. The compacted solids accounted for the third 100 samples. An XAS sample was prepared by coating some of the compacted solids onto a piece of tape. The 50 slurry samples from the eight frit runs were analyzed for slurry and supernate elementals, slurry anions, and $\mathrm{wt} \%$ solids. The 50 slurry samples from the eight bead runs were archived. An altered sampling plan was developed for the eight bead runs to answer some questions about supernate elementals that were raised by the 50 slurry sample supernate results from the XAS samples. 


\subsection{Process Modeling and Calculations}

The raw data obtained during the run and analysis of samples by AD and PSAL required subsequent analysis in many cases. This section outlines how these analyses and calculations were made.

\subsubsection{Temperature-corrected $\mathbf{p H}$}

The $\mathrm{pH}$ probe data were recorded by the $\mathrm{PC}$ data acquisition system along with the temperature setting of the $\mathrm{pH}$ probe monitor. The temperature setting must be entered manually by the TA to match the slurry temperature at any given time. The PC data files show when the temperature setting and the SRAT temperature were not always matched. When they were significantly different, it was worthwhile to correct the $\mathrm{pH}$ reading as follows.

$$
\begin{array}{ll}
p H_{c}=7+\left(p H_{r}-7\right) * \frac{59+0.2 *\left(T_{p H}-25\right)}{59+0.2 *\left(T_{S R A T}-25\right)} \\
\mathrm{pH}_{\mathrm{c}} & \text { corrected } \mathrm{pH} \text { reading } \\
\mathrm{pH}_{\mathrm{r}} & \text { recorded } \mathrm{pH} \text { reading } \\
\mathrm{T}_{\mathrm{pH}} & \text { temperature entered on } \mathrm{pH} \text { monitor, } \mathrm{C} \\
\mathrm{T}_{\mathrm{SRAT}} & \text { temperature of SRAT vessel slurry, C }
\end{array}
$$

\subsubsection{DWPF-scale Hydrogen Generation Rate}

The hydrogen generation rate at DWPF scale was calculated from the He flow rate, $\mathrm{He}$ vol\% and $\mathrm{H}_{2}$ vol\% combined with the scale factor and unit conversions as follows:

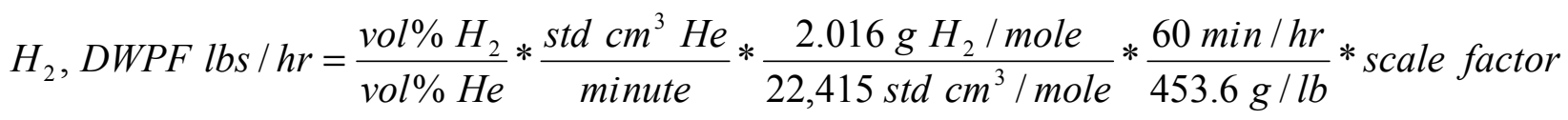

The He flowrate was generally close to 21.3 standard $\mathrm{cm}^{3}$ per minute $(\mathrm{sccm})$ and the scale factor was close to 1520 for the SRAT cycle. The He flowrate was generally close to $6.5 \mathrm{sccm}$ and the scale factor was close to 1600 for the SME cycle. Variations between runs were larger in the SME cycle parameters due to variations in the quantity of samples removed during the SRAT cycle. Similar calculations can be performed on the other gases. Fortunately, the ratio of the $\mathrm{H}_{2}$ and $\mathrm{He}$ volume percents is not as sensitive to the $\mathrm{GC}$ injection volume as the individual values are. The other primary source of error in this calculation is the He flowrate.

\subsubsection{Extent of Dissolution of a Cation}

The supernate concentration of noble metals needed to be related to the total concentrations of present in the system in order to evaluate the extent of dissolution. One calculation of the total concentration of a species in the SRAT as a function of time is to take the mass of the species added initially to the vessel and divide it by the time-dependent slurry mass neglecting samples. In this approach, the time-dependent slurry mass is calculated from the initial mass plus all additions less off-gas generation and less dewatered condensates. Samples that fall during nitric acid addition, formic acid addition, and dewatering have gained/lost only a fraction of the total acid or condensate. The start and end times, along with the sample time, are used to calculate the 
fraction of a gain/loss that has occurred up to the sample time. For example, a sample falling 45 minutes into a 3:22 hour formic acid addition would have a total mass calculated as follows

$$
\begin{aligned}
& \text { total slurry mass }=(\text { initial mass }+ \text { initial antifoam mass }+ \text { nitric acid mass } \\
& + \text { second antifoam mass }+(45 / 202) * \text { formic acid mass })- \text { current total offgas mass }
\end{aligned}
$$

The total mass concentration of a given species at a given time is then calculated simply as

$$
\frac{\text { grams of species } A}{k g \text { slurry }}=\left(\frac{\text { initial mass of species } A}{\text { total slurry mass }}\right)
$$

Neglecting the masses of small slurry samples ( $\sim 15 \mathrm{~g}$ out of $17,000 \mathrm{~g})$, along with the mass of the species removed in the sample, is a trivially small potential source of error when compared to actual run data which show about $1-2 \%$ missing mass in the SRAT product relative to what can be counted. The current hypothesis is that small leaks inevitably present in the system allow a small loss of water vapor to occur over the lengthy process simulation. The corresponding air loss goes unmeasured and is of no consequence, since non-condensable gases and He are lost equally fast, and the outlet He flow is assumed to be equal to the inlet He flow.

When supernate samples are submitted, the results obtained are not grams of species per $\mathrm{kg}$ of slurry. Instead, the results are reported either as grams of species per $\mathrm{kg}$ supernate, or grams of species per liter of supernate. In these cases, it is necessary to relate the supernate mass or volume to the corresponding slurry mass. An accurate estimate of $\mathrm{wt} \%$ insoluble solids is needed in both cases, and the supernate density is also needed when results are reported per unit volume.

The SRAT receipt slurry contained about $16 \mathrm{wt} \%$ insoluble solids, and the SRAT products ranged from about 14.5-16.8 $\mathrm{wt} \%$ insoluble solids. The time of minimum insoluble solids occurred at the end of acid addition and prior to dewatering, where the insoluble solids were probably about $91-92 \%$ of what they were in the SRAT product based on the dewatered mass relative to the SRAT product mass. Simply assuming that the wt $\%$ insoluble solids was $15 \%$ throughout the SRAT cycle would not introduce a large error in the grams supernate/gram slurry calculation, although the actual process material balance data were used to provide better estimates as a function of time. Similarly, the supernate density of the untrimmed sludge was $1.053 \mathrm{~g} / \mathrm{mL}$, while the supernate density of the SRAT products ranged from $1.054-1.093 \mathrm{~g} / \mathrm{mL}$. The high values occurred in runs with low catalytic activity, while the low values occurred in runs with a lot of catalytic activity (destruction of soluble anions). Although a single average supernate density of $1.07 \mathrm{~kg} / \mathrm{L}$ would only lead to $2 \%$ errors in the conversion calculations, actual data and process knowledge were used to reduce that potential error even further. The conversion of a result in grams/L supernate to grams species dissolved $/ \mathrm{kg}$ total slurry is illustrated below: 
$\frac{\text { grams species }}{\mathrm{kg} \text { slurry }}=\frac{\text { grams species }}{L \text { su pernate }} * \frac{L}{1.07 \mathrm{~kg} \text { su pernate }} * \frac{100 \mathrm{~g} \text { slurry }}{(100 \%-w t \% \text { insoluble solids }) \mathrm{g} \text { supernate }}$

The determination of percent dissolution of a given species follows from the last two calculations by forming the ratio of dissolved species grams/kg slurry with the total species grams/kg slurry.

\subsubsection{Dissolution-Precipitation Model}

Analytical data for minor species tend to contain more error or noise than data for major species. Recognizing that this would be the case, an attempt was made to determine the qualitative form that a graph of extent of dissolution versus time would take for a species in the SRAT. An extremely simple model was constructed for this purpose. The rate of dissolution of an insoluble species was assumed to be totally controlled by the acid addition rate until the initial insoluble form was consumed, at which point the dissolution rate was set to zero. The precipitation rate of the soluble form was assumed to be first-order in the concentration of the dissolved species and independent of all other species (most other species are present in relatively large concentrations in a single noble metal test, and their concentrations would not change much if they were participating in the precipitation reaction kinetics, i.e. the reaction could still be pseudo-first order even if formate or nitrate concentration was a player). The system was assumed to be essentially constant volume. This approach led to the following model:

$$
\begin{aligned}
& \text { dissolved concentration }=A^{*}\left(1-e^{-k t}\right) \text {, initial insoluble form still present } \\
& \text { dissolved concentration }=B e^{-k\left(t-t_{d}\right)} \text {, initial insoluble form consumed at } t_{d}
\end{aligned}
$$

The model constants ( $\mathrm{A}, \mathrm{B}, \mathrm{k}$, and $\mathrm{t}_{\mathrm{d}}$ ) were treated as adjustable parameters when performing the fits presented in the discussion of results, subject to the constraint that the curve be continuous across the transition between the two equations, $A^{*}\left(1-e^{-k^{*}-d}\right)=B$ and the constraint that $t_{d}$ needed to fall near the transition from increasing extent of dissolution to decreasing extent of dissolution. Consequently, the above model has three free parameters, one that shifts the time of maximum dissolution relative to an arbitrary zero time value when dissolution appears to commence, while the other two parameters change the height and breadth of the curve. The model is essentially an exponential approach to A (which, however, is never reached) followed by an exponential decline to zero. 


\subsection{SRAT DATA DISCUSSION}

The discussion of the noble metal dissolution data and hydrogen generation rate data during processing on the eight individual pairs of starting conditions presents certain challenges since data from the all noble metal run needs to be compared with data from single noble metal runs with $\mathrm{Rh}, \mathrm{Ru}$, and $\mathrm{Pd}$. The four individual noble metals were all tested at $0.2 \mathrm{wt} \%$ loadings in the absence of the other three noble metals, forming another basis for comparison. A forward progression in noble metal complexity was taken. The no noble metal baseline case data are discussed first, followed by four sections on the individual noble metal results, and the all noble metal case data are discussed last. Comparative discussions of different cases are made after all of the data have been presented.

Although this report will not focus on off-gas data other than hydrogen, it must be mentioned that the other off-gas data within each matched bead-frit pair showed remarkably high degrees of correlation as to when events occurred during the SRAT. The onsets and peaks in $\mathrm{CO}_{2}, \mathrm{~N}_{2} \mathrm{O}$, and NO generation occurred at virtually identical points in the SRAT cycle. Oxygen consumption behaved similarly. Small timing differences during acid addition were easily explained by correcting from units of time to moles acid added. SRAT product anion data for any given pair, while not identical, were within normal analytical error for formate and nitrate. These factors support the hypothesis that the runs within each pair were virtually identical in terms of the major process chemistry. This conclusion was used to justify combining the sample data obtained from the two different runs within a pair into a single curve for that case even when select individual data do not appear to be that well aligned.

Data obtained from the oxidation-reduction probe (ORP) during acid addition in six of sixteen tests indicated that the SRAT supernate became reducing within an hour of the start of the $\sim 3.5$ hour formic acid addition period and became progressively more reducing up until the end of formic acid addition. There was little evidence of fine structure in the data. It appears that the SRAT supernate was a reducing environment during hydrogen generation. The raw ORP data are given in the SRAT chemistry report. ${ }^{6}$ One test with delayed boiling indicated that the supernate became more oxidizing as hydrogen was generated.

\subsection{No Noble Metal Baseline Data}

Two 22-L runs, H2Frit7 and H2Bead11, were performed with no added noble metals in order to baseline the processing data. SRAT hydrogen generation data are shown in Figure 1. The results are only marginally significant, i.e. they were just above the reportable detection limit set on the GC. The largest hydrogen concentration in the SRAT off-gas of H2Frit7 was about 0.005 vol\%. H2Bead11 had no recorded hydrogen peaks on any of the GC scans in the SRAT cycle, but it did have some small nonzero readings in the SME cycle. Any SRAT cycle peaks were less than 100 area units set as the recordable cutoff on the Agilent 3000A GC. (Peaks can occasionally be seen unambiguously in the hydrogen retention time window that are distinct from the baseline and relatively symmetric, but are smaller than the recordable cutoff.) 


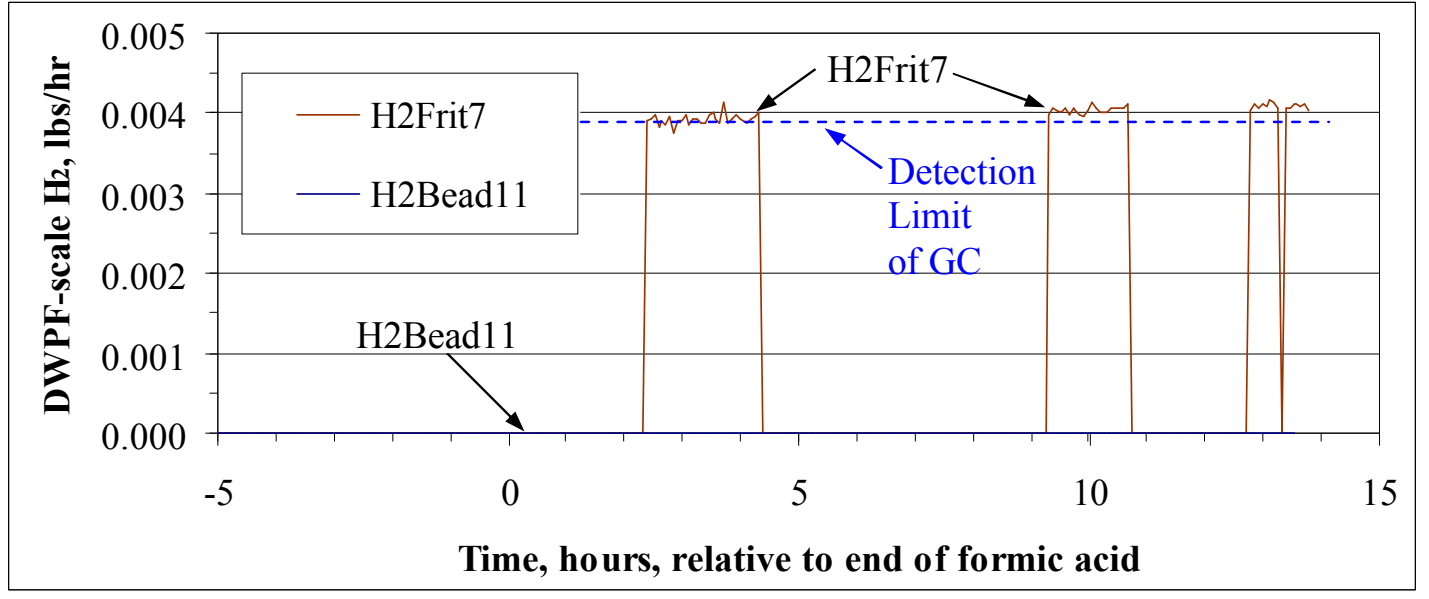

Figure 1. Hydrogen generation in the absence of noble metals

There were several instances during the H2Frit7 SRAT where hydrogen just exceeded the $\sim 0.005$ vol\% detection limit set in the Agilent software through the slope sensitivity setting. The three separated blocks were connected by some slightly smaller hydrogen generation rates that were below the detection limit. In any case, the nonzero values were extremely small and may not be statistically distinguishable from noise in magnitude although they were consistent in elution time. These two runs provide confirmation that the other species in the simulated waste were not significant producers of hydrogen. The data also indicate that residual noble metal contamination could potentially contribute a small amount of hydrogen generation to that from the fresh trimmed sludge and give an estimate of the likely magnitude of such an effect.

\subsection{Runs with Rh Only}

Two pairs of 22-L runs were performed with rhodium, one pair at $0.2 \mathrm{wt} \% \mathrm{Rh}$ in the trimmed sludge total solids and one at $0.1 \mathrm{wt} \% \mathrm{Rh}$ in the total solids. Rh was also present in the run with all noble metals. The $\mathrm{Rh}$ data from that run are discussed in Section 3.6.1.

\subsubsection{Rh at $0.2 \mathrm{wt} \%$}

$\mathrm{H} 2 \mathrm{Frit1}$ and $\mathrm{H} 2 \mathrm{Bead} 10$ were given an initial charge of $0.2 \mathrm{wt} \% \mathrm{Rh}$ in the trimmed sludge total solids. The extent of Rh dissolution is plotted as a function of time in Figure 2. The majority of the data are from ICP-MS analysis of AD aqua regia prepped supernate samples. Five additional data points from ICP-AES analysis of filtered supernate at PSAL are also shown. 


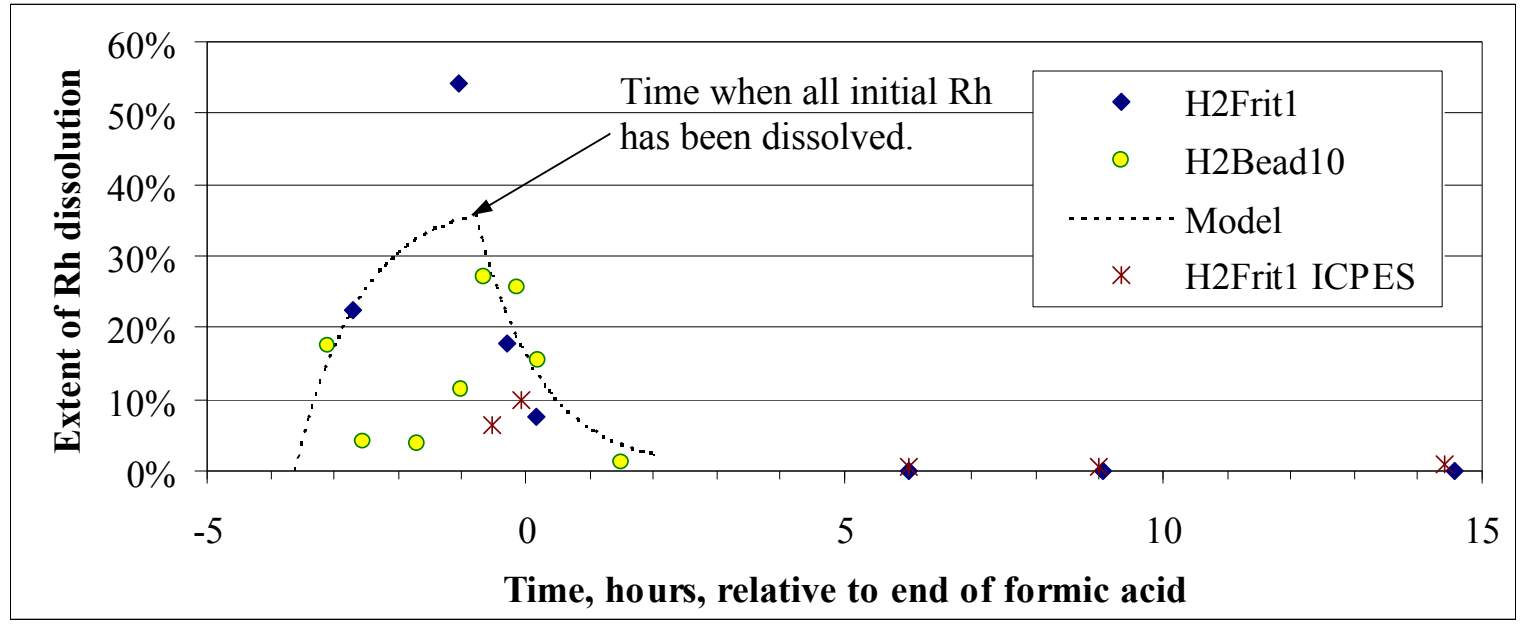

Figure 2. Rh dissolution during SRAT processing

The solubility of $\mathrm{Rh}$ in acidic solution is sufficient for $100 \%$ of the trimmed $\mathrm{Rh}$ to have been dissolved in the supernate at some moment in time. This extent of dissolution was not observed in any of the snapshot samples. The most likely explanation is that the dissolved $\mathrm{Rh}$ was undergoing a chemical transformation that was returning it to the insoluble solids. Similar behavior was observed in the $\mathrm{Pd}$ and $\mathrm{Ru}$ systems. This general behavior prompted the development of a dissolution-precipitation model, Section 2.4.3. The discussion below is placed here where the model can be compared to some actual data rather than in Section 2.4.3 where it would be more hypothetical in nature.

Many data points do not fall near the model curve or any other simple smooth curve that could be drawn through the data. An evolving chemical system presents sampling challenges until the chemistry is understood in detail. Ideally, the dissolution and precipitation reactions need to be stopped after a sample is pulled, but in such a way that the distribution of dissolved and precipitated noble metal is left unchanged in the sample. The protocol used was to immediately centrifuge the sample, separate the supernate, allow any solids to form in the separated supernate phase, and then to perform an aqua regia dissolution on the supernate sample to reverse any noble metal precipitation that may have occurred prior to the ICP-MS analysis.

The centrifuge preparation took about 10-15 minutes to run (less time did not always produce a clear supernate). The slurry sample cooled considerably during centrifuging. Cooling reduces chemical rate constants, which is good; but it can also change solubility which might or might not be bad. The centrifugation time might not be insignificant relative to the rate processes occurring in the sample. Furthermore, phase separated samples sat in the centrifuge for various periods of time (of the order of 0-15 minutes) after the timed centrifuge preparation completed. Additional time may have resulted in some noble metals precipitating and dropping out of the supernate prior to decanting. If additional precipitation occurred, then the ICP-MS results would be expected to understate supernate concentration relative to the time that the sample was pulled. There are some individual results on many of the extent of dissolution graphs in this report that may fall into this category (ICP-MS sample matrix biased low in concentration due to a failure to adequately stop the chemistry before decanting). If additional noble metal dissolution occurred 
during centrifuging, then the dissolved cation would still have to diffuse through the compacted solids to get into the supernate that was decanted. This was almost certainly a slower process than settling of the solids through clear supernate, but, if enough time was allowed, it could lead to an increase in supernate noble metals if the dissolution rate exceeded the precipitation rate at the time the sample was pulled. This case seemed intuitively less likely than getting an artificially low result. Anyway, there were many reasons to expect that there might be scatter in the data.

The model curve on a given graph generally attempted to bound the majority of the extent of dissolution data points from above, but it was allowed to miss a few points low (allowance for ICP-MS measurement error) or by up to about ten minutes sideways (potential impact of centrifuge time). If there was a single point that appeared to be an outlier, then the model curve often had to ignore that point. The $55 \% \mathrm{Rh}$ point in Figure 2 is potentially an outlier, since targeted samples in H2Bead10 failed to reproduce that region of H2Frit1. Three or four H2Bead10 points had the potential to show greater than $35 \%$ extent of dissolution, but none did. Data from the ICP-MS analyses were reviewed without finding any calculation errors associated with the H2Frit1 peak or the three low values for H2Bead10 in the -1 to -3 hour period.

The above $\mathrm{Rh}$ extent of dissolution data were not interpreted to mean that only about $35 \%$ of the initial rhodium hydroxide dissolved during the SRAT. The data were interpreted to mean that essentially $100 \%$ of the rhodium hydroxide dissolved, but that there was a competing precipitation process that was simultaneously removing rhodium from the supernate giving rise to a maximum concentration. The maximum probably occurred close to the time that all of the original rhodium hydroxide had been dissolved, so roughly two-thirds of the total rhodium had reprecipitated as a new insoluble species (potentially $\mathrm{Rh}$ metal) while one-third was still in the supernate about one-half hour before the end of acid addition. It was at about one-half hour before the end of acid addition that the precipitation reaction appeared to become the only process, i.e. the supply of initially soluble $\mathrm{Rh}$ had been exhausted. The point where dissolution of the initial noble metal form stops, and where only precipitation continues, shows up in the model curve as a cusp point, see arrow in Figure 2.

Hydrogen generation started before the end of formic acid addition in both runs. This observation could be taken as a red flag that formic acid addition should be stopped in the fullscale SRAT if hydrogen generation is observed before formic acid addition is complete. Figure 3 gives the two sets of hydrogen data on a DWPF-scale lbs/hr basis superimposed on the Rh dissolution data. 


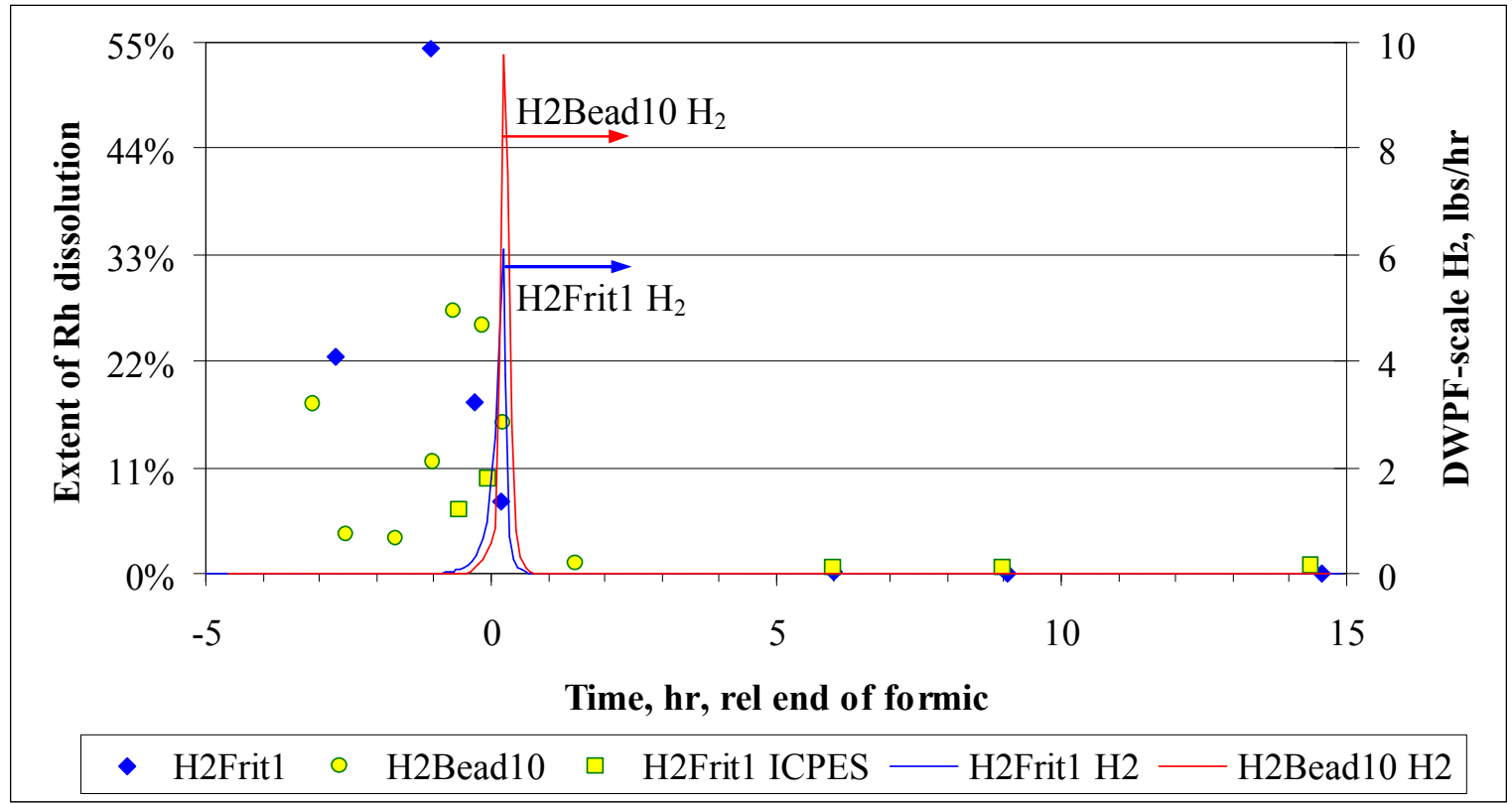

Figure 3. Hydrogen generation at $0.2 \mathrm{wt} \% \mathrm{Rh}$

Although the maximum rate reached in H2Frit1 was less than in $\mathrm{H} 2 \mathrm{Bead10}$, it was not clear that this result was particularly accurate. The peaks occurred extremely quickly against a background of major changes in the air purge rate that were attempting unsuccessfully to keep the hydrogen concentration below $1 \mathrm{vol} \%$ in the off-gas. Accumulated $\mathrm{He}$ in the off-gas equipment had to transition to a new steady-state concentration as the air purge changed, and the He concentration was governed by different process dynamics than the $\mathrm{H}_{2}$ concentration (different hold-up volumes, different generation rates). A small offset in peak timing between runs may simply be an artifact of the data processing. The peaks do divide the extent of $\mathrm{Rh}$ dissolution data fairly cleanly into values greater than $2 \%$ before the peaks and values less than $2 \%$ after the peak.

The dissolved $\mathrm{Rh}$ concentration was clearly falling rapidly about twenty minutes prior to the end of formic acid addition in Figure 3 at the same time that the hydrogen generation rate was increasing. Close to $80-90 \%$ of the initial $\mathrm{Rh}$ had dissolved and reprecipitated by the time that the peak in hydrogen generation occurred. This claim follows from Figure 2, where only $\sim 10-$ $20 \%$ of the $\mathrm{Rh}$ remained to be precipitated out of solution at the time of hydrogen generation. It can be inferred that the other $80-90 \%$ of the Rh must have already dissolved and reprecipitated at this point, since it occurred at the end of the initial dissolution process.

These two runs achieved 55\% (H2Frit1) and 58\% (H2Bead10) formate destructions in the SRAT cycle. The $\mathrm{CO}_{2}$ data indicate that roughly $90 \%$ of this loss occurred before the end of the hydrogen generation spike. The slurry $\mathrm{pH}$ was above six in both runs in less than an hour after acid addition. It is therefore likely that there was very little free formic acid remaining in the system when the hydrogen generation peak came back to near zero. This lack of acid may have impacted the hydrogen generation kinetics. Both runs continued to produce small quantities of hydrogen during reflux, and the SRAT cycle ended with both runs producing approximately $0.010 \mathrm{lbs} / \mathrm{hr}$ of hydrogen at DWPF-scale. The hydrogen generation rates were actually slowly 
rising during reflux after they had fallen to the $0.005-0.006 \mathrm{lbs} / \mathrm{hr}$ range shortly after the spike. These data indicate that the $\mathrm{Rh}$ had not been totally deactivated by some unidentified process. It may be that the $\mathrm{Rh}$ was transitioning to a less catalytically active form however, and that loss of formic acid was not the only cause of the reduced generation rates. Hydrogen generation after the peak is shown using an expanded scale in Figure 4.

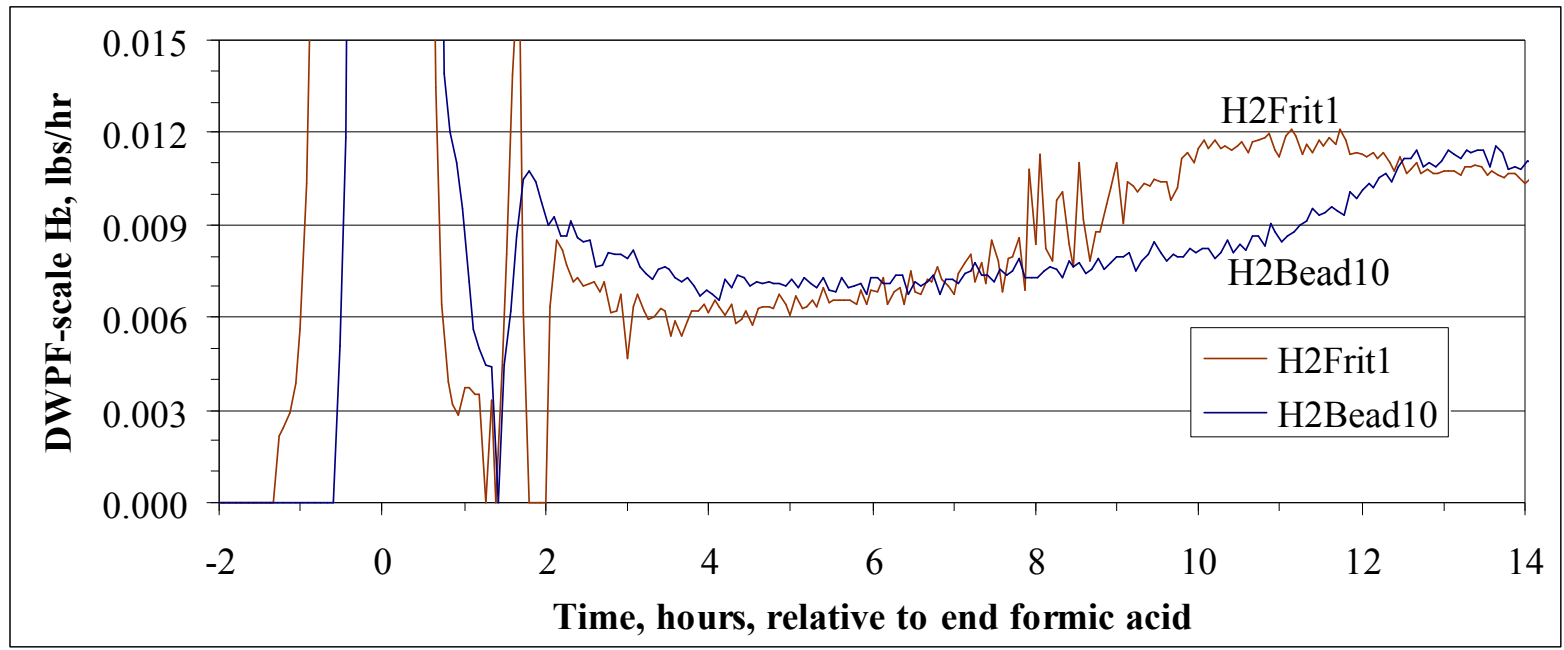

Figure 4. Hydrogen generation at $0.2 \mathrm{wt} \% \mathrm{Rh}$ after the SRAT peak

The two curves are remarkably similar considering what happened just prior to them. No rescaling of the time axis was made, nor should much of one been necessary. The only difference between runs that must be mentioned is that the heating mantle was actually turned off after acid addition in $\mathrm{H} 2$ Frit1 because of the high hydrogen generation rate, while the heating mantle was left on in temperature control at $93^{\circ} \mathrm{C}$ in $\mathrm{H} 2 \mathrm{Bead} 10$. H2Bead10 was run so that essentially the same time elapsed between acid addition and powering up to go to boiling as in H2Frit1. H2Frit1 had cooled to $88^{\circ} \mathrm{C}$ with the mantle off, so there may have been some impact of the hotter wall, slightly average higher temperature, etc. on the H2Bead10 results relative to $\mathrm{H} 2$ Frit1, but the temperature differences weren't that large.

\subsubsection{Rh at $0.1 \mathrm{wt} \%$}

$\mathrm{H} 2 \mathrm{Frit} 6$ and $\mathrm{H} 2 \mathrm{Bead} 16$ were given an initial charge of $0.1 \mathrm{wt} \% \mathrm{Rh}$ in the trimmed sludge total solids. The extent of Rh dissolution is plotted as a function of time in Figure 5. The majority of the data are from ICP-MS analysis of aqua regia prepped supernate samples. Four additional data points from ICP-AES analysis of filtered supernate are also shown. 


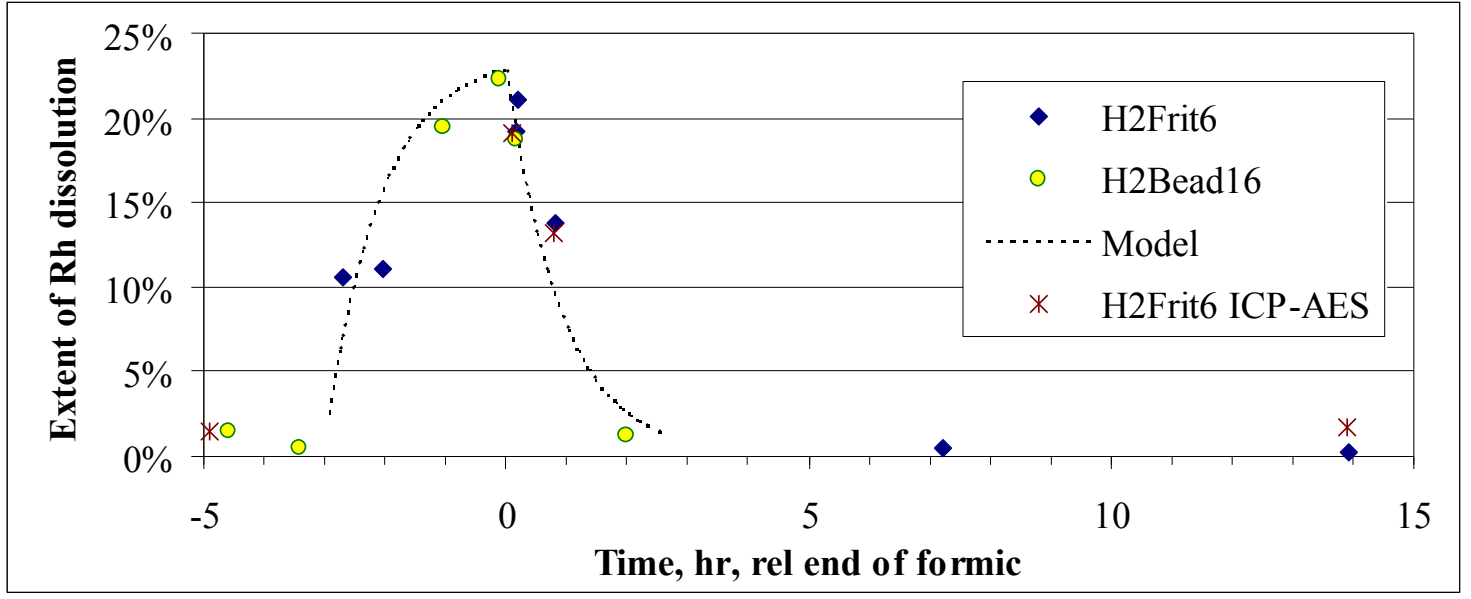

Figure 5. Rh dissolution during SRAT processing at $0.1 \mathrm{wt} \%$

There was much less scatter in the data at $0.1 \mathrm{wt} \% \mathrm{Rh}$ than for $0.2 \mathrm{wt} \% \mathrm{Rh}$. Data conformed fairly well to the simple model. Data from both runs indicated that about $2 \%$ of the $\mathrm{Rh}$ was soluble in the trimmed sludge before acid addition. These two data sets were similar to the data from the $0.2 \mathrm{wt} \% \mathrm{Rh}$ samples that tracked the model curve, but the extent of dissolution in the $0.1 \mathrm{wt} \% \mathrm{Rh}$ system was lower, as were the absolute dissolved concentrations. This result indicates that $\mathrm{Rh}$ dissolution was apparently not limited by a solubility constraint in this pair of runs. Hydrogen production began while formic acid addition was still in progress, Figure 6, as in the $0.2 \mathrm{wt} \%$ Rh pair.

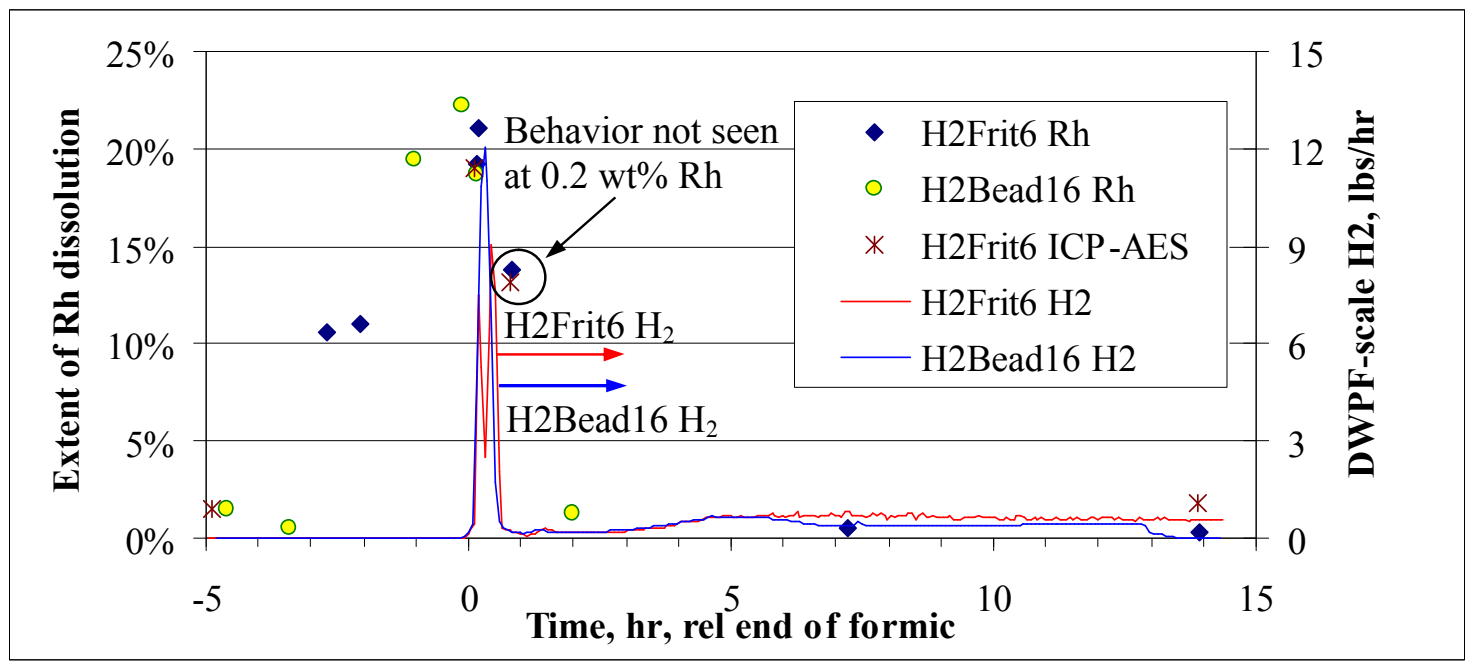

Figure 6. Hydrogen Generation at $0.1 \mathrm{wt} \% \mathrm{Rh}$

Although there are strong similarities to the runs at $0.2 \mathrm{wt} \% \mathrm{Rh}$, including the maximum hydrogen generation rates and extent of $\mathrm{Rh}$ solubility during reflux, there were also some differences. First, and foremost, the maximum hydrogen generation rates were greater for each run compared to the corresponding $0.2 \mathrm{wt} \% \mathrm{Rh}$ runs. Such a phenomenon had been seen once 
before in the form of noble metal testing, but it had never been reproduced. ${ }^{13}$ Rhodium was still found in solution immediately after the hydrogen peak, but at a higher concentration compared to the $0.2 \mathrm{wt} \% \mathrm{Rh}$ case. There were three H2Frit6 data points in the $44-49 \mathrm{mg} / \mathrm{kg}$ range, marked by the circle in Figure 6, while the maximum post-peak concentration seen in the $0.2 \mathrm{wt} \% \mathrm{Rh}$ case was $6 \mathrm{mg} / \mathrm{kg}$. The H2Frit6 spike in hydrogen was actually a double peak, though this may have been induced by the air purge changes that were made to keep the volume percent down.

Significant hydrogen generation occurred after the spike in both runs compared to the $0.2 \mathrm{wt} \%$ $\mathrm{Rh}$ pair. This may or may not have been related to the higher $\mathrm{Rh}$ supernate concentration after the main peak. The hydrogen generation rate axis for this period of time is expanded in Figure 7.

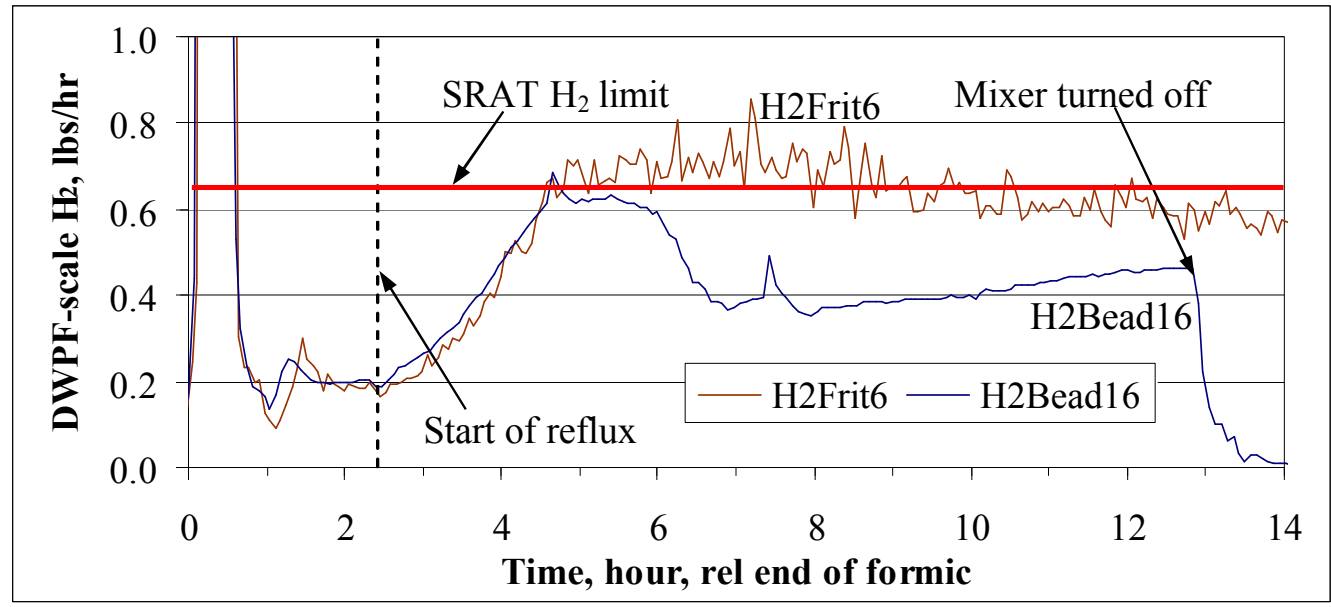

Figure 7. Hydrogen generation during reflux at $0.1 \mathrm{wt} \% \mathrm{Rh}$

The first six hours after acid addition appear to have been nearly identical for the two runs. Hydrogen generation rates were still near the DWPF SRAT maximum of $0.65 \mathrm{lbs} / \mathrm{hr}$ during the remainder of these two runs. This range was almost two orders of magnitude greater than in the $0.2 \mathrm{wt} \% \mathrm{Rh}$ runs during this period, Figure 4.

H2Frit16 developed some mixing issues during the latter stages of reflux, which ultimately led to the mixer shaft coming uncoupled from the mixer motor. Prior to that event, it appeared that the shaft may have been slipping, and that mixing intensity may have been less than in H2Frit6. Degraded mixing intensity may have impacted the hydrogen generation rate in the second half of the twelve hour reflux period (based on comparing the two curves in Figure 7). The mixer was not shut down to attempt repairs until nearly 13 hours after formic acid addition when the shaft stopped turning entirely. The large decrease in hydrogen generation at that time is due to the mixer being completely off. Boiling was also supplying a certain amount of mixing. The heating mantle was also turned off when the mixing blades stopped turning, but the temperature remained above $97^{\circ} \mathrm{C}$ on the SRAT thermocouple past 14 hours after the end of formic acid addition. When mixing was resumed, the temperature came to equilibrium at about $86^{\circ} \mathrm{C}$, so there were cooler zones away from the thermocouple. 


\subsection{Runs with Ru Only}

Pairs of 22-L runs were performed at $0.2 \mathrm{wt} \% \mathrm{Ru}$ in the trimmed sludge total solids and at 0.375 $\mathrm{wt} \% \mathrm{Ru}$ in the total solids. One 4-L test was also performed at $0.2 \mathrm{wt} \% \mathrm{Ru}$ with $1.5 \mathrm{wt} \% \mathrm{Hg}$. $\mathrm{Ru}$ was also present in the run with all noble metals. The $\mathrm{Ru}$ data from that run are discussed in Section 3.6.2.

\subsubsection{Ru at $0.2 \mathrm{wt} \%$}

H2Frit2 and H2Bead13 were given an initial charge of $0.2 \mathrm{wt} \% \mathrm{Ru}$ in the trimmed sludge total solids. The extent of Ru dissolution is plotted as a function of time in Figure 8. The majority of the data are from ICP-MS analysis of aqua regia prepped supernate samples. Five additional data points from ICP-AES analysis of filtered supernate samples during the SRAT cycle are shown, along with one SRAT product result for supernate by ICP-AES.

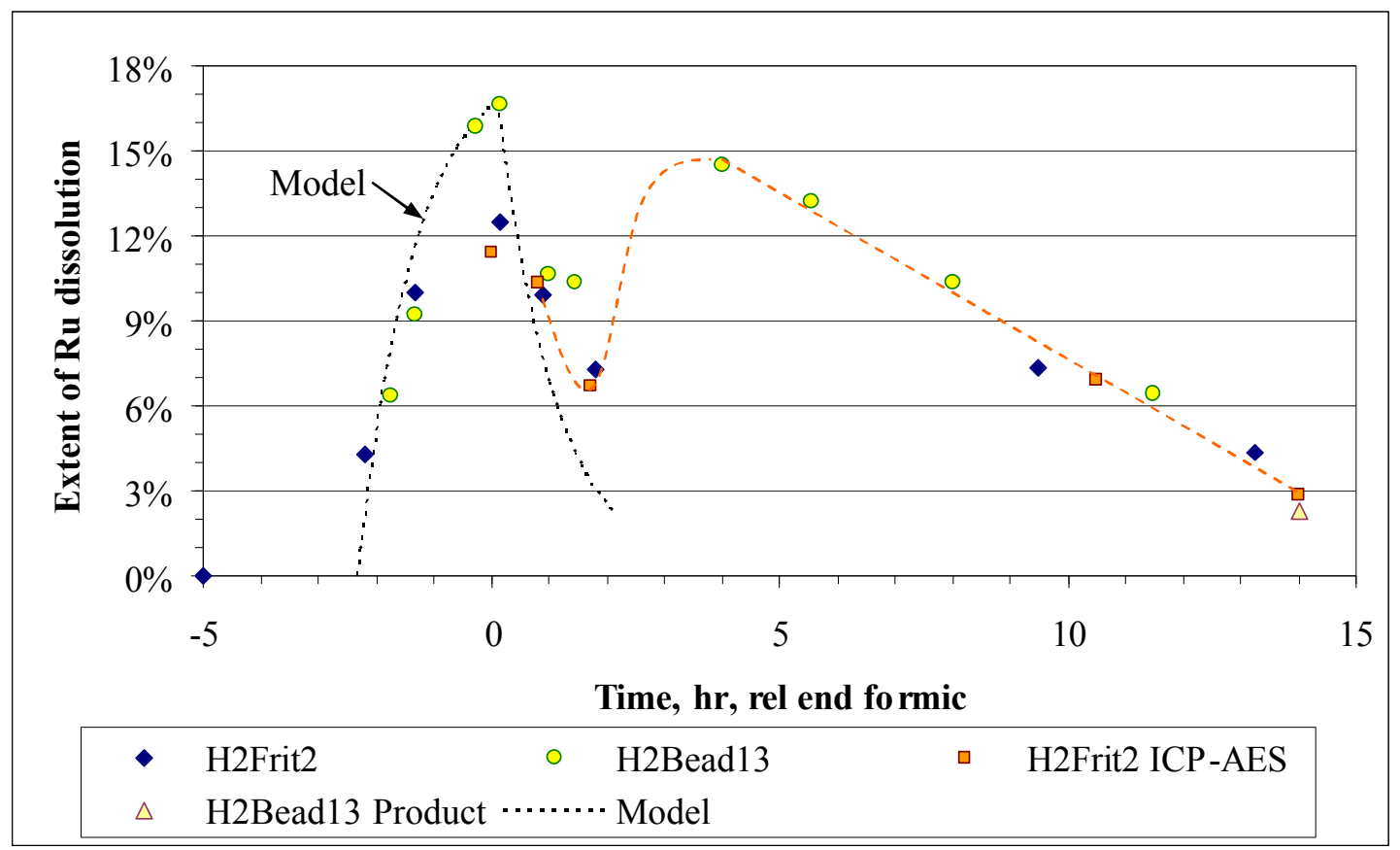

Figure 8. Extent of SRAT Ru dissolution at $0.2 \mathrm{wt} \%$

Unfortunately, $\mathrm{pH}$ data profiles were not obtained in either run during the period around -2 hours when the $\mathrm{Ru}$ began dissolving. Some $\mathrm{pH}$ data was obtained in H2Frit2. The $\mathrm{pH}$ was probably between 7.9 (last value of the failed probe) and 4.2 (first replacement probe reading) at about -2 hours. The behavior of Ru at $0.2 \mathrm{wt} \%$ loading was characterized more extensively than some of the other cases as is apparent from the 24 data points on Figure 8 . The primary reason for this was the emerging structure of the data. The region from 1-9 hours after acid addition was not well characterized by H2Frit2 due to a lack of samples. The H2Bead13 data clearly show two maxima in the extent of Ru dissolution, one near the end of acid addition resembling the Rh data, and a second maximum several hours later that was less well defined by the samples. While the H2Frit2 data do not show the second peak, all of theH2Frit2 points obtained were consistent with 
the H2Bead13 points. The high solubilities at +9 to +14 hours, however, were distinctly different from the behavior of $\mathrm{Rh}$.

The model derived in section 2.4 was too simple to describe these data. The model captures the essential features of the initial dissolution and onset of the first precipitation. The model lacks rate effects for a subsequent dissolution. Adding such terms to a potentially overly simple model did not seem justified. Once the second dissolution commenced, the sample data began to fall above the model curve. A free-hand curve (orange dashed curve) was added to the graph to trace out the later data.

The discussion above is made relevant when the data are aligned with the hydrogen generation rate data. The two sets of superimposed data are shown in Figure 9.

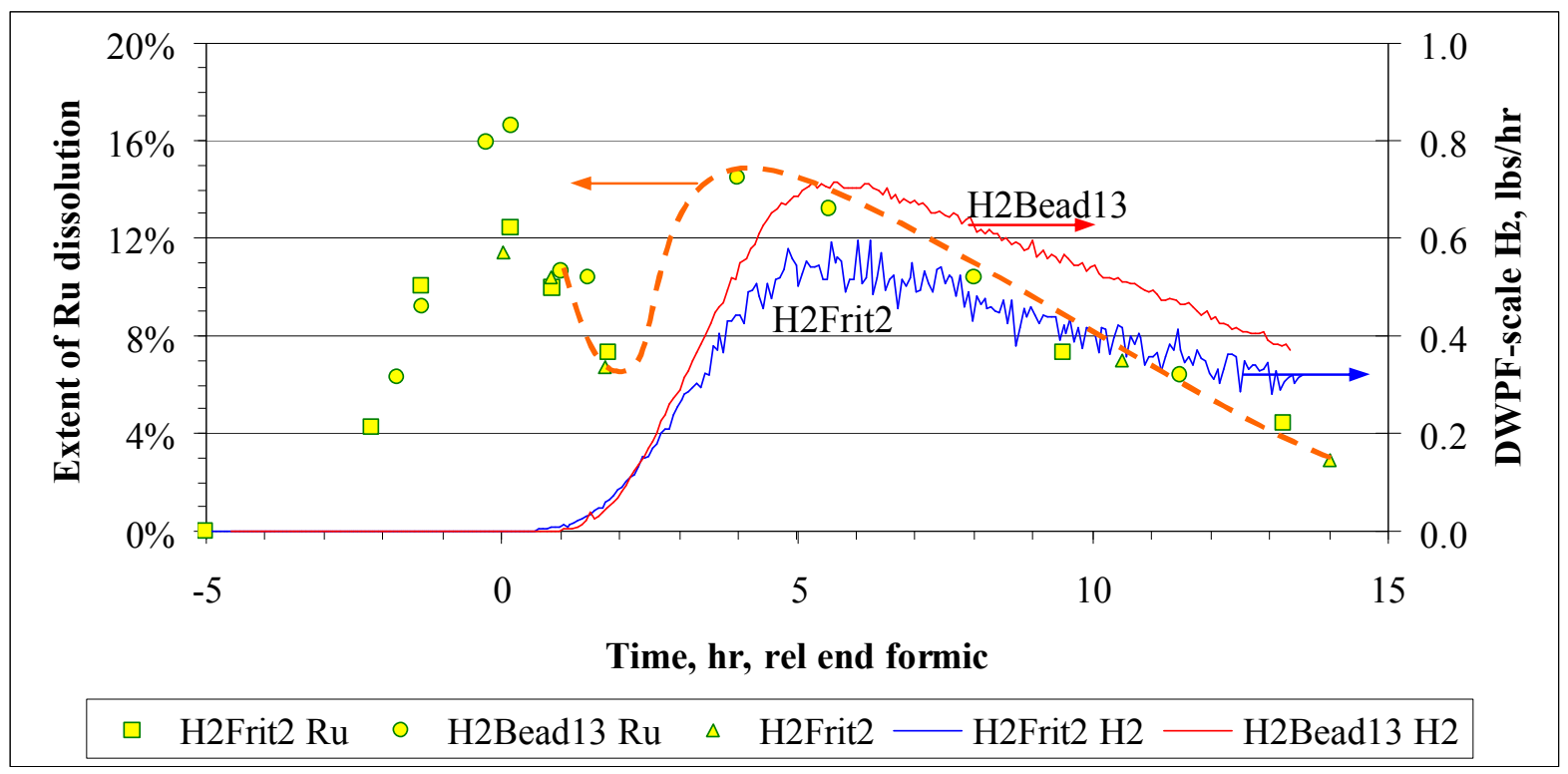

Figure 9. Hydrogen generation at $0.2 \mathrm{wt} \% \mathrm{Ru}$

The $\mathrm{Ru}$ hydrogen generation rate profile was much different than that seen for $\mathrm{Rh}$. It was slower to start, peaked later at a lower maximum rate, and was much broader in extent. The hydrogen generation rate data show an initiation as the $\mathrm{Ru}$ dropped out of the initial dissolution period during acid addition. This was very close to the time that nitrite ion disappeared completely. The hydrogen generation rate then proceeded to increase as the soluble $\mathrm{Ru}$ concentration increased. Shortly after the soluble Ru concentration peaked in the second dissolution period, the hydrogen generation rate also started to decline. Total hydrogen production was $1.4-1.8 \mathrm{~g}$ in the two $0.2 \mathrm{wt} \% \mathrm{Ru}$ runs compared to $0.5-0.6 \mathrm{~g}$ in the two runs at $0.2 \mathrm{wt} \% \mathrm{Rh}$, so $\mathrm{Ru}$ was responsible for more than twice as much total hydrogen generation as the corresponding quantity of Rh. Furthermore, $\mathrm{Ru}$ is also generally present in actual DWPF sludge at 3-4 times the concentration of $\mathrm{Rh}$ due to the relative fission yields. Therefore, $\mathrm{Ru}$ must be considered a significant catalytic species along with Rh during the SRAT cycle. This conclusion differs from the single $\mathrm{Ru}$ test done along with the nitrite ion impact on Rh-catalyzed hydrogen study (BoleyLambert study) reported in the last major catalytic hydrogen review. ${ }^{8}$ This conclusion is more 
consistent with the correlations seen between hydrogen generation and soluble $\mathrm{Rh}$ and $\mathrm{Ru}$ concentrations during the form of noble metal testing. ${ }^{13}$

\subsection{2 $\mathrm{Ru}$ at $0.375 \mathrm{wt} \%$}

H2Frit5 and H2Bead12 were given an initial charge of $0.375 \mathrm{wt} \% \mathrm{Ru}$ in the trimmed sludge total solids or $87.5 \%$ more than the pair at $0.2 \mathrm{wt} \%$. The extent of $\mathrm{Ru}$ dissolution is plotted as a function of time in Figure 10. The majority of the data are from ICP-MS analysis of aqua regia prepped supernate samples. Five additional data points from ICP-AES analysis of filtered supernate are also shown.

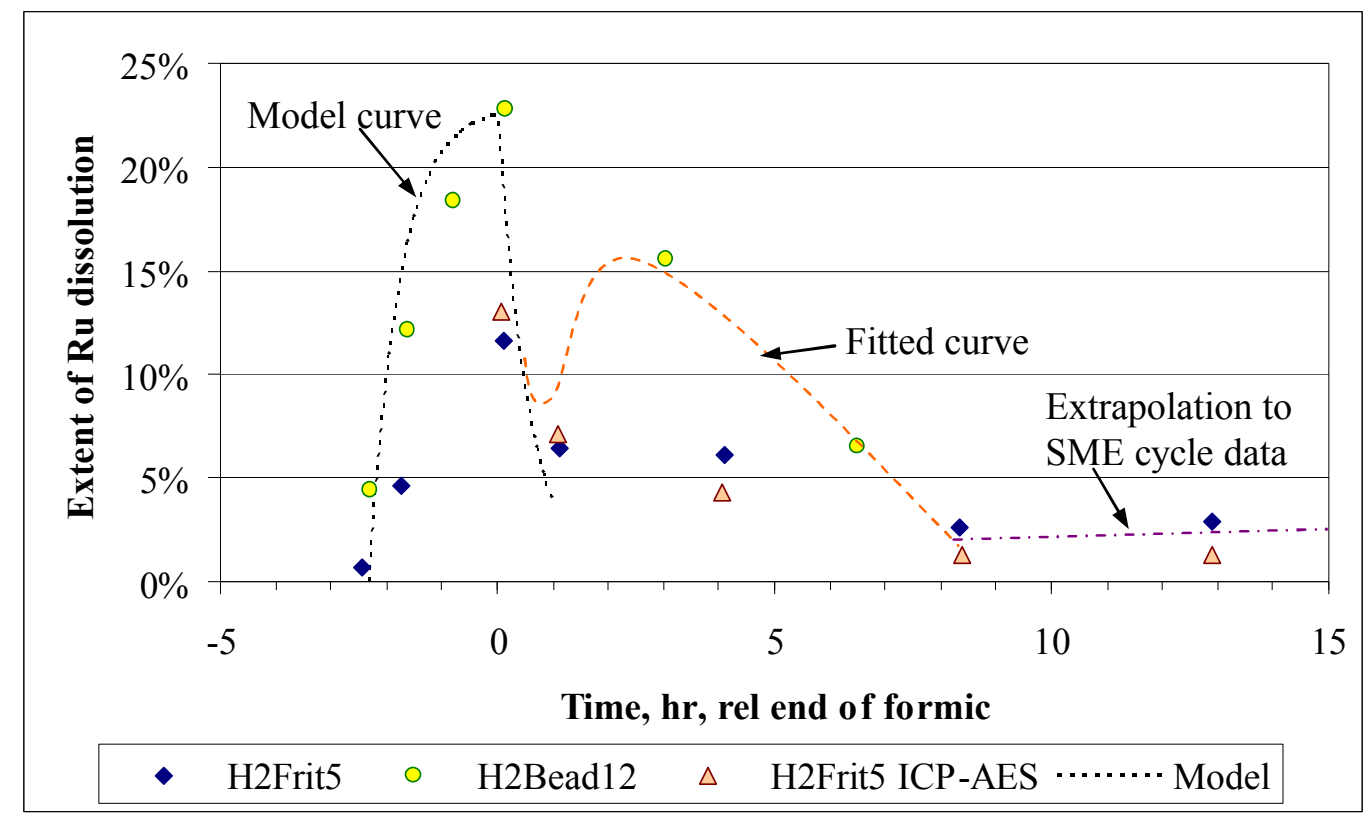

Figure 10. Extent of SRAT Ru dissolution at 0.375 wt $\%$

The $\mathrm{pH}$ readings at 2.3 hours before the end of formic acid (onset of $\mathrm{Ru}$ dissolution) were 5.7 and 5.5 in the two runs. This $\mathrm{pH}$ range is both narrower than and consistent with the finding at $0.2 \mathrm{wt} \%$. Presumably the onset of $\mathrm{Ru}$ dissolution occurred at about $\mathrm{pH} 5.6$ at $0.2 \mathrm{wt} \% \mathrm{Ru}$. Significant $\mathrm{Ru}$ dissolution did not appear to occur in the $0.375 \mathrm{wt} \%$ case until the $\mathrm{pH}$ fell below 5.8 plus or minus the uncertainty of the $\mathrm{pH}$ probes (which have not been quantified for this period). These $\mathrm{pH}$ values collectively define the approximate conditions for the onset of $\mathrm{Ru}$ dissolution (this is relevant to constructing a timeline of SRAT reactions).

The initial dissolution peak captured by the model curve was about $40 \%$ higher in extent of dissolution than for the $0.2 \mathrm{wt} \%$ case and the maximum actual dissolved concentrations were more than twice as high, $211 \mathrm{mg} / \mathrm{kg}$ versus $81 \mathrm{mg} / \mathrm{kg}$, perhaps due to some non-offsetting random errors in the data (predicted analytical uncertainties were $\pm 25 \%$ on the noble metal concentrations). It seemed unlikely that an $88 \%$ increase in total $\mathrm{Ru}$ would produce a $>88 \%$ increase in maximum dissolved concentration. 
Although there are considerably fewer data points after acid addition than in Figure 8, the H2Bead12 data also suggest the presence of a second maximum in Ru solubility following acid addition. The dashed orange line attempted to capture that possible aspect of the data, though the Word drawing menu auto-shape is less adjustable than desired. In particular, this data set does not indicate that there wasn't an extent of dissolution minimum and second maximum. There were two samples pulled sequentially at +4 hours in H2Frit5. The Ru results from these two samples, one by ICP-MS and one by ICP-AES, were well off the fitted curve. It may be that the sample tube into the SRAT slurry did not get adequately purged of older material, or the samples sat too long in the centrifuge, or H2Frit5 may have actually differed from H2Bead12 during this period. The favored choice is that the extent of solubility data at $0.375 \mathrm{wt} \% \mathrm{Ru}$ were of the same qualitative form as for the $0.2 \mathrm{wt} \% \mathrm{Ru}$ case (dual peaks), and the most likely reason was that dissolved $\mathrm{Ru}$ was lost from the supernate of some of the H2Frit5 samples for one or more of the above reasons.

Extra ICP-MS samples could have been added to the H2Bead12 sampling plan like those added to second $0.2 \mathrm{wt} \% \mathrm{Ru}$ run in order to better fill in the region of a possible minimum in extent of $\mathrm{Ru}$ dissolution. However, the results from $\mathrm{H} 2 \mathrm{Bead} 12$ were not available when this decision had to be made. Defining this region once at the lower Ru concentration was deemed sufficient to determine if future investigations of the shape of the $\mathrm{Ru}$ dissolution profile were worthwhile.

An alternative explanation for the $\mathrm{Ru}$ data would be that $\mathrm{Ru}$ dissolution ran higher in $\mathrm{H} 2 \mathrm{Bead} 12$ than in H2Frit5 throughout the period after acid addition and that there was no minimum separating two peaks (perhaps H2Bead12 had more Ru initially). This was initially proposed to explain the $0.2 \mathrm{wt} \%$ data as well, which led to two additional samples being analyzed to remove doubt. The H2Bead12 SRAT product chloride was about $10 \%$ greater than H2Frit5, and chloride is a marker for the $\mathrm{RuCl}_{3}$ addition, although the starting sludge also had chloride. Another possible cause of differences between the two runs, however, could have been an undetected error in weighing the initial charge of $\mathrm{RuCl}_{3}$, e.g. neglecting to account for the tare weight of the weighing boat or not zeroing the balance properly. Much of the H2Frit5 Ru data, along with the $\mathrm{H}_{2}$ data in Figure 11 seem to indicate behavior that could be expected and explained if the runs had unequal concentrations of $\mathrm{Ru}$ (not grossly unequal, but perhaps $5-20 \%$ different).

SME cycle sampling in H2Frit5 indicated that the process removing $\mathrm{Ru}$ from the sampled supernates stopped short of $100 \%$ removal of $\mathrm{Ru}$, i.e. it was consistent with the SRAT data at +13 hours being nonzero. SME samples showed similar to slightly larger supernate concentrations of Ru than the last SRAT samples even though considerable additional processing time at boiling had passed (4-8 hours).

Hydrogen generation rate data at DWPF-scale are given in Figure 11. The onset of hydrogen occurred about one hour after acid addition, and the peak rate occurred about three hours after acid addition in both runs. The hydrogen onset appeared to coincide with the postulated minimum in extent of dissolution in Figure 10, while the hydrogen maximum appeared to coincide roughly with the postulated time of maximum dissolution in the period after acid addition. The hydrogen onset also appeared to coincide with the time of nearly total nitrite destruction ( $\mathrm{Ru}$ molar concentration definitely greater than $\mathrm{NO}_{2}^{-}$molar concentration). 


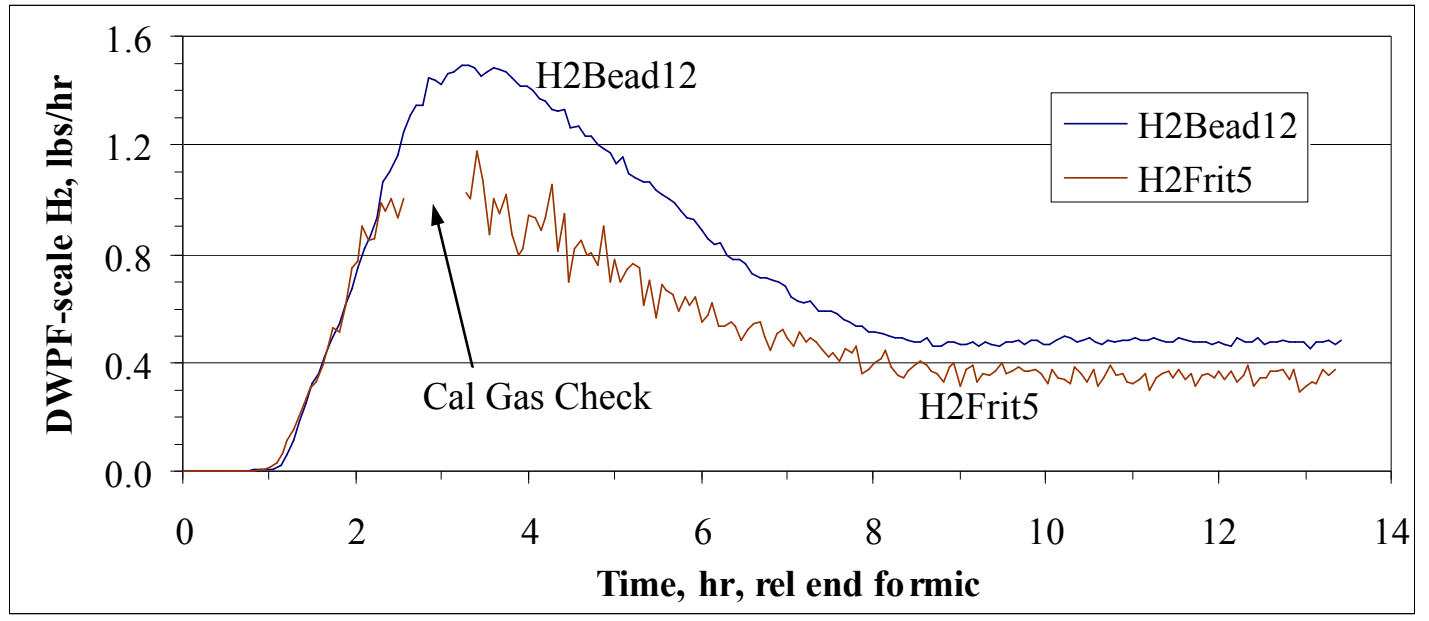

Figure 11. Hydrogen generation at 0.375 wt\% Ru

The timing and general structure of the two hydrogen generation rate profiles is identical, but the $\mathrm{H} 2 \mathrm{Bead} 12$ data is consistently higher after the onset period ( +1 to +2 hours). H2Frit5, however, was one of the runs with GC issues, so, for example, the GC data couldn't be used to prove that $\mathrm{H} 2 \mathrm{Frit} 5$ had less initial $\mathrm{Ru}$ than $\mathrm{H} 2 \mathrm{Bead} 12$. The gap in H2Frit5 data at +3 hours was a break in process data while the GC calibration was rechecked. The peak hydrogen generation rates came about two hours sooner than in the $0.2 \mathrm{wt} \% \mathrm{Ru}$ pair.

The H2Frit5 data were visibly noisier than H2Bead12 suggesting possible mechanical issues with the GC. This much noise is unusual at $\mathrm{He}$ and $\mathrm{H}_{2}$ concentrations above 0.4 vol\%, since these values are nowhere near the detection limits of the GC. Conversely, the traces of the two B-column gases, $\mathrm{CO}_{2}$ and $\mathrm{N}_{2} \mathrm{O}$, were virtually identical for the two runs, suggesting that processing conditions were being reproduced (this doesn't say anything definitive about a possible difference in initial $\mathrm{Ru}$ concentration either). The B-column in H2Frit5 appeared to lose sensitivity about five hours after acid addition, further complicating the reprocessing of data for this run. Consequently, the differences in the two hydrogen generation rates may be entirely due to issues with the A-column compositions from the $\mathrm{GC}$ and/or to an unidentified issue with the He MKS flow controller rather than to actual processing differences or to a potential difference in total $\mathrm{Ru}$.

The extent of dissolution and the hydrogen generation rate data were combined in Figure 12. 


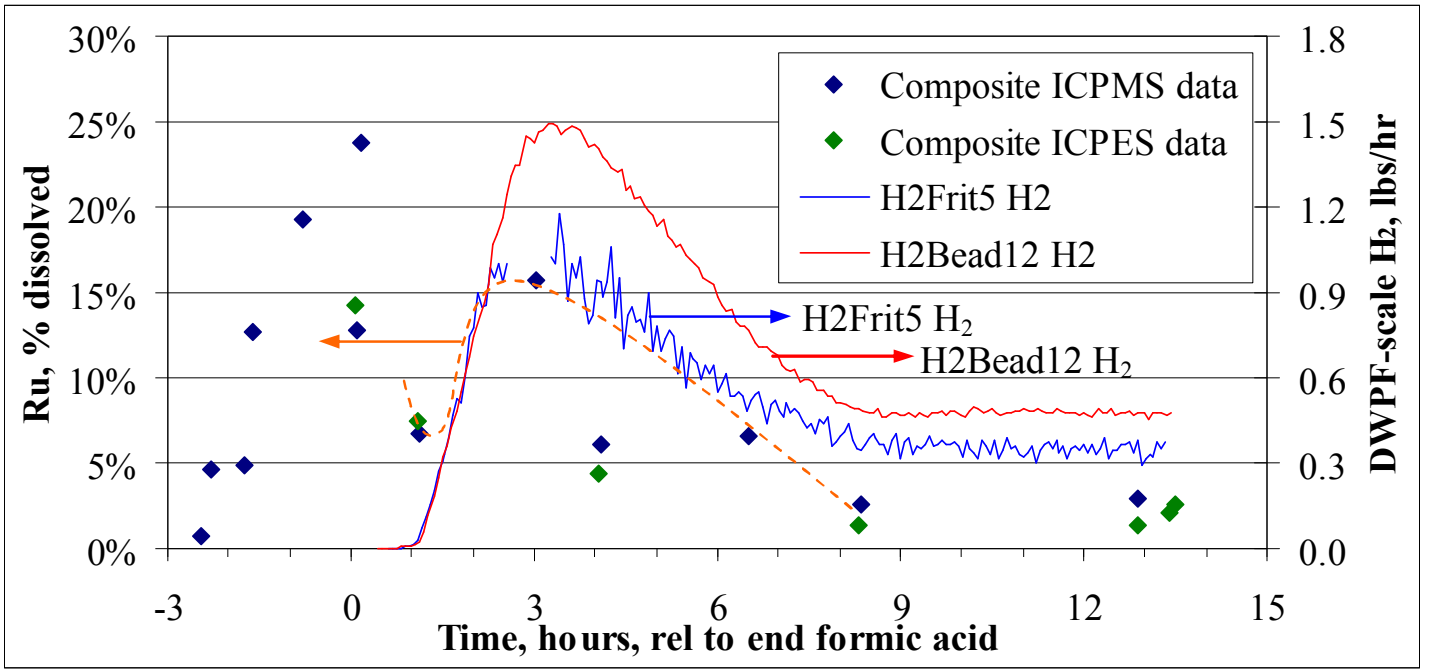

Figure 12. Hydrogen generation rate vs. Ru dissolution at $0.375 \mathrm{wt} \%$

The general pattern seen at $0.2 \mathrm{wt} \% \mathrm{Ru}$ was followed at $0.375 \mathrm{wt} \%$. Initiation of hydrogen generation came about an hour after the end of formic acid addition as it did at $0.2 \mathrm{wt} \% \mathrm{Ru}$. Ru was falling from an initial dissolution peak at the time of hydrogen generation initiation. $\mathrm{Ru}$ dissolution either peaked a second time (only one data point) or at the very least hit a stable plateau for about seven hours during boiling while the hydrogen generation rate peaked.

$\mathrm{H} 2 \mathrm{Bead} 12$ produced $2.7 \mathrm{~g}$ of hydrogen and H2Frit5 produced $1.9 \mathrm{~g}$ of hydrogen. The difference may be due to issues with the experimental equipment. The total hydrogen generated in the SRAT was about $40-50 \%$ more than the $1.4-1.8 \mathrm{~g}$ produced at $0.2 \mathrm{wt} \% \mathrm{Ru}$. Increased hydrogen production was the expected impact of increasing noble metal concentration. Total SRAT formate loss was in the 26-34\% range. The increase in the peak generation rate was more pronounced. The change was from $0.60-0.71 \mathrm{lbs} / \mathrm{hr}$ to $1.18-1.49 \mathrm{lbs} / \mathrm{hr}$ as $\mathrm{Ru}$ went from $0.2 \mathrm{wt} \%$ to $0.375 \mathrm{wt} \%$. The average increase in peak rate was about $100 \%$ for the $87.5 \%$ increase in $\mathrm{Ru}$ loading. While there was unresolved uncertainty as to whether H2Bead12 or H2Frit5 had the most accurate data for $0.375 \mathrm{wt} \% \mathrm{Ru}$, the uncertainty was smaller than the differences between the $0.375 \mathrm{wt} \%$ and $0.2 \mathrm{wt} \% \mathrm{Ru}$ data sets.

\subsubsection{Ru at $0.2 \mathrm{wt} \%$ with $\mathrm{Hg}$}

A 4-L SRAT simulation was performed to provide XAS samples containing Ru in the presence of $\mathrm{Hg}$. The simulation did not include a SME cycle. A small stoichiometric amount of additional acid was added to reduce the $\mathrm{HgO}$ to elemental mercury. Processing conditions were otherwise equivalent to the sixteen 22-L runs. Six SRAT slurry samples were analyzed for anions, slurry elementals, and wt\% solids, as well as for elemental composition of the supernate using ICP-AES to support the XAS program. There were no ICP-MS samples during this test. The ICP-AES analyses provided the only $\mathrm{Ru}$ dissolution data for this run. A plot of the five points during processing is given in Figure 13. The sixth point was the SRAT receipt sample with negligible $\mathrm{Ru}$ solubility. Data from the two runs with $0.2 \mathrm{wt} \% \mathrm{Ru}$ and no $\mathrm{Hg}$ are shown for comparison. 


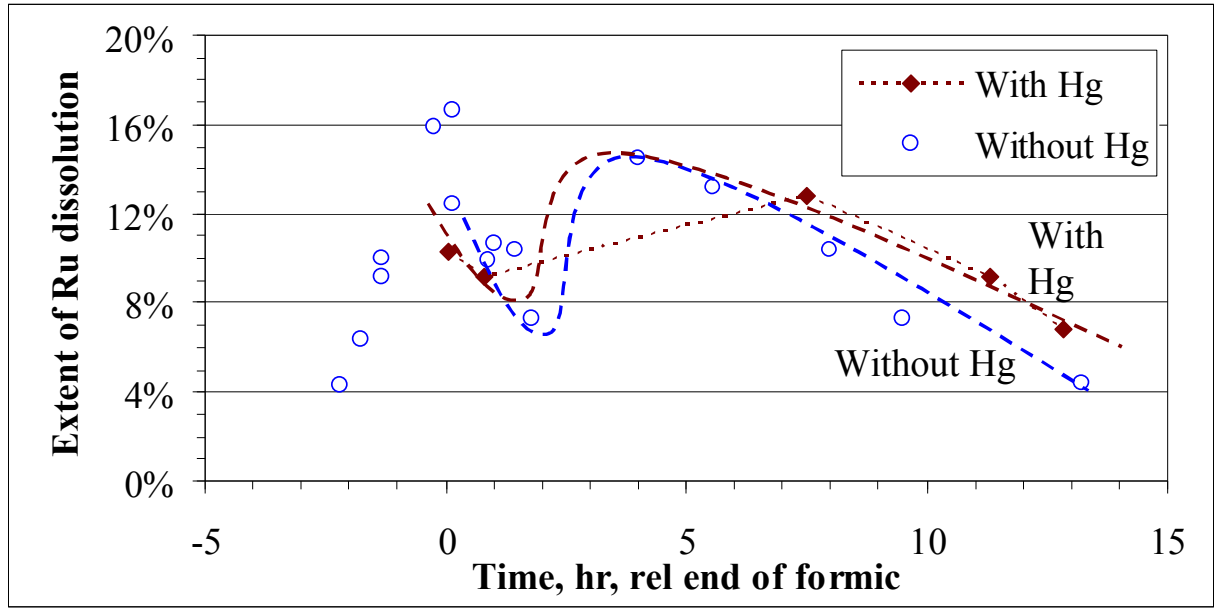

\section{Figure 13. Extent of Ru dissolution with and without $\mathrm{Hg}$}

The five new $\mathrm{Ru}$ dissolution data points from the run with $\mathrm{Hg}$ generally fell in the neighborhood of the ICP-MS points from the two matching 22-L runs without $\mathrm{Hg}$. The $\mathrm{Hg}$ was not obviously affecting the measured $\mathrm{Ru}$ supernate solubility. The five new points also seem to be consistent with a two maximum extent of dissolution data fit. The first two points fall with the data associated with the period after the first maximum, while the last three points fall with the data associated with the decline after the second maximum. There are not nearly enough data points, however, to independently identify the location of either maximum for the mercury run.

The hydrogen generation rate profiles with and without mercury are compared in Figure 14.

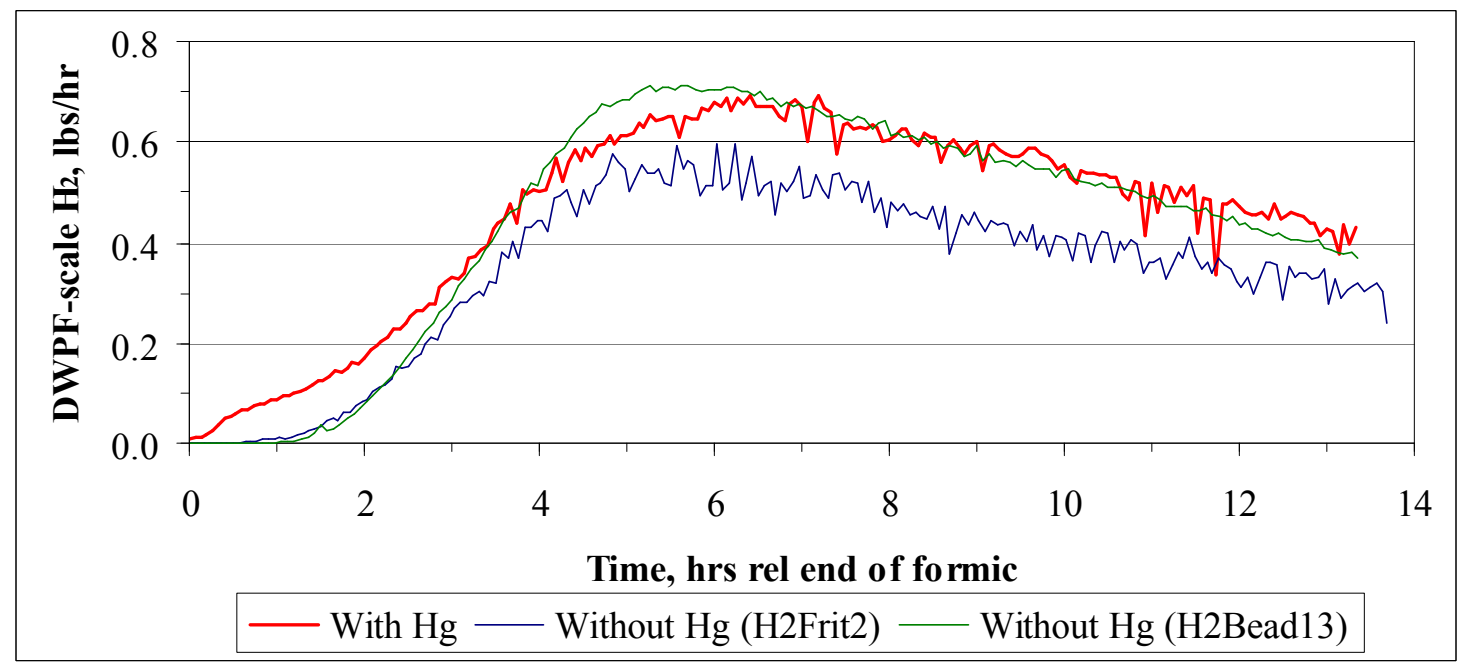

Figure 14. Hydrogen generation at $0.2 \mathrm{wt} \% \mathrm{Ru}$ with and without $\mathrm{Hg}$

The hydrogen generation rate curves with and without mercury are generally similar in form. They reached a maximum about six hours after acid addition followed by a slow, gradual decline up until the end of the SRAT cycle. Mercury was expected to inhibit the onset of hydrogen 
generation. The opposite occurred, although peak timing did not appear to be significantly impacted by an earlier onset. The current data are not sufficient to identify subtle differences that may be due to the altered scale of the test. Potential uncertainty in the timing of the end of formic acid addition due to the different equipment used at the two scales (when the last drop mixed with the slurry), however, is not sufficient to explain the differences. The rate of nitrite destruction may have been somewhat faster in the smaller vessel used for the test with $\mathrm{Hg}$ due to superior mixing and shorter mass transfer distances, which may have eliminated an inhibitor to $\mathrm{Ru}$-catalysis of formic acid to hydrogen.

The general trend in recent flowsheet testing for sludge batches 2-4 has been that increasing mercury inhibits the peak hydrogen generation rate. If, however, the peak hydrogen generation rate in general flowsheet runs is due primarily to $\mathrm{Rh}$ instead of $\mathrm{Ru}$, then the above observation showing a lack of inhibition from $\mathrm{Hg}$ would not be inconsistent with general flowsheet data. One implication of this hypothesis, however, would be that at some level of mercury, the Rhdriven peak generation rate would potentially be inhibited to the point that it was eclipsed by the $\mathrm{Ru}$-driven peak generation rate in magnitude. A separate study is underway to statistically test for $\mathrm{Rh}-\mathrm{Ru}-\mathrm{Hg}$ interaction effects at more typical (lower) concentrations of noble metals and in systems that contain reasonable quantities of $\mathrm{Ag}$ and $\mathrm{Pd}$ in addition to the three primary study elements.

It should be pointed out that at $0.2 \mathrm{wt} \% \mathrm{Ru}$ and $1.5 \mathrm{wt} \% \mathrm{Hg}$, the molar ratio of $\mathrm{Hg} / \mathrm{Ru}$ is only about 3.5 at the start of the SRAT, and that this ratio should decline during the SRAT as Hg is steam stripped into the MWWT. Consequently, there may not have been enough $\mathrm{Hg}$ to significantly inhibit the $\mathrm{Ru}$ during reflux. For example, if $\mathrm{Ru}$ is trapped into an amalgam inside mercury droplets, then it might take 5-20 atoms of mercury per atom of $\mathrm{Ru}$ to contain it as a dissolved species. This much mercury was not present initially and only decreased with time. Still, the nearly perfect overlay of the hydrogen data with the data from H2Bead13 seems to suggest a minimal or nonexistent role for mercury during catalytic hydrogen generation by Ru.

\subsection{Runs with Pd Only}

$\mathrm{H} 2 \mathrm{Frit} 4$ and $\mathrm{H} 2 \mathrm{Bead} 15$ were given an initial charge of $0.2 \mathrm{wt} \% \mathrm{Pd}$ in the trimmed sludge total solids. The extent of Pd dissolution is plotted as a function of time in Figure 10. The majority of the data are from ICP-MS analysis of aqua regia prepped supernate samples. No additional data points from ICP-AES analysis of filtered supernate are shown, because Pd had essentially dropped out of solution before any of the ICP-AES samples were taken. 


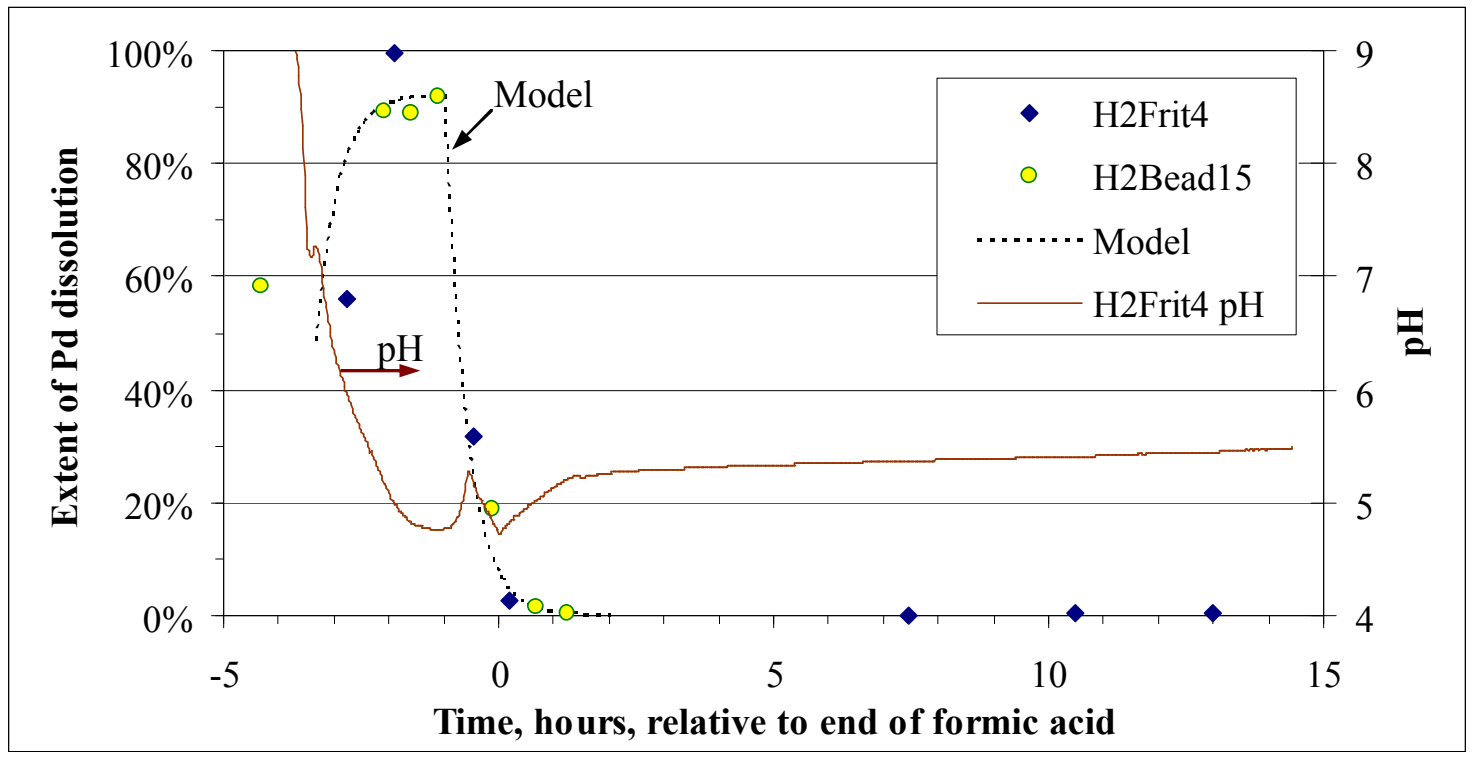

Figure 15. Pd dissolution during SRAT processing

Form of noble metal testing in the 2004-2005 period did not experience detectable Pd losses during simulant preparation with coprecipitated noble metals indicating that the Pd had become insoluble in the presence of a washed sludge supernate. ${ }^{14}$ The Pd was added as a soluble nitrate in this simulant work and in the coprecipitated form of noble metal testing. Both simulants were at about $\mathrm{pH} \mathrm{10,} \mathrm{so} \mathrm{the} \mathrm{Pd} \mathrm{was} \mathrm{expected} \mathrm{to} \mathrm{be} \mathrm{insoluble} \mathrm{initially.} \mathrm{It} \mathrm{had} \mathrm{typically} \mathrm{been} \mathrm{assumed}$ that the starting Pd in actual waste fed to DWPF was mostly insoluble, since it survived washing steps during sludge batch preparation. The above extent-of-Pd dissolution data, however, show that the fully trimmed starting simulant had a fairly high fraction (50-60\%) of the Pd in the supernate. This was unexpected based on prior observations of Pd chemistry in real and simulant wastes. If this simulant had been prepared in an unwashed state, Pd added, and the sludge washed to the present SRAT receipt composition, then a significant quantity of the Pd could have been lost to the decanted wash water.

The insoluble $\mathrm{Pd}$ appeared to start dissolving as soon as the system became mildly acidic $(\mathrm{pH}<7)$. Essentially $90 \%$ dissolution was achieved before the $\mathrm{Pd}$ began to significantly reprecipitate. This high extent of dissolution was also achieved about an hour sooner than the maximum extents reached for $\mathrm{Rh}$ and $\mathrm{Ru}$ which occurred very close to the end of acid addition. No evidence was found for any significant dissolution of the Pd after acid addition. Pd behaved a lot like $\mathrm{Rh}$, however, in the sense that both elements seemed to follow a relatively simple dissolution-precipitation model.

The relatively small hydrogen generation rates for these two runs are plotted against the extent of palladium dissolution in Figure 16. 


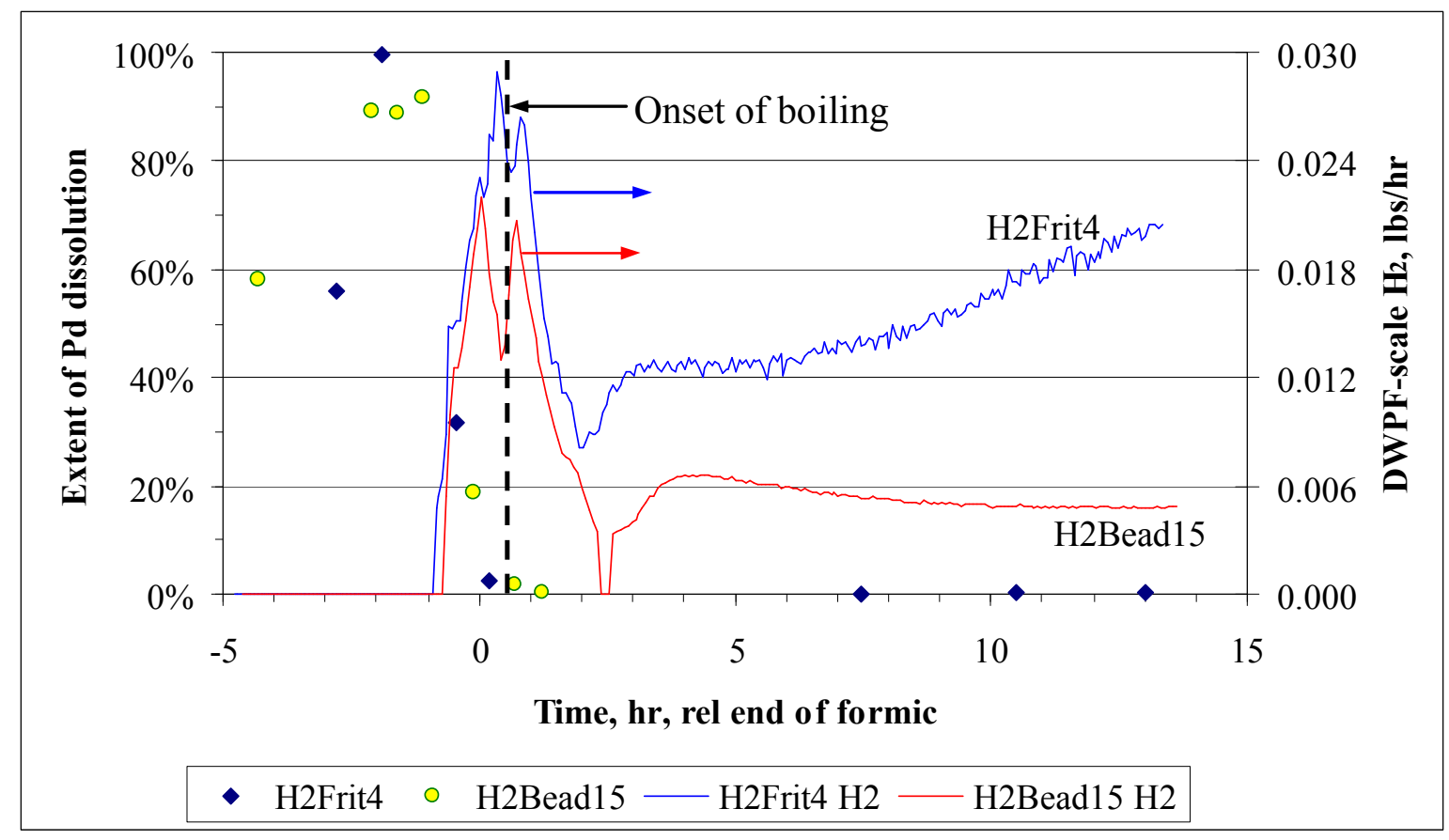

Figure 16. Hydrogen generation versus Pd dissolution at $0.2 \mathrm{wt} \%$

Both Pd hydrogen generation rate traces show a double maximum in the period from -1 to +1 hour. These were not due to changes in the air purge rate which was being held constant, but instead were caused by the onset of boiling after acid addition. Pd was much less active for hydrogen generation at $0.2 \mathrm{wt} \%$ than either $\mathrm{Rh}$ or $\mathrm{Ru}$ as evidenced by the very low DWPF-scale hydrogen generation rates which were about two orders of magnitude lower than in the matching $\mathrm{Rh}$ and $\mathrm{Ru}$ runs.

\subsection{Runs with Ag Only}

Silver was tested at $0.2 \mathrm{wt} \%$ to complete the set of studies of the four noble metals at constant $\mathrm{wt} \%$ in the SRAT receipt sample total solids. The two tests with silver were H2Frit3 and H2Bead9. There is no graph of extent of Ag dissolution to present, unlike the other three noble metals. Samples of supernate were taken throughout the H2Frit3 SRAT cycle. Silver was below the detection limit in every sample. The detection limits ranged from $0.79-0.99 \%$ of the total silver present in the slurry. Either $99+\%$ of the silver did not dissolve during SRAT processing, something caused it to reprecipitate prior to analysis of the supernate samples, or it transitioned from one insoluble form to another so rapidly that there was never any appreciable accumulation in the supernate.

The hydrogen generation rate profiles for the two silver only runs are given in Figure 17. 


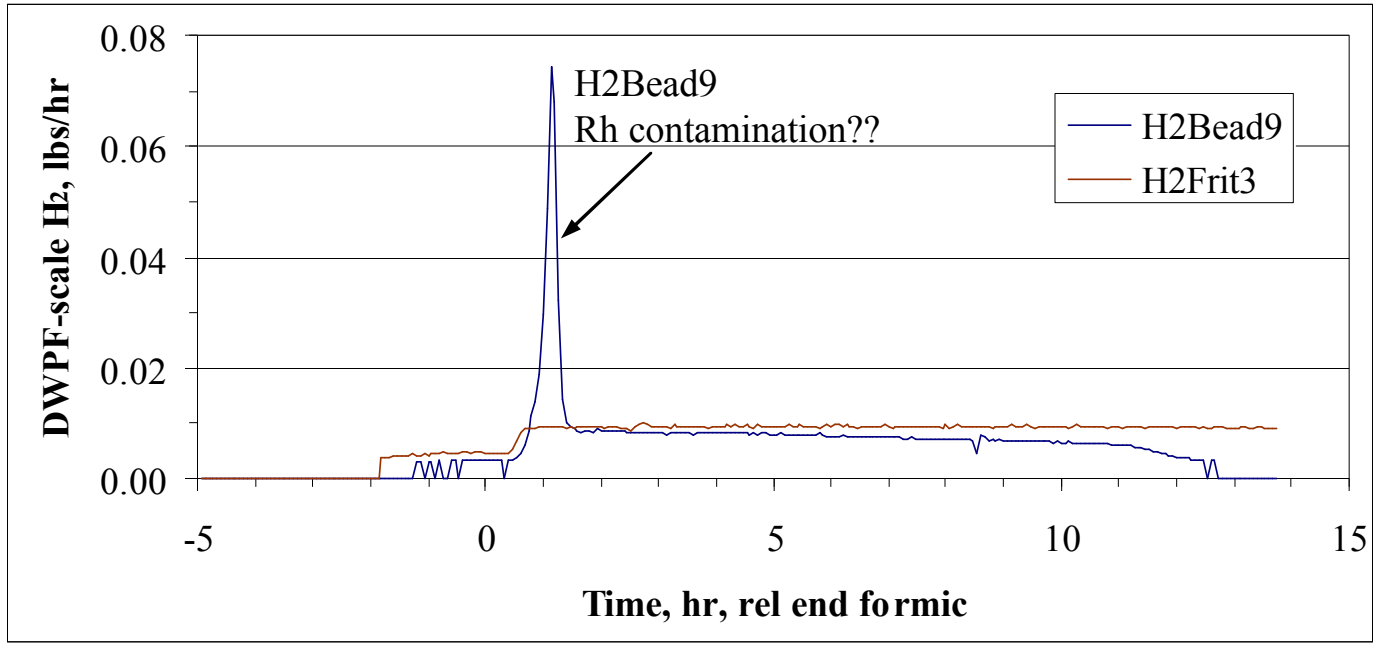

Figure 17. Hydrogen generation at $0.2 \mathrm{wt} \%$ silver

The two generation rate profiles were nearly identical except for a sharp spike in the H2Bead9 data at about an hour after acid addition. This singular spike occurred during dewatering. It is unclear whether the spike was due to silver or to a small amount of noble metal contamination in the equipment, perhaps by $\mathrm{Rh}$ given the spiked shape of the peak. Although the observed hydrogen generation rates were very low and the Ag concentrations were much greater than in normal sludges, the hydrogen generation rates were nevertheless greater than the rates observed in the two baseline runs with no noble metals. Therefore, the insoluble silver species has some catalytic activity toward hydrogen generation.

\subsection{Runs with all Noble Metals}

One pair of runs included all four noble metals. H2Frit8 and H2Bead14 were given an initial charge of $0.1 \mathrm{wt} \% \mathrm{Rh}, \mathrm{Pd}$, and $\mathrm{Ag}$ in the trimmed sludge total solids. Ru was added at 0.375 $\mathrm{wt} \%$. This created comparable pairs for $\mathrm{Rh}$ at $0.1 \mathrm{wt} \%$ by itself to these two runs and for $\mathrm{Ru}$ at $0.375 \mathrm{wt} \%$ by itself to these two runs. Pd was not studied separately at $0.1 \mathrm{wt} \%$, but the Pd data was examined in the context of the $0.2 \mathrm{wt} \% \mathrm{Pd}$ runs. The role of silver in the all noble metal runs was ignored based on the data from the silver only runs.

The $\mathrm{pH}$ profiles varied between the all noble metal run and the runs with a single noble metal especially starting about one hour before the end of acid addition through the period of peak hydrogen generation, Figure 18. 


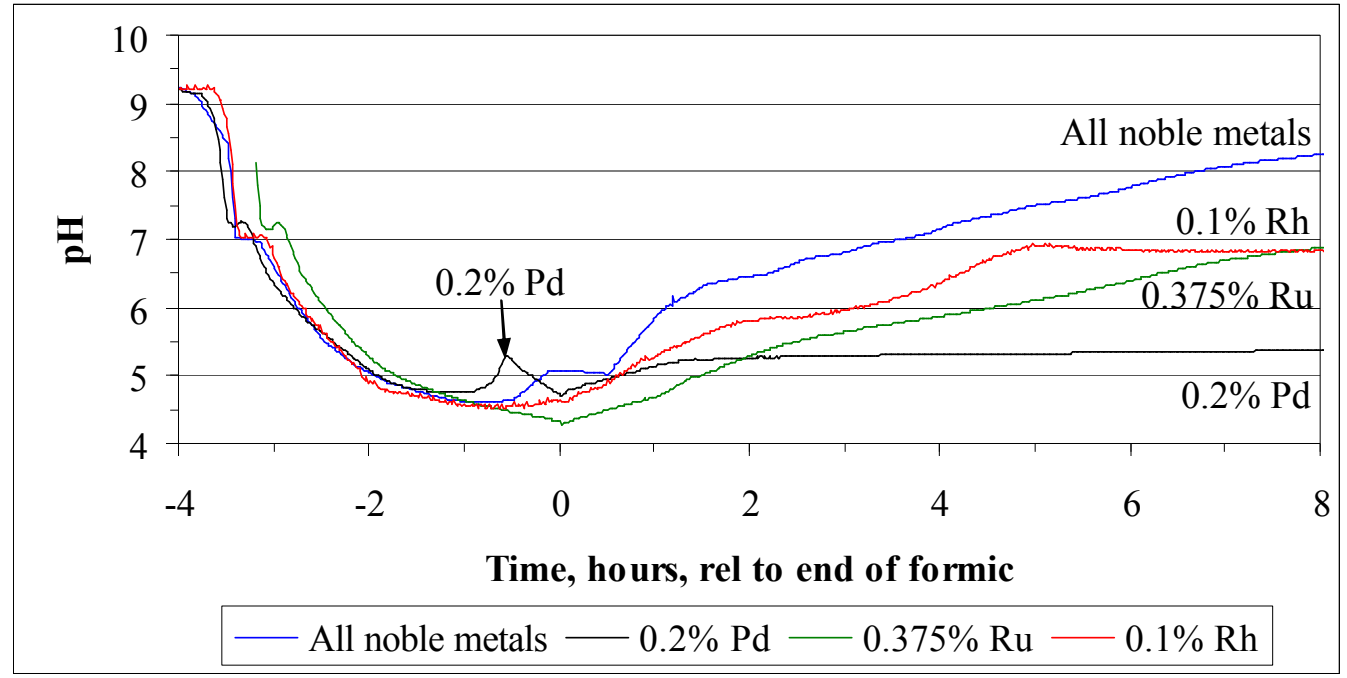

Figure 18. Comparison of $\mathrm{pH}$ profiles

An up-down wiggle in the $\mathrm{pH}$ trace versus time occurred in many of the runs just before the $\mathrm{pH}$ passed through seven. There was not much change in $\mathrm{pH}$ during the last 4-5 hours of reflux in any of the runs relative to the values at +8 hours, although $\mathrm{pH}$ continued to drift slowly up in the $\mathrm{Rh}, \mathrm{Ru}$, and all noble metal runs. The $\mathrm{Ru}$ and $\mathrm{Rh}$ runs barely got above $\mathrm{pH} 7$ by the end of the SRAT.

\subsubsection{Rh data with other noble metals present}

The extent of $\mathrm{Rh}$ dissolution in the all noble metal runs is plotted as a function of time in Figure 19. The majority of the data are from ICP-MS analysis of prepped supernate samples. Seven additional data points from ICP-AES analysis of filtered supernate are also shown.

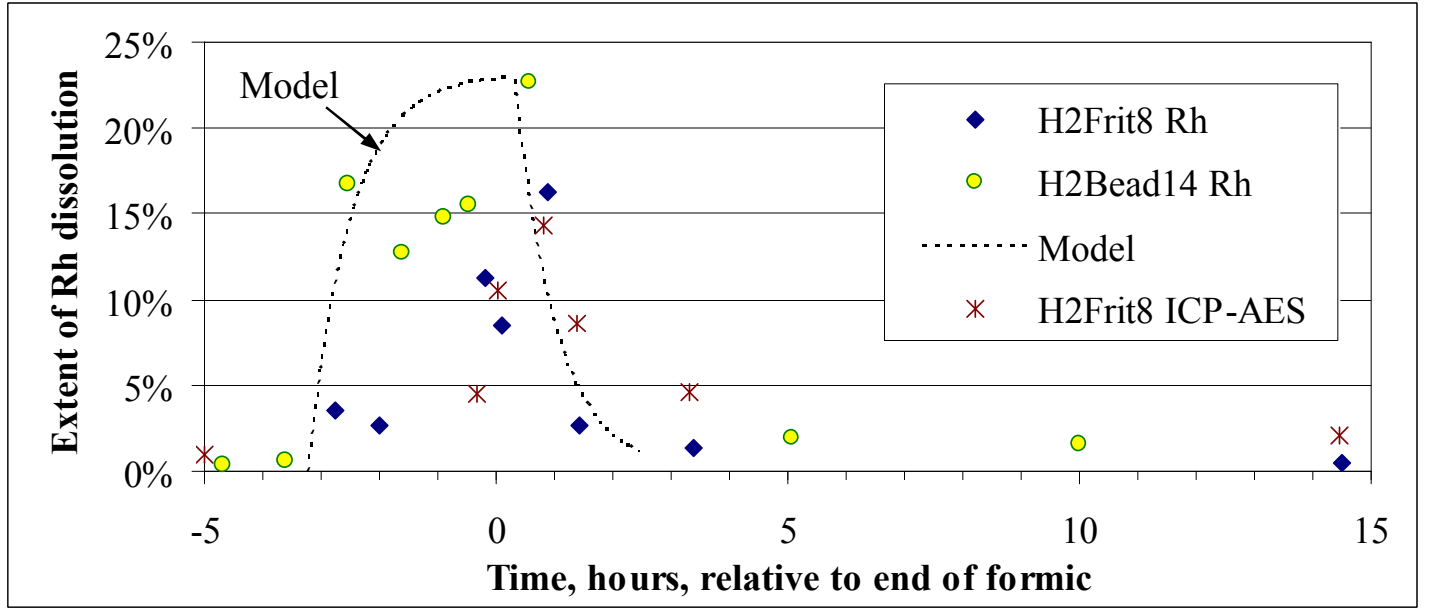

Figure 19. Rh dissolution during processing with all noble metals 
The data are very similar to Figure 5 for the same $\mathrm{Rh}$ loading without the other three noble metals, except that the results show more scatter as was seen with the $0.2 \mathrm{wt} \% \mathrm{Rh}$ case, Figure 2 . Samples in H2Bead14 were targeted into the region around the maximum in H2Frit8 with somewhat unusual results. It would be reasonable for the $\mathrm{Rh}$ to follow the same behavior in the all noble metal runs as in the $0.1 \mathrm{wt} \% \mathrm{Rh}$ only runs if there are no early interactions between $\mathrm{Rh}$ and the other noble metals. The height and breadth of the model that bounds most of the data was chosen to be similar to Figure 5, but the exact placement of the model is relatively arbitrary.

The hydrogen generation rate data for the two all noble metal runs are shown in Figure 20 along with the raw extent of dissolution data for Rh from Figure 19.

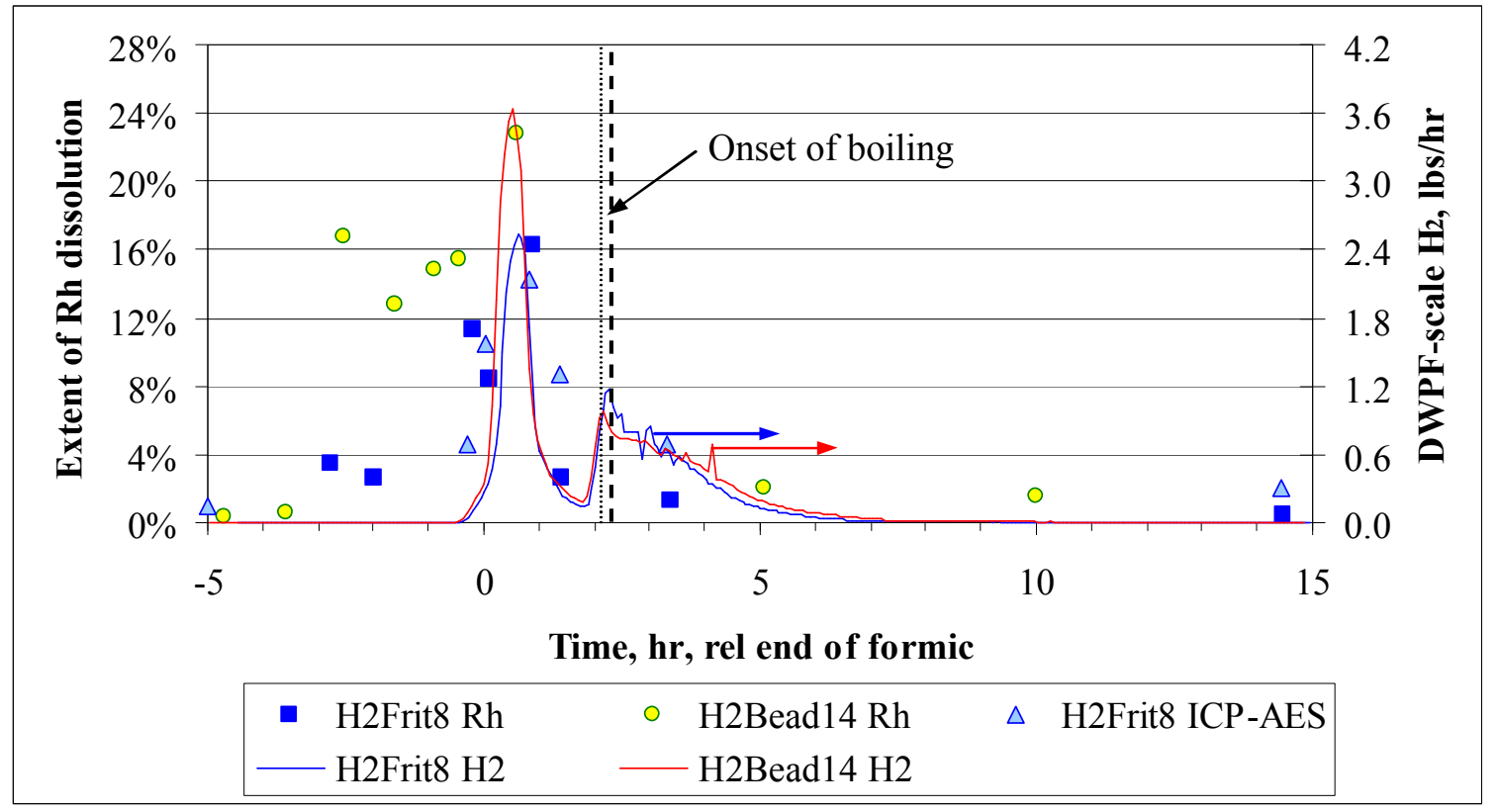

Figure 20. Hydrogen generation from all noble metals with $\mathrm{Rh}$ data

Perhaps the biggest surprise in the data was that the peak hydrogen generation rates of these two runs were both less than half the peak rates of either of the two runs with $0.1 \mathrm{wt} \% \mathrm{Rh}$ alone. The reduced peak height seems to imply that the presence of the other noble metals actually inhibited the activity of rhodium for hydrogen generation. The form of the peak at +0.5 hours strongly resembles that of the Rh peaks in the two prior cases. Fewer increases in the air purge were needed in these runs to keep the hydrogen concentration down. The initial peaks coincide closely with the decrease in soluble $\mathrm{Rh}$ as well, but there is still significant soluble Rh during the decline in hydrogen generation from the initial peak like Figure 6 and unlike Figure 3.

The two Rh only cases also suggest that the hydrogen generation starting at two hours after the end of formic acid addition (onset of boiling) could be primarily due to one of the other noble metals rather than $\mathrm{Rh}$, e.g. $\mathrm{Ru}$. The onset of boiling did not seem to reinvigorate the $\mathrm{Rh}$ in the two earlier pairs of tests, although there was the expected small increase in rate due to the $8^{\circ} \mathrm{C}$ temperature rise. The hydrogen generation rates got fairly small about five hours after acid addition. One reason may be that the formic acid was largely destroyed by this point. 
Calculated SRAT formate losses were $85 \%$ in H2Frit8 and 79\% in H2Bead14. These losses were the highest seen in the sixteen 22 -L runs. Consequently, some of the catalytic activity was apparently diverted into destruction of formic acid/formate that did not produce hydrogen, e.g. catalytic wet air oxidation to form carbon dioxide and water or some other reaction(s). These high formate destruction levels indicate that there was more catalytic activity present in these runs compared to typical DWPF flowsheet studies where formate loss is in the $20-30 \%$ range.

\subsubsection{Ru data with other noble metals present}

The extent of $\mathrm{Ru}$ dissolution in the all noble metal runs is plotted as a function of time in Figure 21. The majority of the data are from ICP-MS analysis of prepped supernate samples. Four additional data points from ICP-AES analysis of filtered supernate are also shown.

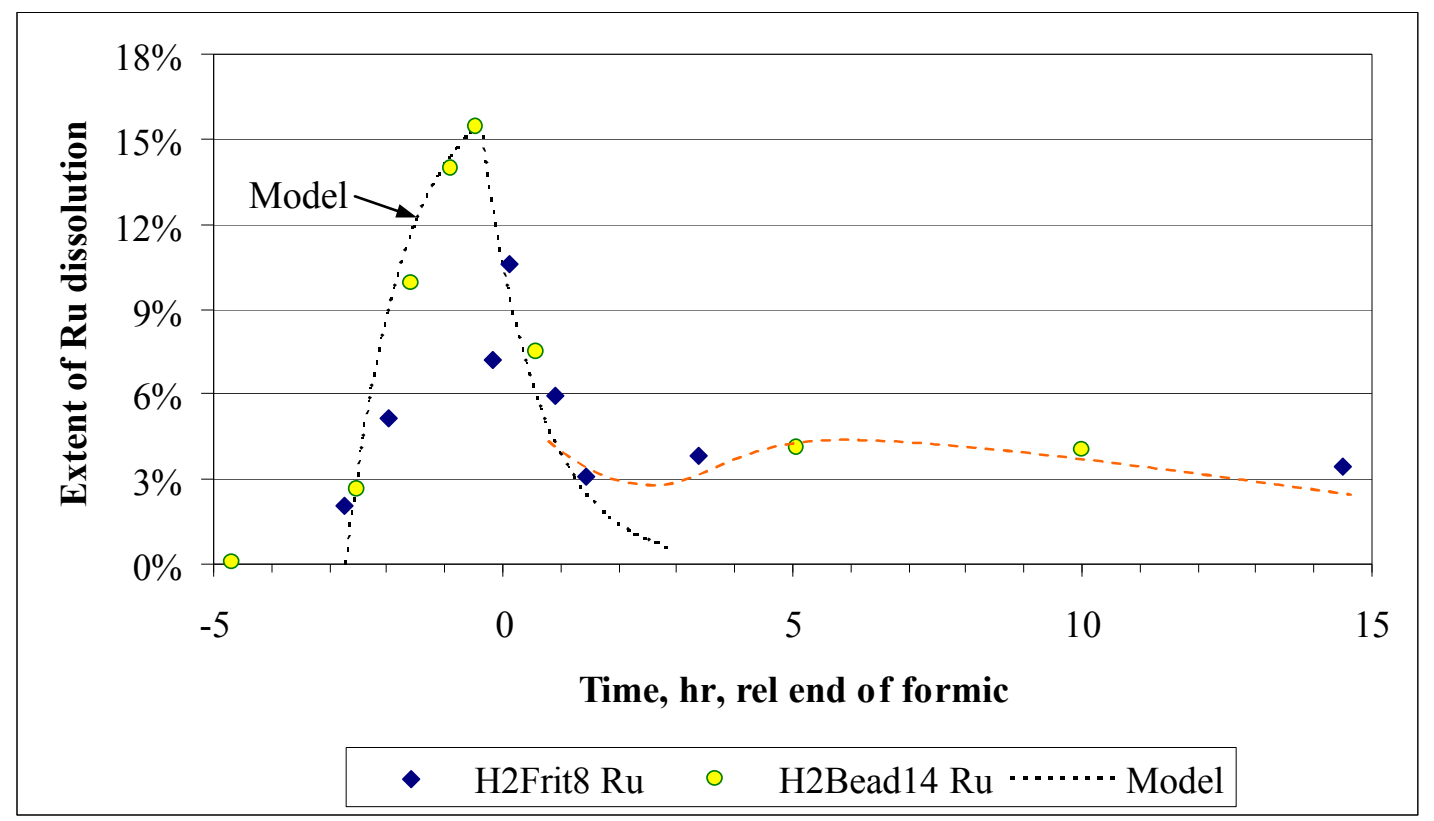

Figure 21. Extent of SRAT Ru dissolution at $0.375 \mathrm{wt} \%$ with other noble metals

It is less clear in this case whether or not $\mathrm{Ru}$ may have had a second maximum in extent of dissolution or if the precipitation just stopped at about $3-4 \%$ still dissolved. The point at +1.3 hours had the smallest extent of dissolution of any points after the maximum. There are not many data points by design. H2Bead13 was picked to study Ru dissolution in detail. The all noble metals data, however, seem to indicate that any secondary maximum in extent of Ru dissolution was less significant than in the two runs without the other noble metals. This observation may signify that there is an interaction occurring between $\mathrm{Ru}$ and one or more of the other noble metals. The points starting more than one hour after acid addition until the end of the SRAT all have about a 4\% extent of dissolution, which is similar to the range seen in the comparable run with $\mathrm{Ru}$ only $(\sim 3 \%)$.

The hydrogen generation rate data are plotted versus the extent of Ru dissolution data for these two runs in Figure 22. The timing of events in the two all noble metal runs was very similar. 


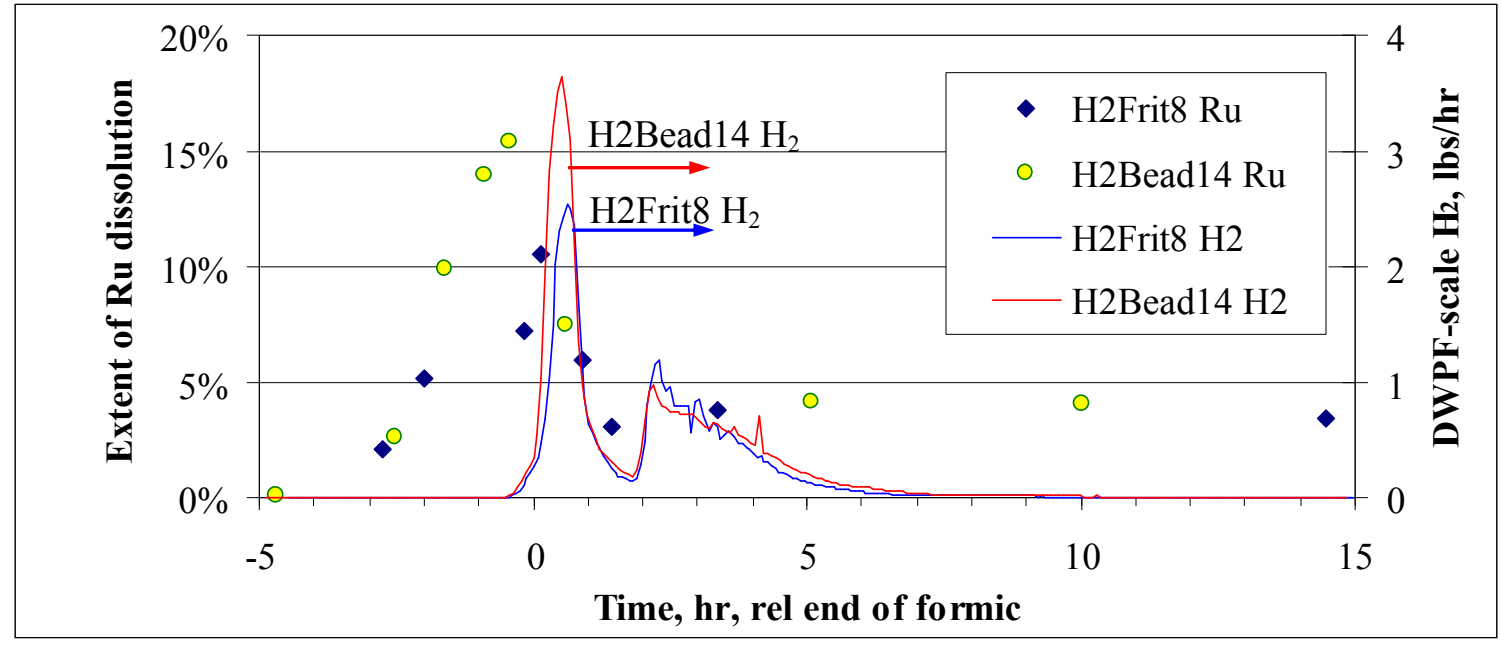

Figure 22. Hydrogen generation vs. Ru dissolution with other noble metals

Ruthenium seems to be coming out of its initial dissolution maximum just prior to the first hydrogen generation rate peak at +0.5 hours. Rhodium was also coming out of solution at this time, but more slowly. It may be that these two species interacted during precipitation.

\subsubsection{Pd data with other noble metals present}

The extent of Pd dissolution is plotted as a function of time in Figure 23. The majority of the data are from ICP-MS analysis of prepped supernate samples. Four additional data points from ICP-AES analysis of filtered supernate are also shown.

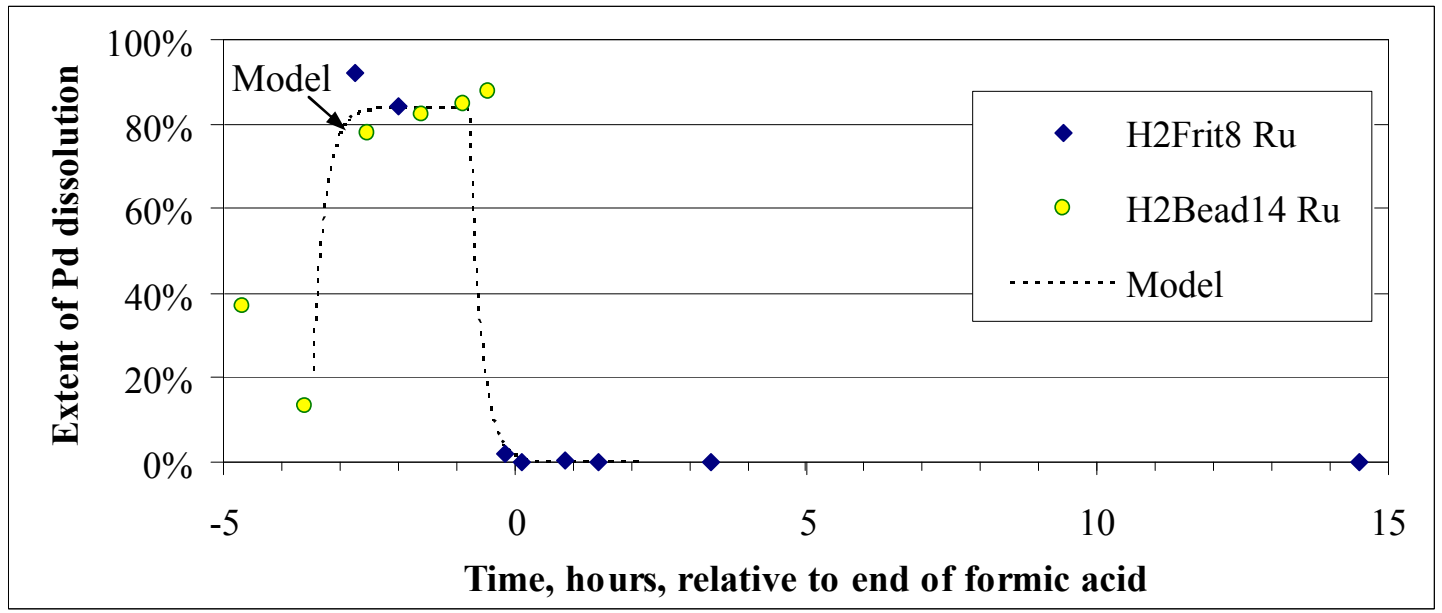

Figure 23. Pd dissolution at $0.1 \mathrm{wt} \%$ in the presence of other noble metals

The data for Pd in the all noble metals runs followed the same trends as seen in the $0.2 \mathrm{wt} \%$ run with Pd only. Dissolution was rapid and reached about $90 \%$ before a sharp decline to essentially no soluble Pd. The maximum extent of dissolution did appear to be sustained until closer to the end of acid addition relative to the $0.2 \mathrm{wt} \%$ data. These all noble metal runs followed a much 
different $\mathrm{pH}$ profile near the end of acid addition than the Pd only runs, H2Frit run data for $\mathrm{pH}$ given in Figure 24.

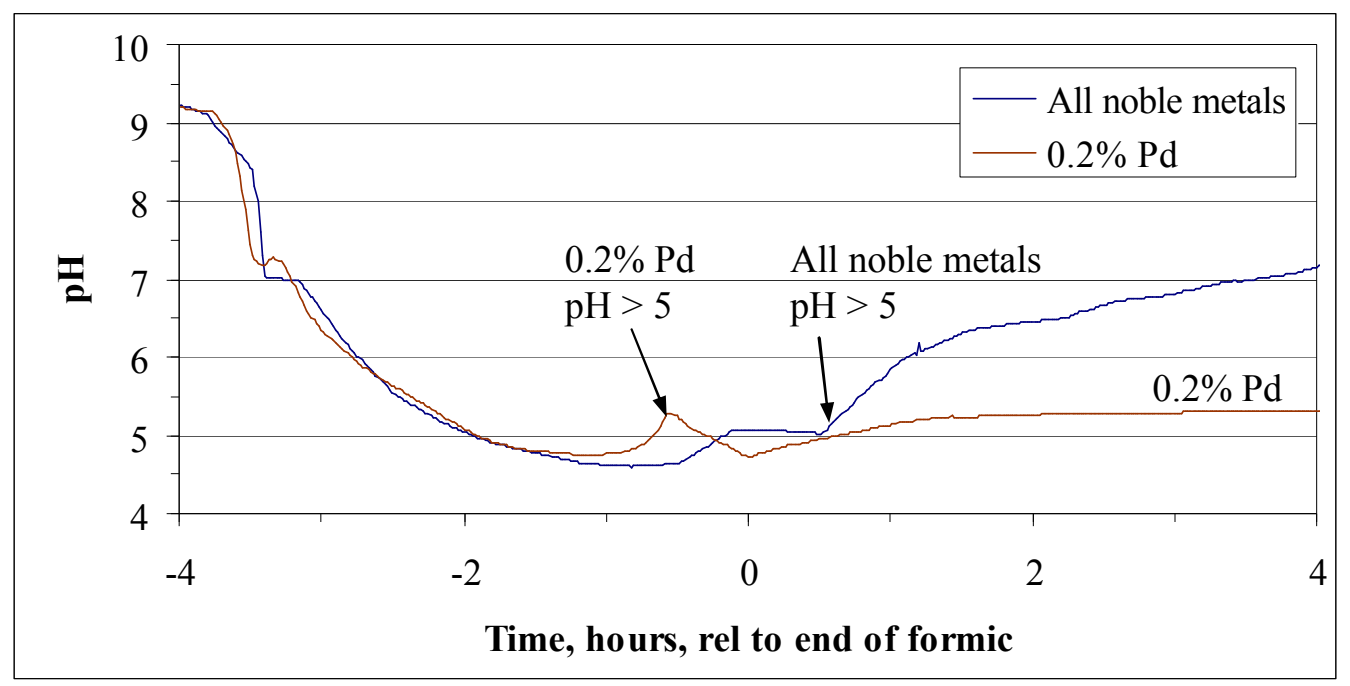

Figure 24. Comparison of pH profiles for Pd with/without other noble metals

The $\mathrm{pH}$ changes could have impacted the timing of the $\mathrm{Pd}$ precipitation. The $\mathrm{pH}$ stayed below $\sim 5.2$ for about an hour longer in the all noble metal run. The highly active Rh and Ru destroyed a lot of formic acid near the end of acid addition resulting in higher $\mathrm{pH}$ 's on average in the period after the end of formic acid addition until the end of reflux. The hydrogen generation rate data were given above. It seems likely that the hydrogen generated in the all noble metal runs was due to the activity of $\mathrm{Rh}$ and $\mathrm{Ru}$, and that the effect of Pd acting independently would be too small to notice. Pd may be interacting with $\mathrm{Rh}$ and/or $\mathrm{Ru}$ to lower their catalytic activities, however, given that the peaks were lower than in the $0.1 \mathrm{wt} \% \mathrm{Rh}$ only runs.

\subsubsection{Hydrogen-noble metal comparison}

The true noble metal supernate concentrations in $\mathrm{mg}$ metal $/ \mathrm{kg}$ supernate are plotted together for $\mathrm{Pd}, \mathrm{Rh}$, and $\mathrm{Ru}$ in Figure 25 using data from H2Bead14. The DWPF-scale hydrogen generation rate is plotted on the same time axis with a second $y$-axis in order to show how the hydrogen production compared to the noble metal concentration data for H2Bead14. 


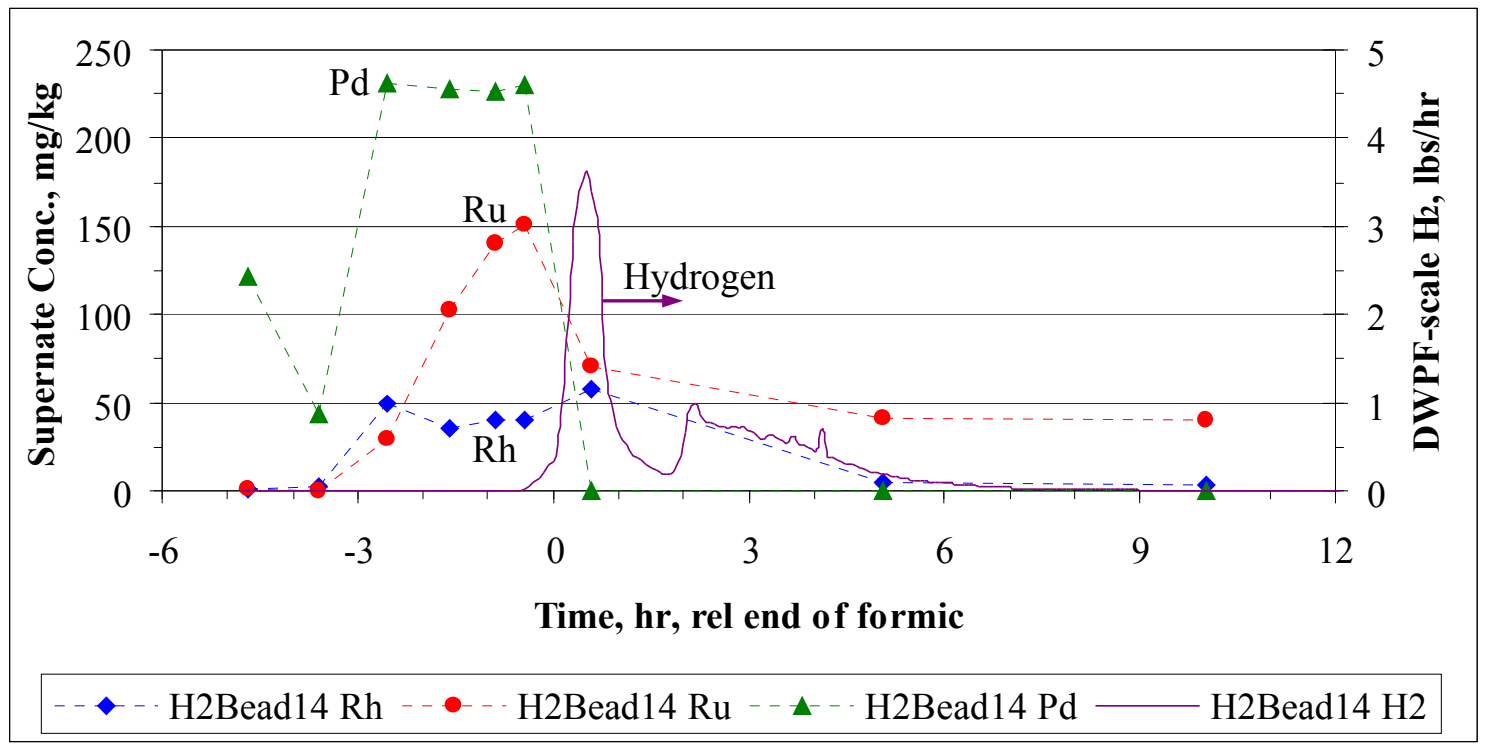

Figure 25. Hydrogen and noble metal supernate concentration

Palladium had dropped out of solution before the hydrogen generation rate peak, while both $\mathrm{Ru}$ and $\mathrm{Rh}$ were present at $50-70 \mathrm{mg} / \mathrm{kg}$. H2Frit8 data indicate that $\mathrm{Rh}$ had dropped to a tenth this concentration before the second hydrogen generation period starting at two hours after the end of formic acid addition.

\subsection{Summary of SRAT Hydrogen - Noble Metal Data}

The rhodium runs gave a variety of unexpected results. Form of noble metal testing had shown a correlation between dissolved $\mathrm{Rh}$ and declining hydrogen generation after the peak when all noble metals were present. The current $\mathrm{Rh}$ runs had very abrupt peaks at the time of maximum hydrogen generation that presented sampling challenges, however it appeared in at least the 0.2 $\mathrm{wt} \% \mathrm{Rh}$ case that most of the $\mathrm{Rh}$ had precipitated out of solution before the hydrogen peaked. Another surprise was the sustained catalytic activity of the $0.1 \mathrm{wt} \% \mathrm{Rh}$ run relative to the other two pairs. These two runs made more hydrogen during and after the peak than the $0.2 \mathrm{wt} \%$ or all noble metal runs. This trend of higher hydrogen generation rates continued through the SME cycle. The new SRAT data provided confirmation to one piece of data from the form of noble metal testing that increasing noble metal concentration can lead to a reduced peak hydrogen generation rate when other conditions are right. The question of how more catalyst can inhibit hydrogen generation is explored further in Section 5.0.

Ruthenium behavior seemed to be fairly consistent under the four conditions tested. The onset of hydrogen generation was relatively slow and late compared to $\mathrm{Rh}$ and $\mathrm{Pd}$. The peak also occurred later than in either the Rh or Pd based systems. Total hydrogen generation, however, was greater than in corresponding runs with the other noble metals. A transition in the character of $\mathrm{Ru}$ seemed to occur around the end of acid addition when a minimum in solubility was observed prior to the onset of hydrogen. It may or may not be coincidental that this was the time when nitrite essentially disappeared, i.e. there may have been an inactive (for hydrogen) nitro-Ru complex in the supernate until the nitrite disappeared. 
The presence of $\mathrm{Ru}$ with $\mathrm{Rh}$ and the other noble metals appeared to trigger a decrease in the initial peak generation rate that empirically appears to be driven by $\mathrm{Rh}$ catalysis, i.e. $\mathrm{Ru}$ may inhibit Rh activity. One possible mechanism could be linked to the parallel precipitation of Rh and $\mathrm{Ru}$ that occurred near the end of formic acid addition. The two species may coprecipitate when both are present, rather than precipitating independently in parallel, giving rise to a less active form of Rh contaminated with Ru. Potentially, an Rh-Ru alloy could be detected by XAS, since both species have sufficient atomic mass to be detected. Another mechanism for inhibition could be $\mathrm{Ru}$ (or $\mathrm{Pd}$ ) catalyzed destruction of the nitrite ion needed to sustain the nitro-Rh complex postulated to be a very active hydrogen generation catalyst, see Section 5.0. This mechanism would have shortened the time that the nitro-rhodium complex was effective causing a smaller peak generation rate because it had to occur sooner (before too much of the nitrorhodium complex was destroyed).

The time-dependent hydrogen generation rates were integrated numerically using Simpson's Rule to calculate the total hydrogen produced in each test.

Table 6. Summary of Maximum Rate and Total Hydrogen Production

\begin{tabular}{|c|c|c|c|c|}
\hline & $\begin{array}{l}\text { Frit Peak } \\
\text { lbs } \mathrm{H}_{2} / \mathrm{hr}\end{array}$ & $\begin{array}{c}\text { Bead Peak } \\
\mathrm{lbs} \mathrm{H}_{2} / \mathrm{hr}\end{array}$ & $\begin{array}{c}\text { Frit Total } \\
\mathrm{g} \mathrm{H}_{2}\end{array}$ & $\begin{array}{c}\text { Bead Total } \\
\mathrm{g} \mathrm{H}_{2}\end{array}$ \\
\hline $0.2 \% \mathrm{Rh}$ & 6.1 & 9.8 & 0.50 & 0.67 \\
\hline $0.2 \% \mathrm{Ru}$ & 0.60 & 0.71 & 1.43 & 1.79 \\
\hline $0.2 \% \mathrm{Ag}$ & 0.010 & $0.074^{1}$ & 0.040 & 0.032 \\
\hline $0.2 \% \mathrm{Pd}$ & 0.029 & 0.022 & 0.067 & 0.029 \\
\hline $0.375 \% \mathrm{Ru}$ & 1.18 & 1.49 & 1.89 & 2.75 \\
\hline $0.1 \% \mathrm{Rh}$ & 9.0 & 12.1 & 3.07 & 2.61 \\
\hline None & 0.004 & 0.0 & 0.005 & 0.0 \\
\hline All noble metals & 2.5 & 3.6 & 1.10 & 1.36 \\
\hline
\end{tabular}

1 - There was a short duration spike in the Ag bead run that was not in the frit run, but the two profiles were otherwise almost identical.

The agreement of the peak and total measures in Table 6 between runs within a pair was not impressive. Totals generally agreed better than peak rates. Generally, the two totals within each bead-frit run pair were distinctly different from the pairs of totals for each other case. The Ag and Pd pairs, however, were essentially indistinguishable from each other because their values were so small. Some of the differences in total hydrogen production were more disturbing from a standpoint of data reproducibility. The process of integration tends to smooth out variations and minimize the impact of occasional small random errors. Ultimately, the differences in total hydrogen may simply reflect the fact that hydrogen generation is one of the last significant reactions during the SRAT cycle, and that this reaction is very sensitive to all the small processing differences that have occurred before it. Similar numerical measures for $\mathrm{CO}_{2}$ and $\mathrm{N}_{2} \mathrm{O}$, however, agreed much more closely within a bead-frit pair unless there was a serious GC issue. These non-hydrogen results are discussed in the related report on SRAT chemistry and acid consumption. ${ }^{6}$ 
One reason for differences in the peak rates above the DWPF limit of $0.65 \mathrm{lbs} / \mathrm{hr}$ may lie in the process dynamics of the experimental equipment during major changes in the air purge rates. The timing and magnitude of purge rate changes were not identical within a pair of matched runs (the air purge was increased to over $400 \%$ of nominal in extreme cases with an associated large decrease in the helium concentration; the helium inlet flowrate was held constant). Altering the air purge flowrate changes the gas-phase residence times of the glassware and the steady-state He concentration. While He concentrations were transitioning between steady states following a purge rate change, the assumption that the outlet He flowrate at the GC sample point was equal to the inlet He flowrate was no longer totally accurate. The less accurately known He flow during the air purge rate transitions introduced an additional source of uncertainty in the calculated hydrogen generation rates. This air purge impact was normally not an issue in flowsheet simulation work which stays below the DWPF limit and does not require air purge rate changes. 
WSRC-STI-2008-00002

Revision 0

This page left blank. 


\subsection{SME DATA DISCUSSION}

The SME cycle hydrogen generation data contained less total information than the SRAT. The four no noble metal and silver runs produced essentially no detectable SME cycle hydrogen. The $0.2 \mathrm{wt} \% \mathrm{Rh}$ runs were only marginally active by the SME cycle, while the Pd runs continued to produce hydrogen at low rates. The runs with $\mathrm{Ru}$ produced significant hydrogen in the SME, and these runs in many instances exceeded the DWPF SME cycle hydrogen limit of $0.223 \mathrm{lbs} / \mathrm{hr}$. A sample was taken after dewatering the first frit addition in seven of the frit runs to check for noble metal dissolution. The extent of noble metal dissolution was very small in all cases, consistent with the data from the SRAT and SME products. The time axes on the SME cycle plots for pairs of matching runs were aligned by making a small adjustment to one of the two timelines to bring it into closer agreement with the other run. The adjustment was always less than an hour and was due to variations in the transition time between the end of the SRAT and start of the SME cycle.

\subsection{Ru Only Runs and All Noble Metal Runs}

The SME cycle hydrogen generation rate data for the runs with $0.375 \mathrm{wt} \% \mathrm{Ru}$ are shown in Figure 26.

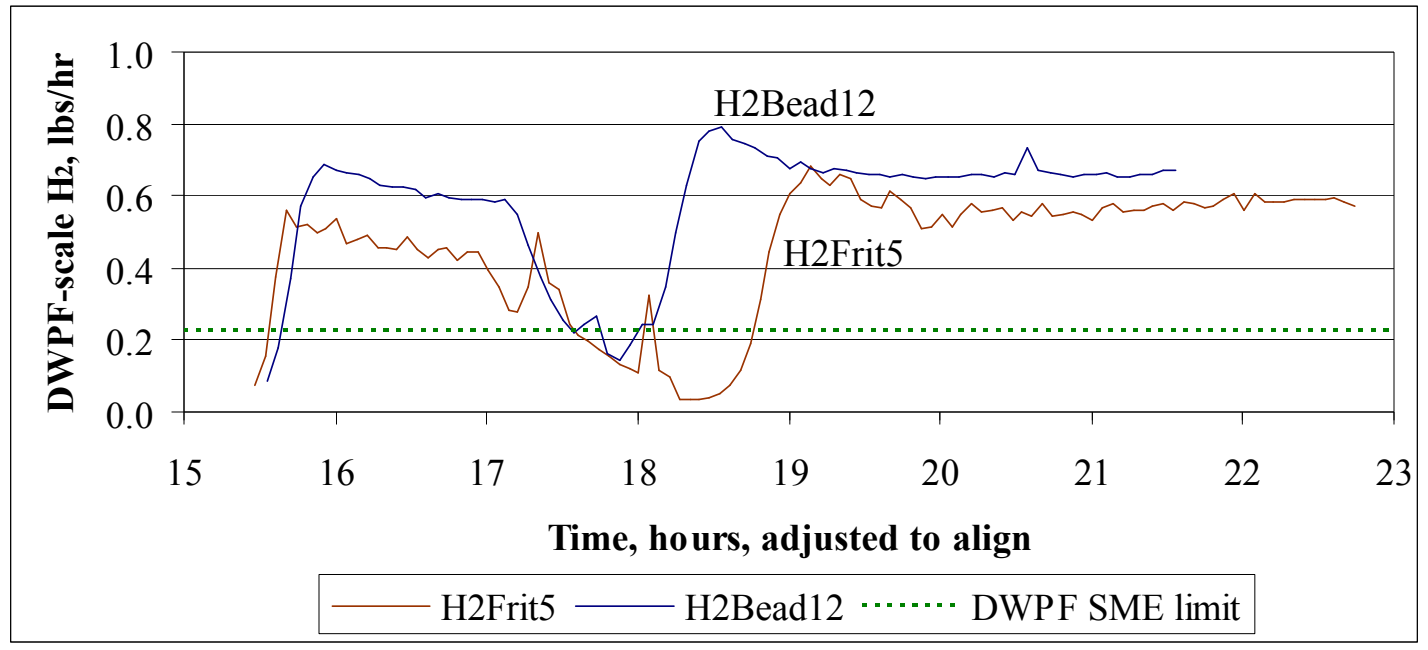

Figure 26. SME hydrogen at $0.375 \mathrm{wt} \% \mathrm{Ru}$

The SME cycle hydrogen generation rate data for the runs with $0.375 \mathrm{wt} \% \mathrm{Ru}$ and the other three noble metals are shown in Figure 27. 
WSRC-STI-2008-00002

Revision 0

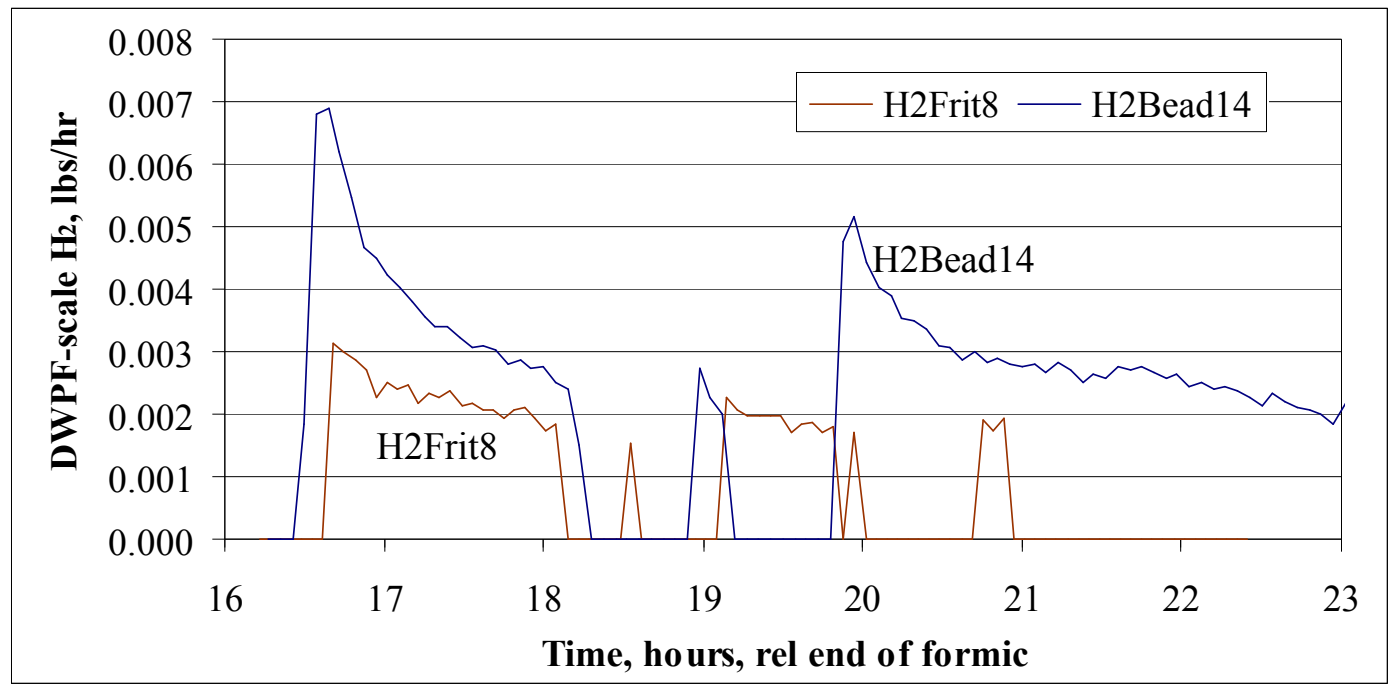

Figure 27. SME hydrogen with all noble metals

The major reduction in hydrogen generation between these two pairs was attributed to the extensive destruction of formic acid and formate in the SRAT cycle of the two all noble metal runs compared to the two runs with $\mathrm{Ru}$ alone at $0.375 \mathrm{wt} \%$. The hydrogen generation data for the two runs at $0.2 \mathrm{wt} \% \mathrm{Ru}$ are shown in Figure 28.

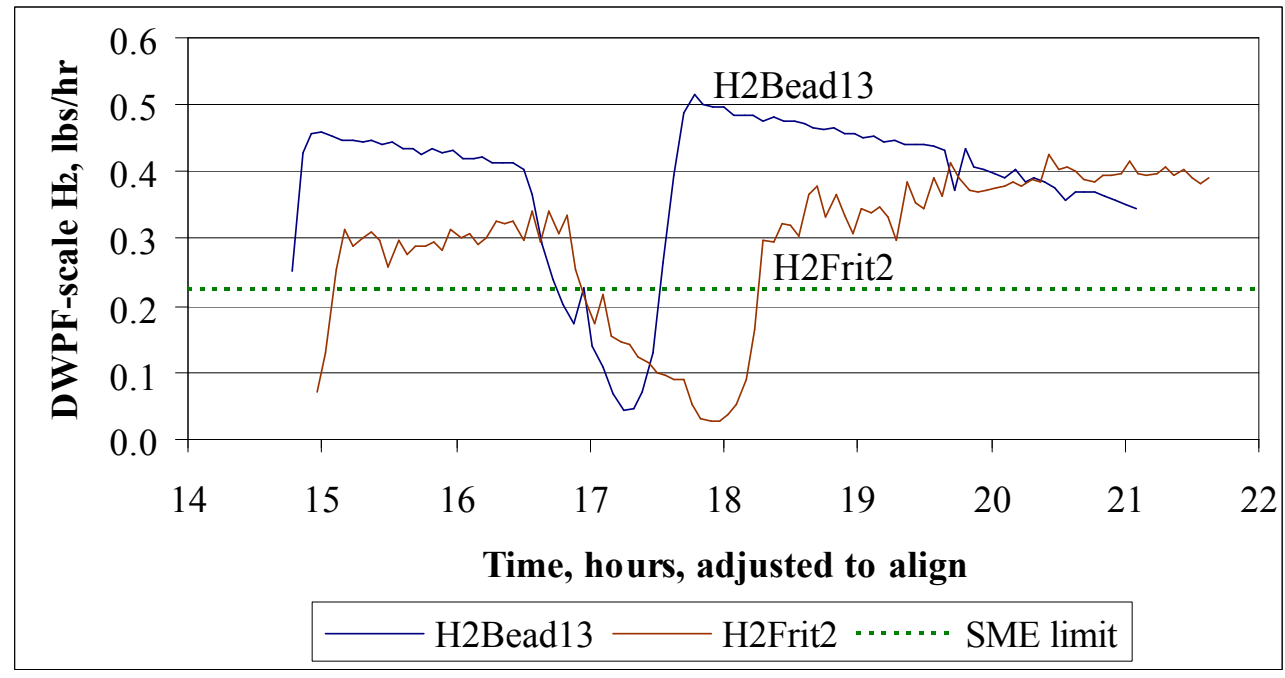

Figure 28. SME hydrogen at $0.2 \mathrm{wt} \% \mathrm{Ru}$

The hydrogen generation rates in the SME cycle were about $70 \%$ of those in the two runs at $0.375 \mathrm{wt} \% \mathrm{Ru}$. This result could indicate that the catalytic activity increased less than linearly with increasing $\mathrm{Ru}$ concentration or that there was less remaining formate (reactant for $\mathrm{H}_{2}$ generation) available at the start of the $0.375 \mathrm{wt} \% \mathrm{Ru}$ SME cycles. 


\subsection{Rh Only Runs}

The SRAT cycles of the four $\mathrm{Rh}$ runs all had a large peak near the end of acid addition followed by a substantial reduction in the hydrogen generation rate, although the $0.1 \mathrm{wt} \% \mathrm{Rh}$ runs were still producing hydrogen near the DWPF SRAT limit at the end of the SRAT cycle. The hydrogen generation rate data for the SME cycles of the $0.1 \mathrm{wt} \% \mathrm{Rh}$ runs are shown in Figure 29.

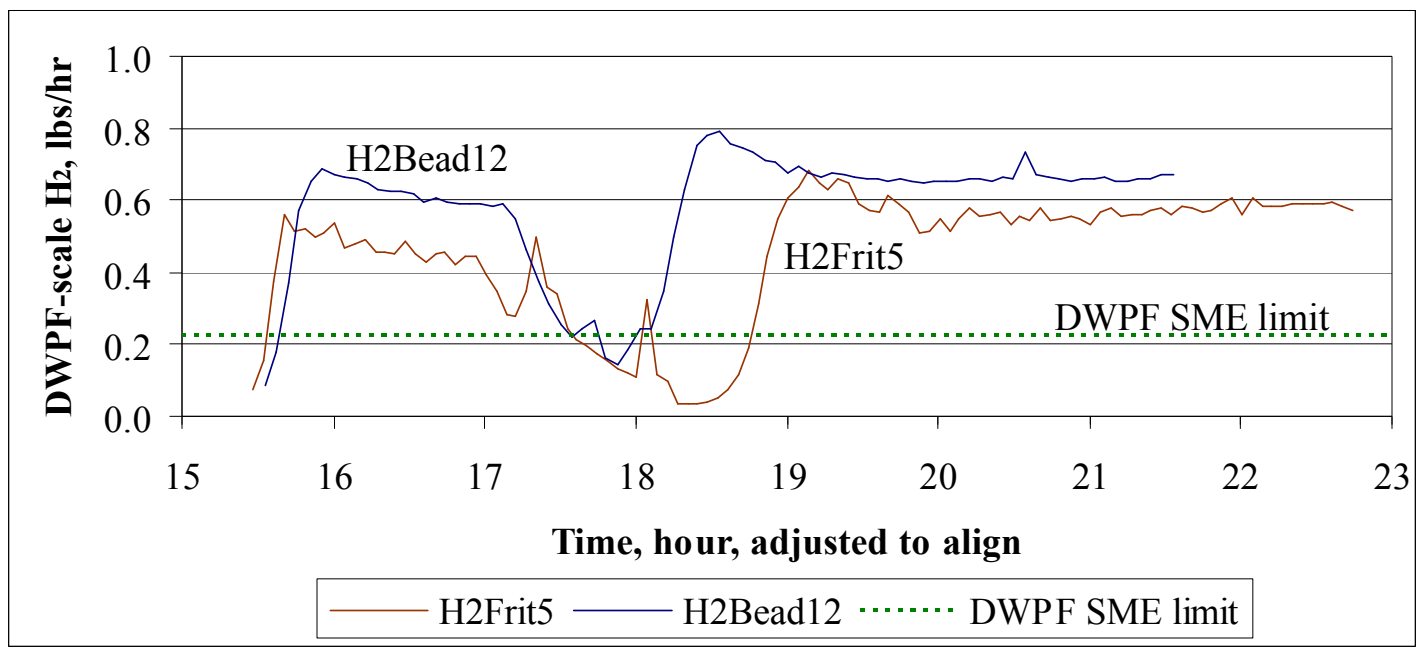

Figure 29. SME hydrogen at $0.1 \mathrm{wt} \% \mathrm{Rh}$

The equivalent data for the $0.2 \mathrm{wt} \% \mathrm{Rh}$ run are shown in Figure 30.

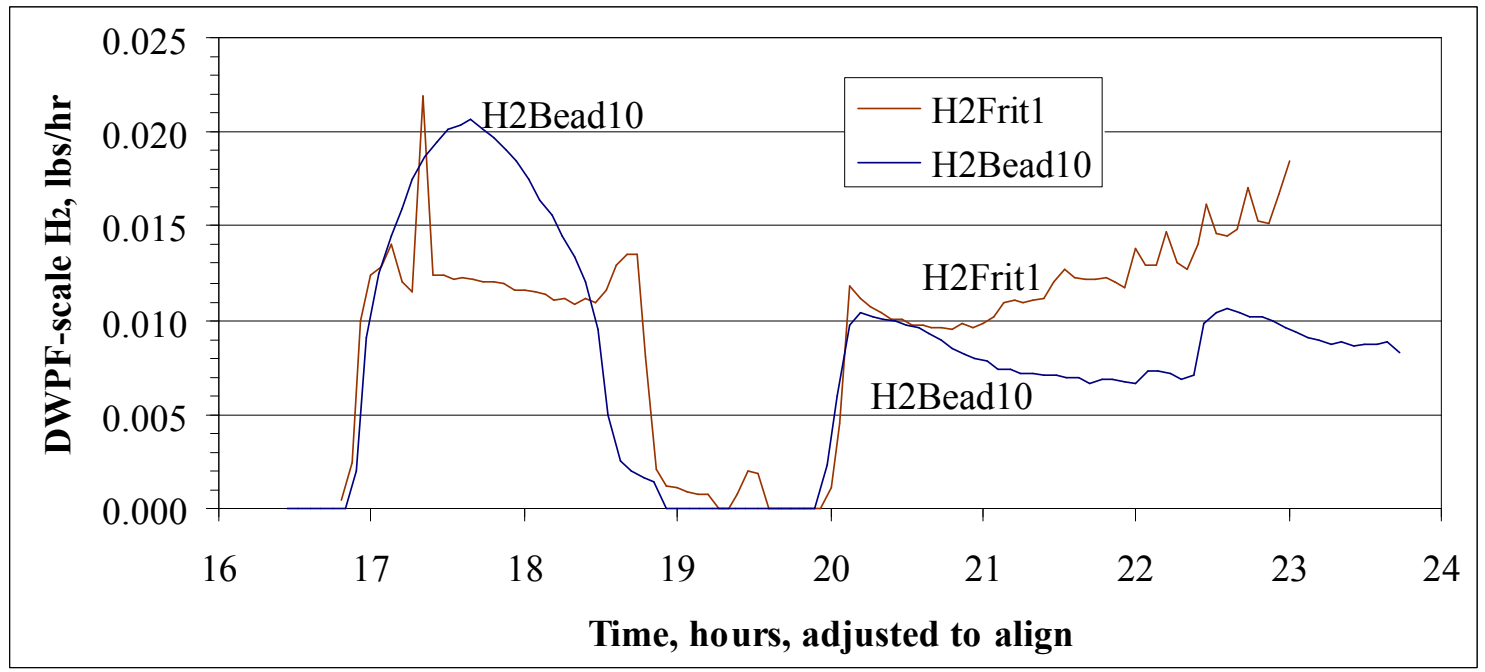

Figure 30. SME hydrogen at $0.2 \mathrm{wt} \% \mathrm{Rh}$

The SME cycle hydrogen generation rates were about twenty times smaller with $0.2 \mathrm{wt} \% \mathrm{Rh}$ than with $0.1 \mathrm{wt} \% \mathrm{Rh}$. This result was attributed to the higher cumulative formate destruction in the $0.2 \mathrm{wt} \% \mathrm{Rh}$ SRAT cycle. The rates with all noble metals present, Figure 27, were smaller 
than either of the runs with $\mathrm{Rh}$ in the absence of other noble metals. The all noble metal runs had the highest cumulative formate loss in the SRAT.

\subsection{Pd Only Runs}

The SME cycles of the two runs with $0.2 \mathrm{wt} \% \mathrm{Pd}$ are shown in Figure 31.

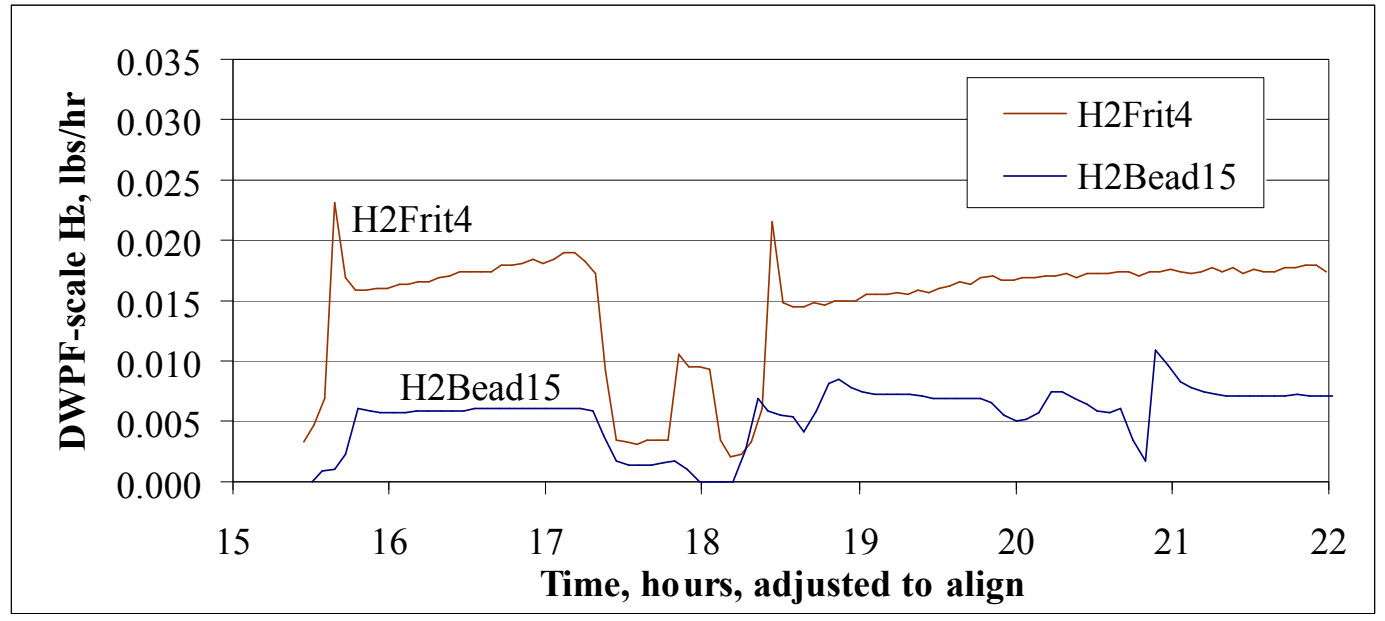

Figure 31. SME hydrogen at 0.2 wt\% Pd

These data appear to indicate that the catalytic activity of Pd was being sustained through the SRAT and SME cycles, but the level was considerably less for hydrogen generation than either $\mathrm{Rh}$ or Ru.

\subsection{General SME Hydrogen Summary}

Table 7 presents the summary statistics of peak hydrogen generation rate at DWPF-scale and the total grams of hydrogen produced during the SME cycle.

Table 7. Summary of SME Maximum Rate and Total Hydrogen Production

\begin{tabular}{|l|c|c|c|c|}
\hline & $\begin{array}{c}\text { Frit Peak } \\
\mathrm{lbs} \mathrm{H}_{2} / \mathrm{hr}\end{array}$ & $\begin{array}{c}\text { Bead Peak } \\
\mathrm{Lbs} \mathrm{H}_{2} / \mathrm{hr}\end{array}$ & $\begin{array}{c}\text { Frit Total } \\
\mathrm{g} \mathrm{H}_{2}\end{array}$ & $\begin{array}{c}\text { Bead Total } \\
\mathrm{g} \mathrm{H}_{2}\end{array}$ \\
\hline $0.2 \% \mathrm{Rh}$ & 0.022 & 0.021 & 0.018 & 0.017 \\
\hline $0.2 \% \mathrm{Ru}$ & 0.462 & 0.516 & 0.617 & 0.709 \\
\hline $0.2 \% \mathrm{Ag}$ & 0.014 & 0.004 & 0.014 & 0.003 \\
\hline $0.2 \% \mathrm{Pd}$ & 0.021 & 0.011 & 0.029 & 0.010 \\
\hline $0.375 \% \mathrm{Ru}$ & 0.681 & 0.789 & 1.011 & 0.994 \\
\hline $0.1 \% \mathrm{Rh}$ & 0.664 & 0.795 & 0.840 & 1.003 \\
\hline None & 0.005 & 0.002 & 0.0063 & 0.0027 \\
\hline All noble metals & 0.003 & 0.007 & 0.0015 & 0.0049 \\
\hline
\end{tabular}

Four of the five bead runs with $\mathrm{Rh}$ and/or $\mathrm{Ru}$ had a higher peak generation rate and total than the matching frit runs. The fifth case was essentially a tie. The differences may lie within the experimental measurement error for SME cycle hydrogen values, but the apparent trend was 
worth noting. The calculated SME formate losses in the two runs with $0.2 \mathrm{wt} \% \mathrm{Ru}$ were $29 \%$ and $8 \%$ even though the hydrogen generation totals were quite comparable. The variability of the formate loss results was probably dominated by error propagation. Accurate SRAT and SME product masses and SRAT and SME product formate concentrations are needed to calculate an accurate SME formate loss. The normal errors on formate ion concentrations by IC coupled with the estimation methods needed to develop a SRAT product mass from either the starting sludge mass or SME product mass should be adequate to cover the range of loss values seen. ${ }^{1}$ Similar SME formate results were found for the two runs at $0.375 \mathrm{wt} \% \mathrm{Ru}$ where the losses were $33 \%$ and $16 \%$. Similar formate results were found for the two runs at $0.1 \mathrm{wt} \% \mathrm{Rh}$ as well where the SME formate losses were $-2 \%$ and $17 \%$.

The primary visual observation of the processed data was that the hydrogen generation rate at the start of the SME cycle was generally comparable to the hydrogen generation rate at the end of the corresponding SRAT cycle. The next series of four figures shows the early SME hydrogen generation rate profiles compared to the end of SRAT hydrogen generation rate profiles for four cases. The SRAT data ends at the time when the mantle was turned off in preparation for sampling. The SME data starts as the vessel was heating up to boiling to dewater the first frit slurry addition.

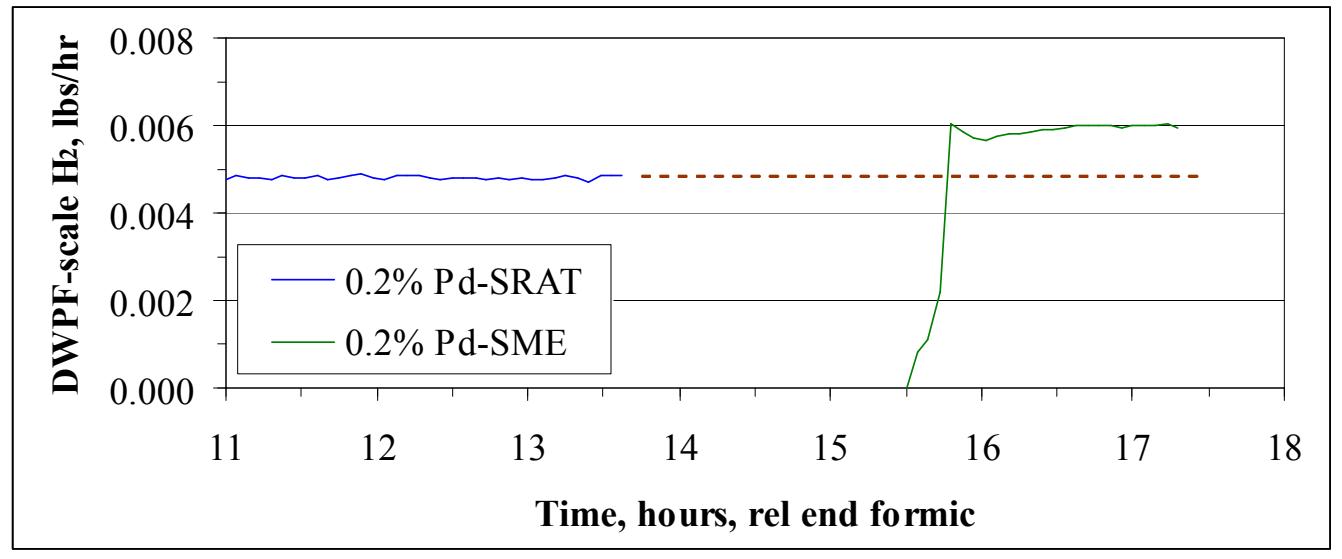

Figure 32. SRAT to SME transition with Pd

\footnotetext{
${ }^{1}$ The SRAT formate addition is known fairly accurately from the molarity of the formic acid added and its volume. The starting sludge is formate free. The primary uncertainty in the SRAT formate loss comes from the unmeasured SRAT product mass and the measured formate concentration, which is subject to typical IC measurement errors. The SRAT product mass uncertainty is bounded by material balance considerations to about $\pm 5 \%$ due to unexplained mass losses. The SME formate loss is calculated from the SRAT product formate (which contains essentially all of the uncertainty in the SRAT calculation), the frit formic acid additions, and the SME product formate (which introduces additional uncertainty through propagation of error considerations). The frit formic acid addition is known as accurately as the SRAT formate addition. The SME product mass is weighed, but residual SME slurry coats the vessel walls, agitator shaft and blades, $\mathrm{pH}$ probe, etc., so the weighed mass is a lower bound on the slurry present in the vessel at the end of the SME cycle. The mass is probably accurate to within two percent. Additional uncertainty is introduced by the IC measurement of the SME product formate. Furthermore, the SME formate loss is generally smaller than the SRAT loss. The magnitude of potential error relative to the magnitude of formate loss increases as the actual loss decreases.
} 


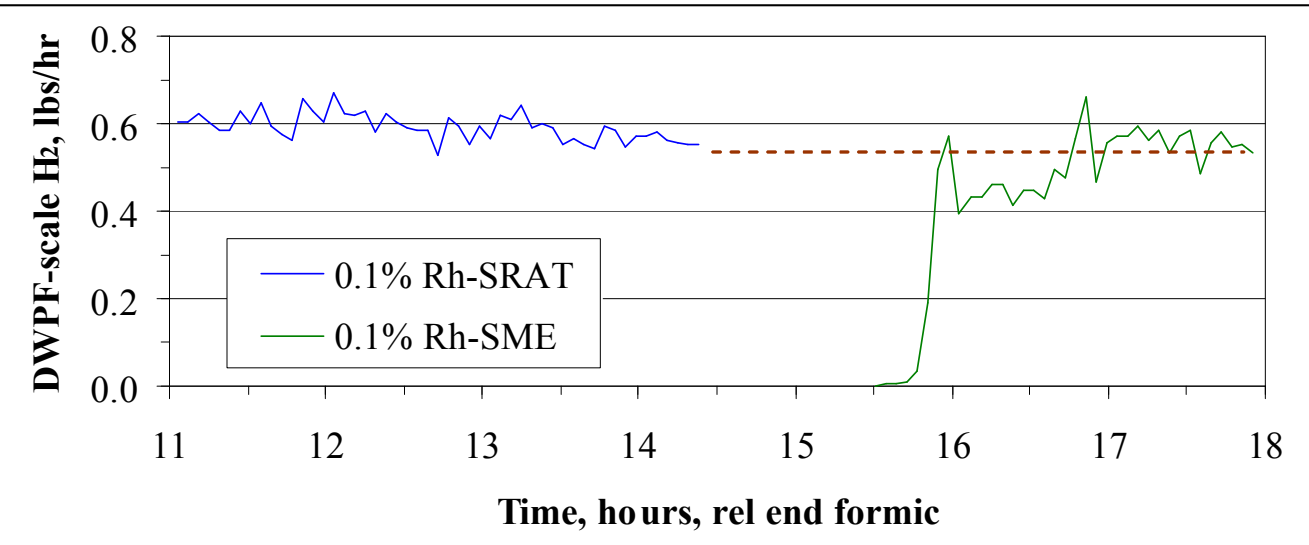

Figure 33. SRAT to SME transition with $0.1 \%$ Rh

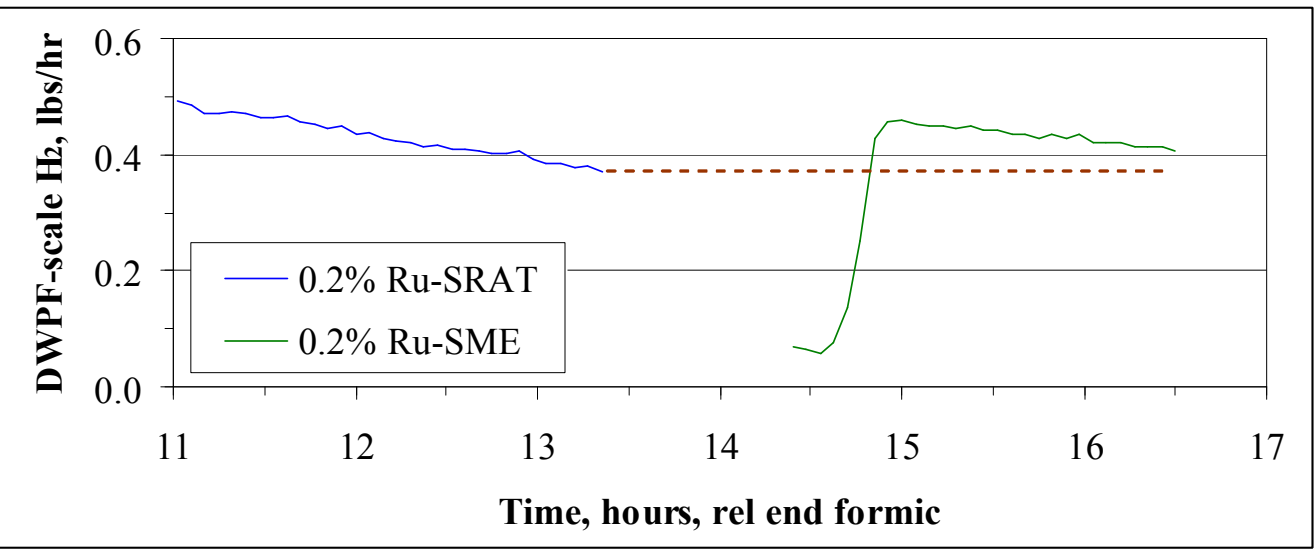

Figure 34. SRAT to SME transition with $0.2 \%$ Ru

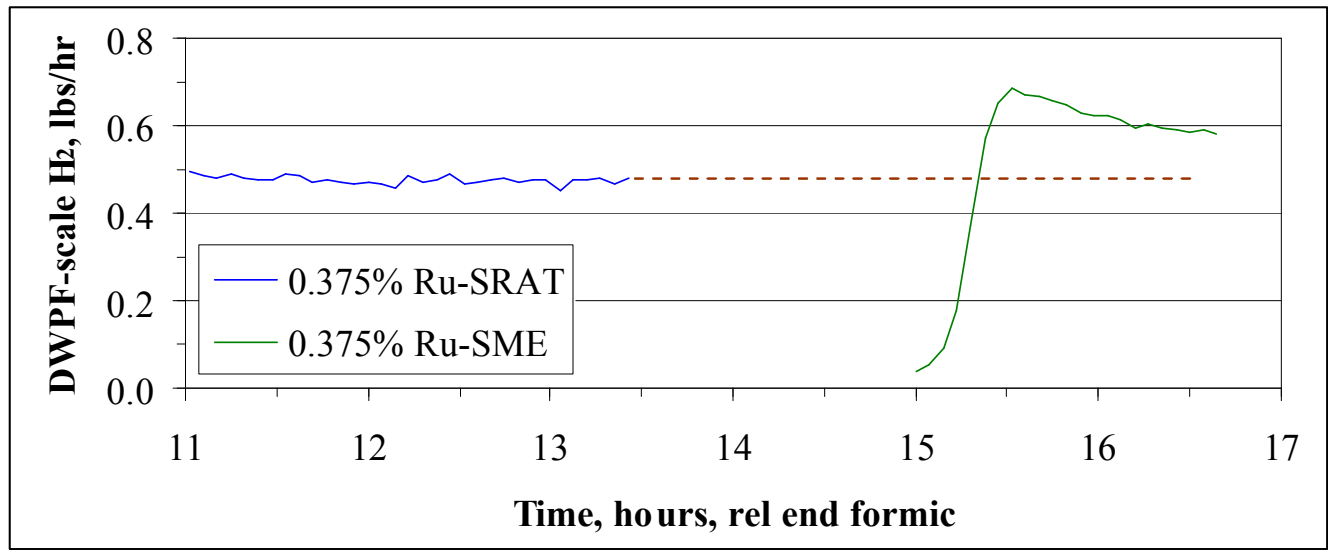

Figure 35. SRAT to SME transition with $0.375 \%$ Ru

Generally the early SME hydrogen generation rates in these systems were slightly above the late SRAT hydrogen generation rates. The increased rate was attributed to the additional formic acid 
introduced with the first frit slurry addition. In other testing where the SME starts with a canister decon water addition and dewatering, the SME often has a nearly identical initial maximum hydrogen generation to the end of SRAT hydrogen generation rate (no added formic acid). The situation is expected to differ somewhat in DWPF where only about $75 \%$ of the SRAT slurry is transferred to the SME. In the lab-scale system, $100 \%$ of the SRAT slurry is transferred to the $\mathrm{SME}$ and there is no dilution of the catalyst or formic acid by the SME heel. 
WSRC-STI-2008-00002

Revision 0

This page left blank. 


\subsection{Insights from Literature and Past Reports}

The differing catalytic activity of $\mathrm{Rh}, \mathrm{Ru}$, and Pd was expected from earlier site work and from the published literature as previously reviewed. ${ }^{9}$ The primary source for this finding during SRS waste processing was summarized in the report by Hsu and Ritter. ${ }^{10}$ Figure 5 from this report, reprinted below, shows behavior very similar to that observed in the bead-frit single noble metal tests. These tests, however, had never been repeated for the redox balanced nitric acid flowsheet.

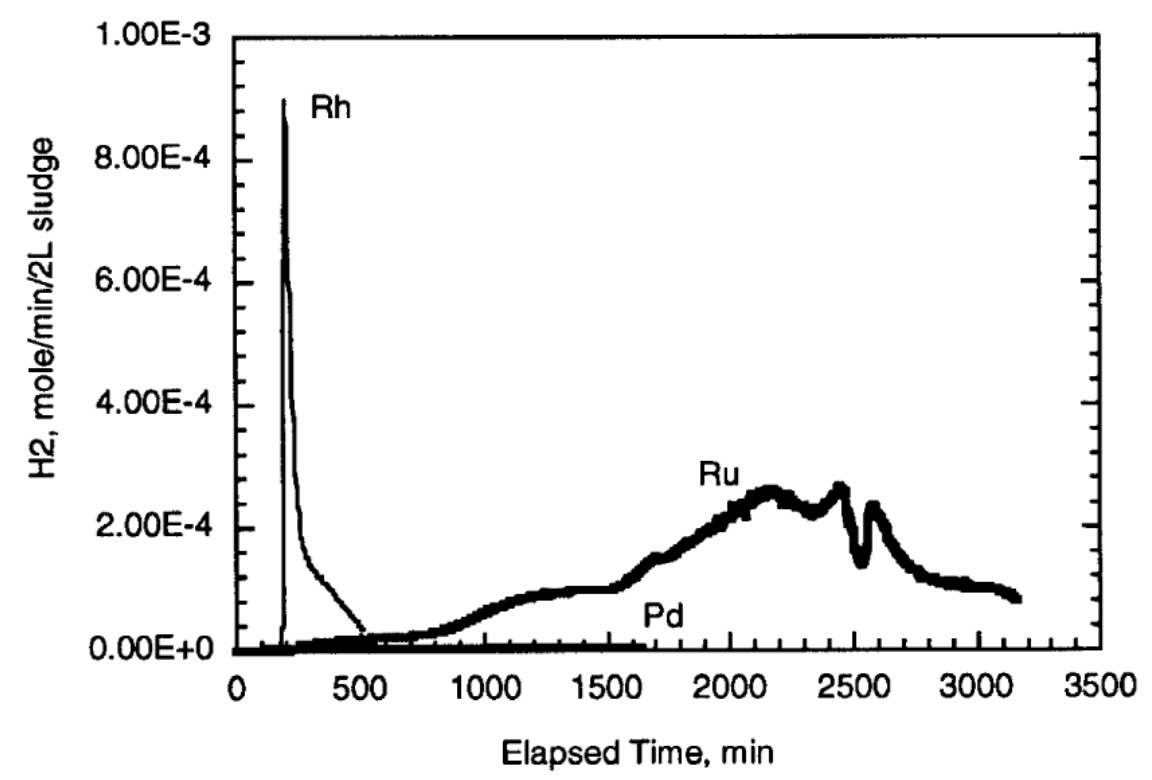

Figure 5. Relative catalytic activities of the individual noble metals $(120 \mathrm{~mL}$ $\mathrm{HCOOH}$ at $0.667 \mathrm{~mL} / \mathrm{min}$ added to sludge at $94^{\circ} \mathrm{C}$, then refluxed at boiling conditions).

Figure 36. Reprint of Figure 5 from Hsu and Ritter

The maximum Rh hydrogen generation rate was largest, the Ru hydrogen generation rates were responsible for the most total hydrogen and came later than the Rh peak, and the production from $\mathrm{Pd}$ was comparatively insignificant compared to $\mathrm{Rh}$ and $\mathrm{Ru}$, but was not zero. An equivalent graph for three bead-frit runs at $0.2 \mathrm{wt} \%$ noble metal is given in Figure 37. The palladium hydrogen generation rates cannot be separated from the baseline using a linear scale that includes the entire rhodium peak. 
WSRC-STI-2008-00002

Revision 0

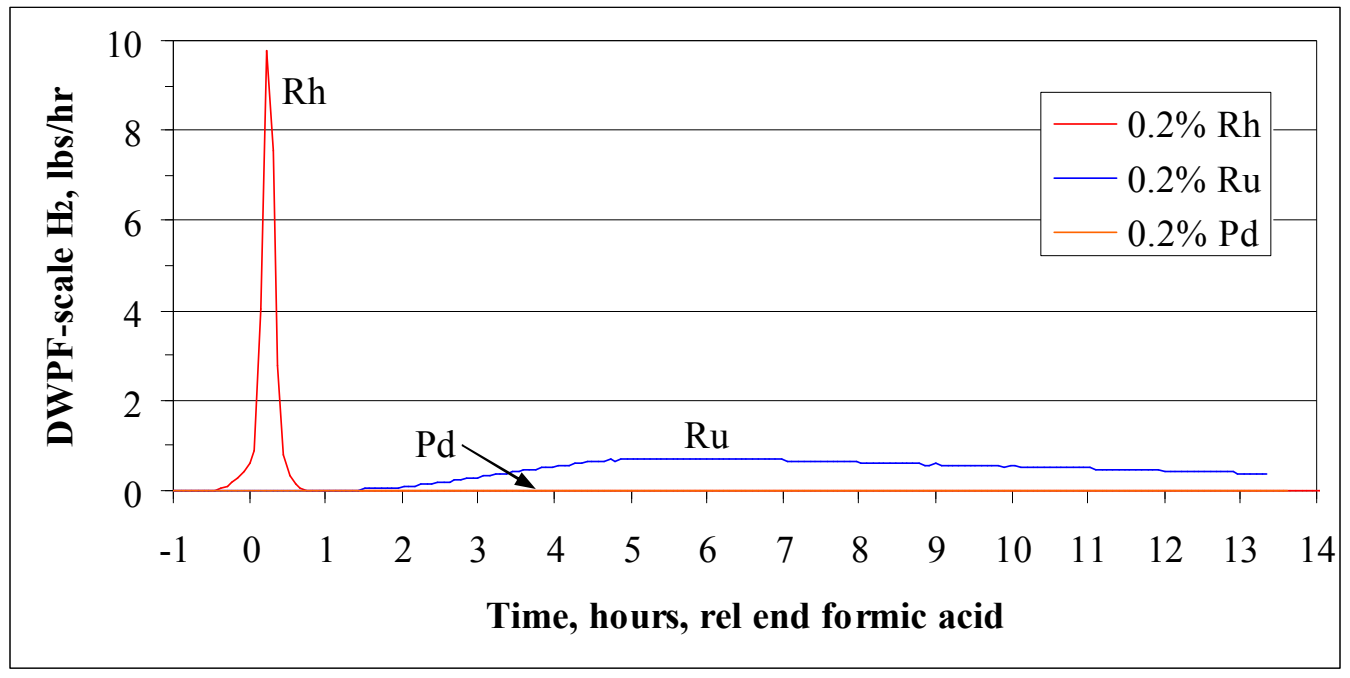

Figure 37. Bead run analog to Hsu and Ritter plot

The bead-frit tests confirm the general pattern of behavior seen fifteen years ago using a Purex simulant with roughly $3,000 \mathrm{mg} / \mathrm{kg}$ nitrite $\left(2.46 \mathrm{wt} \% \mathrm{NaNO}_{2}\right.$ in the dried solids) and $100 \%$ formic acid (no nitric acid). Hsu and Ritter also claimed that the peak hydrogen generation rate came only after nitrite was destroyed.

King et al. noted the role of $\mathrm{NO}_{2}{ }^{-}$as a promoter for Rh-catalyzed formic acid decomposition and as an inhibitor for $\mathrm{Ru}$ and Pd-catalyzed formic acid decomposition. ${ }^{11}$ Nitrite decomposition data were extensively developed during preparation of the parallel report on these same SRAT/SME simulations dealing with SRAT chemistry and acid consumption. The composite nitrite ion data set was fit to a sigmoidal function and plotted against Rh extent of dissolution and hydrogen generation for $0.2 \mathrm{wt} \% \mathrm{Rh}$ and was also plotted against Ru extent of dissolution and hydrogen generation for $0.2 \mathrm{wt} \% \mathrm{Ru}$. The graphical result for $0.2 \mathrm{wt} \% \mathrm{Rh}$ is shown in Figure 38 . 


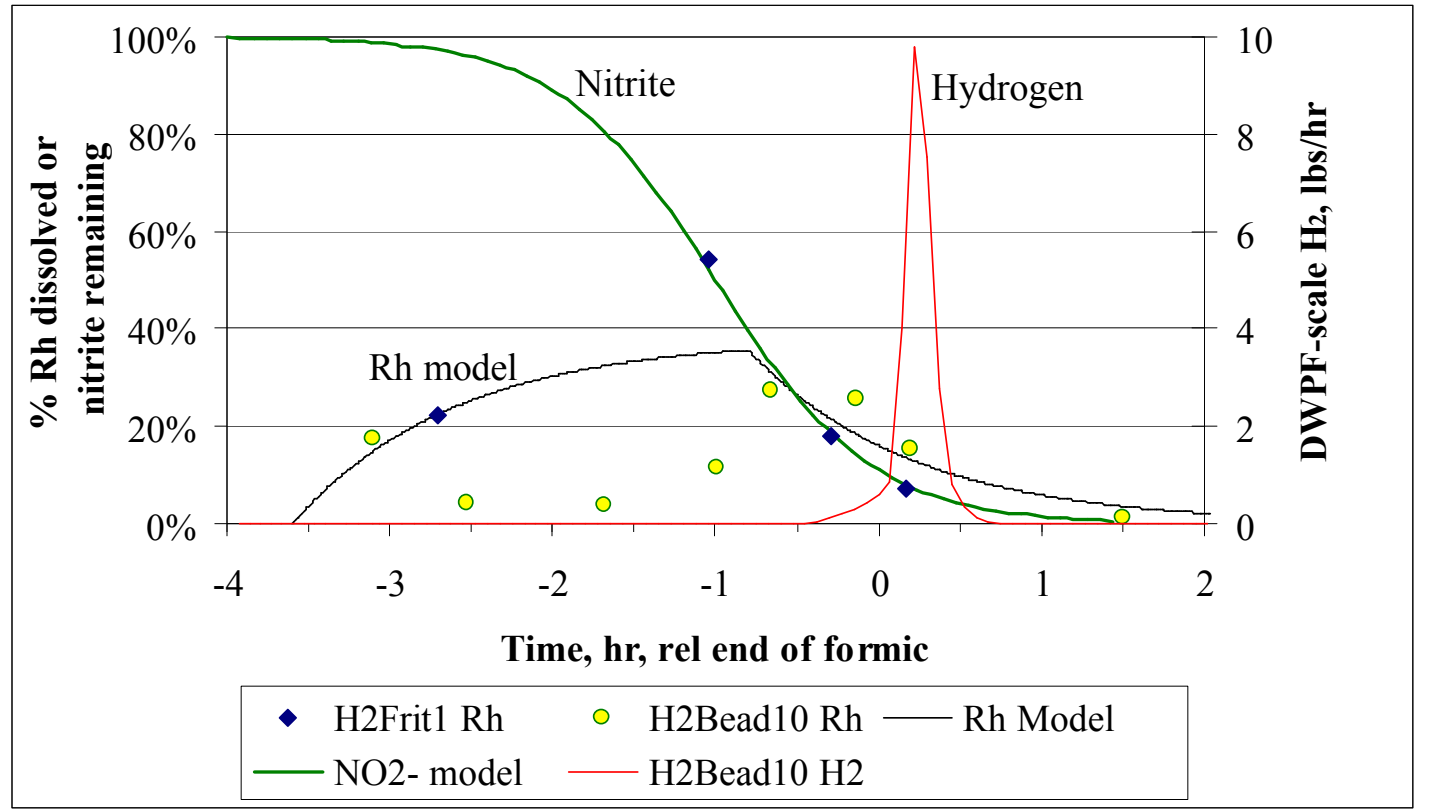

Figure 38. Nitrite and Rh versus hydrogen

The $500-800 \mathrm{mg} / \mathrm{kg}$ of nitrite left around the time of the hydrogen peak corresponds to roughly four moles nitrite per mole of Rh. Significant Rh activity also seemed to end about the time of complete nitrite destruction. The following reaction sequence and selected keywords in the text were drawn from King et al: ${ }^{11}$

$$
\begin{aligned}
& {\left[R h\left(\mathrm{NO}_{2}\right)_{6}\right]^{3-}+2 \mathrm{H}_{2} \mathrm{O} \leftrightarrow\left[R h\left(\mathrm{NO}_{2}\right)_{5}\left(\mathrm{H}_{2} \mathrm{O}\right)\right]^{2-}+\mathrm{NO}_{2}^{-}+\mathrm{H}_{2} \mathrm{O} \leftrightarrow\left[R h\left(\mathrm{NO}_{2}\right)_{4}\left(\mathrm{H}_{2} \mathrm{O}\right)_{2}\right]^{-}+2 \mathrm{NO}_{2}^{-}} \\
& {\left[\mathrm{Rh}\left(\mathrm{NO}_{2}\right)_{4}\left(\mathrm{H}_{2} \mathrm{O}\right)_{2}\right]^{-}+\mathrm{HCO}_{2}^{-} \leftrightarrow\left[R h\left(\mathrm{NO}_{2}\right)_{4}\left(\mathrm{H}_{2} \mathrm{O}\right)\left(\mathrm{HCO}_{2}\right)\right]^{2-}+\mathrm{H}_{2} \mathrm{O}} \\
& {\left[\mathrm{Rh}\left(\mathrm{NO}_{2}\right)_{4}\left(\mathrm{H}_{2} \mathrm{O}\right)\left(\mathrm{HCO}_{2}\right)\right]^{2-} \rightarrow\left[\mathrm{Rh}\left(\mathrm{NO}_{2}\right)_{4}\left(\mathrm{H}_{2} \mathrm{O}\right) \mathrm{H}^{2-}+\mathrm{CO}_{2}\right.}
\end{aligned}
$$

Hydrolysis of this last species, perhaps via acid catalysis, results in $\mathrm{H}_{2}$ evolution:

$$
\left[R h\left(\mathrm{NO}_{2}\right)_{4}\left(\mathrm{H}_{2} \mathrm{O}\right) \mathrm{H}\right]^{2-}+\mathrm{H}_{2} \mathrm{O} \rightarrow\left[R h\left(\mathrm{NO}_{2}\right)_{4}\left(\mathrm{H}_{2} \mathrm{O}\right)(\mathrm{OH})\right]^{2-}+\mathrm{H}_{2}
$$

Formic acid can then reprotonate the complex to give the original diaquo derivative.

$$
\left[\mathrm{Rh}\left(\mathrm{NO}_{2}\right)_{4}\left(\mathrm{H}_{2} \mathrm{O}\right)(\mathrm{OH})\right]^{2-}+\mathrm{HCO}_{2} \mathrm{H} \rightarrow\left[\mathrm{Rh}^{2}\left(\mathrm{NO}_{2}\right)_{4}\left(\mathrm{H}_{2} \mathrm{O}\right)_{2}\right]^{-}+\mathrm{HCO}_{2}^{-}
$$

The sum of the last four reactions gives the appropriate overall reaction: $\mathrm{HCO}_{2} \mathrm{H} \rightarrow \mathrm{H}_{2}+\mathrm{CO}_{2}$ with a formate ion and water molecule canceling out on both sides in addition to all of the complexed rhodium species. It may not be coincidental that the modeled nitrite ion concentration during the period of maximum hydrogen generation was consistent with 4 moles nitrite per mole $\mathrm{Rh}$. There was also some indication that some of the nitrite ion was not in free 
solution in the $\mathrm{Rh}$ tests, in that the nitrite concentration versus time curve that fit the composite nitrite ion data from all of the sixteen tests indicates several hundred $\mathrm{mg} / \mathrm{kg}$ of nitrite should be present during the $\mathrm{Rh}$ peak in $\mathrm{H}_{2}$, but samples from the $0.2 \mathrm{wt} \% \mathrm{Rh}$ runs themselves showed less than $100 \mathrm{mg} / \mathrm{kg}$ were detectable by ion chromatography. A weighted water dilution preparation of the slurry sample would not necessarily destroy the nitro-Rh complex and release the complexed nitrite ions for detection by IC.

At normal SRS waste concentrations of $\mathrm{Rh}$, the concentration of nitrite needed to provide four moles per mole $\mathrm{Rh}$ is below the $100 \mathrm{mg} / \mathrm{kg}$ detection limit of the IC instrument in the presence of large concentrations of nitrate and formate even if the nitrite ions were free to be detected. This is another example of how the testing at high noble metal concentrations allowed observations to be made that would be impossible in normal sludge batch studies with the currently available technology.

The available data do not establish whether a nitro-Rh complex exists, or whether it was exclusively in the supernate phase or was potentially tied up on the surface of the insoluble solids. The data only indicate that $\mathrm{Rh}$ was partitioned between the two phases at the time of the maximum hydrogen generation rate and that there was probably sufficient nitrite to form the complexes postulated by King et al, but there was not so much nitrite that the postulated hydrolysis reaction steps preceding hydrogen generation in the proposed mechanism would be inhibited, i.e. equilibriums shifted to the left away from the diaquo form. Finally, the data indicate that nitrite disappeared nearly entirely about the time that the peak was over in all of the runs with Rh. All of this is circumstantial evidence supporting the proposed reaction scheme, but not hard evidence proving it is correct.

The potential nitrite-rhodium connection to hydrogen generation is somewhat different from the conclusion reached by $\mathrm{Hsu}$ and Ritter, particularly that nitrite must be destroyed before the hydrogen peak. It is possible that nitrite ion was no longer detectable in their system at 2-6 times the molar concentration of $\mathrm{Rh}$ at the smaller noble metal loadings they were using and/or that it was tied up in a nitro-Rh complex and thus not detected by IC. If a nitro-Rh complex is the most active form of hydrogen catalyst in SRS wastes, then addition of $\mathrm{NaNO}_{2}$ after the peak could be expected to reactivate $\mathrm{Rh}$ (assuming that the $\mathrm{Rh}$ has not been reduced by formic acid to metallic form, i.e. it might be possible to delay the addition of $\mathrm{NaNO}_{2}$ past the time when it could be effective at reactivating the $\mathrm{Rh}$ ). Such experiments are part of the planned deactivation testing phase of the hydrogen generation program which are tentatively planned for late 2008 .

In a separate paper, King et al reported that the quantity of hydrogen produced was pseudo firstorder in the rhodium concentration. ${ }^{12}$ Two comparisons were made to test this, one with the frit pair at 0.1 and $0.2 \mathrm{wt} \%$, and a second with the matching bead pair. 


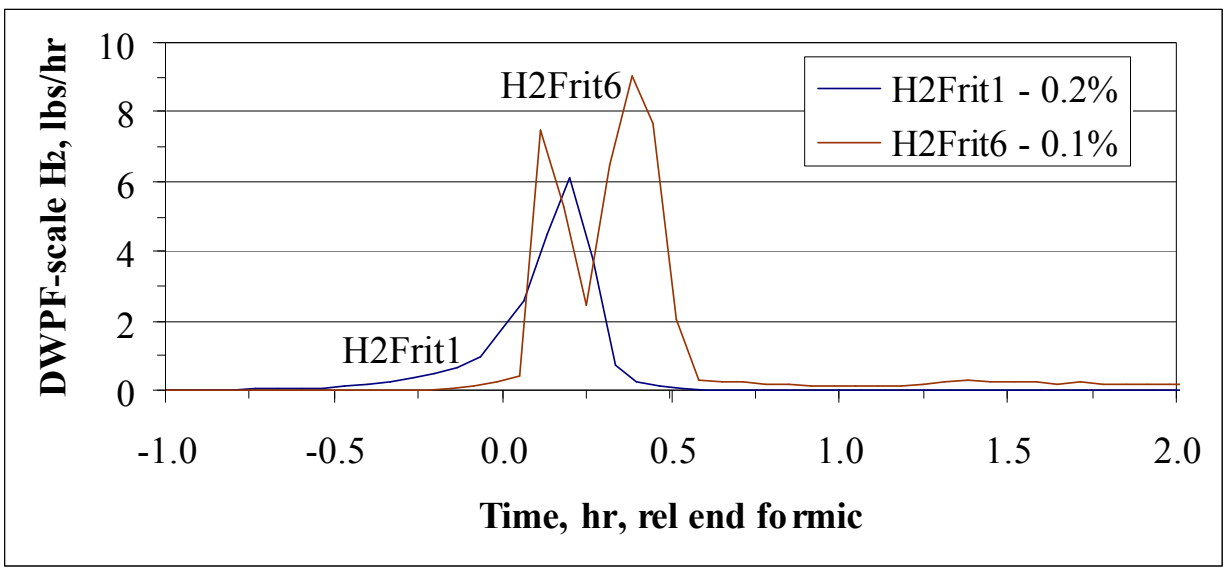

Figure 39. Effect of Rh on hydrogen - 1

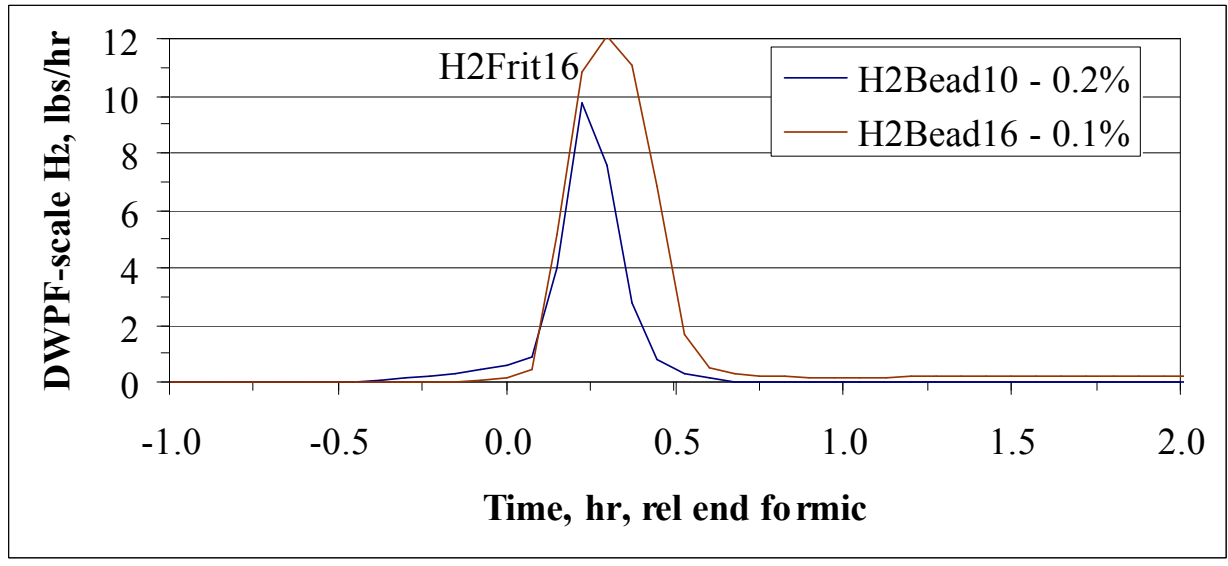

Figure 40. Effect of Rh on hydrogen - 2

In both of the instances tested here, the peak was actually higher in the run with $0.1 \mathrm{wt} \% \mathrm{Rh}$ than in the corresponding run with $0.2 \mathrm{wt} \% \mathrm{Rh}$. These two comparisons do not represent a direct comparison to King's finding, however, since the reaction rates were sufficiently large that the premises necessary for a "pseudo" first-order model (that other significant effects are essentially constant) may have been violated in the H2Bead and H2Frit systems, e.g. the rate of change in nitrite ion or formate ion concentrations could have altered the equilibrium states of the above complexation reactions away from the optimum conditions for maximum hydrogen generation.

Some data were obtained for four different concentration sets of noble metals in the earlier form of noble metal hydrogen study. ${ }^{13,14}$ These tests had all four noble metals, but at more normal concentrations. The peak in hydrogen came later and was generally smaller when the concentrations of the noble metals decreased. There was one pair in the form of noble metal study, however, where all of the noble metal concentrations were decreased, and the peak in hydrogen increased. No confirmation had been obtained until the data above. The form of noble metal tests were performed without mercury, just like the bead-frit tests. More data will be available from the $\mathrm{Rh}-\mathrm{Ru}-\mathrm{Hg}$ matrix study on the impact of changing $\mathrm{Rh}$ concentration on the peak in hydrogen generation. In particular, the new data will not be from a mercury free system. 
King et al also reported on the impact of nitrite ion on Ru-catalyzed $\mathrm{H}_{2}$ generation. ${ }^{12}$ They reported that the presence of nitrite ion inhibited $\mathrm{Ru}$-catalyzed $\mathrm{H}_{2}$ generation. Data for the 0.2 $\mathrm{wt} \% \mathrm{Ru}$ testing were plotted versus nitrite ion concentration and hydrogen generation rate, Figure 41.

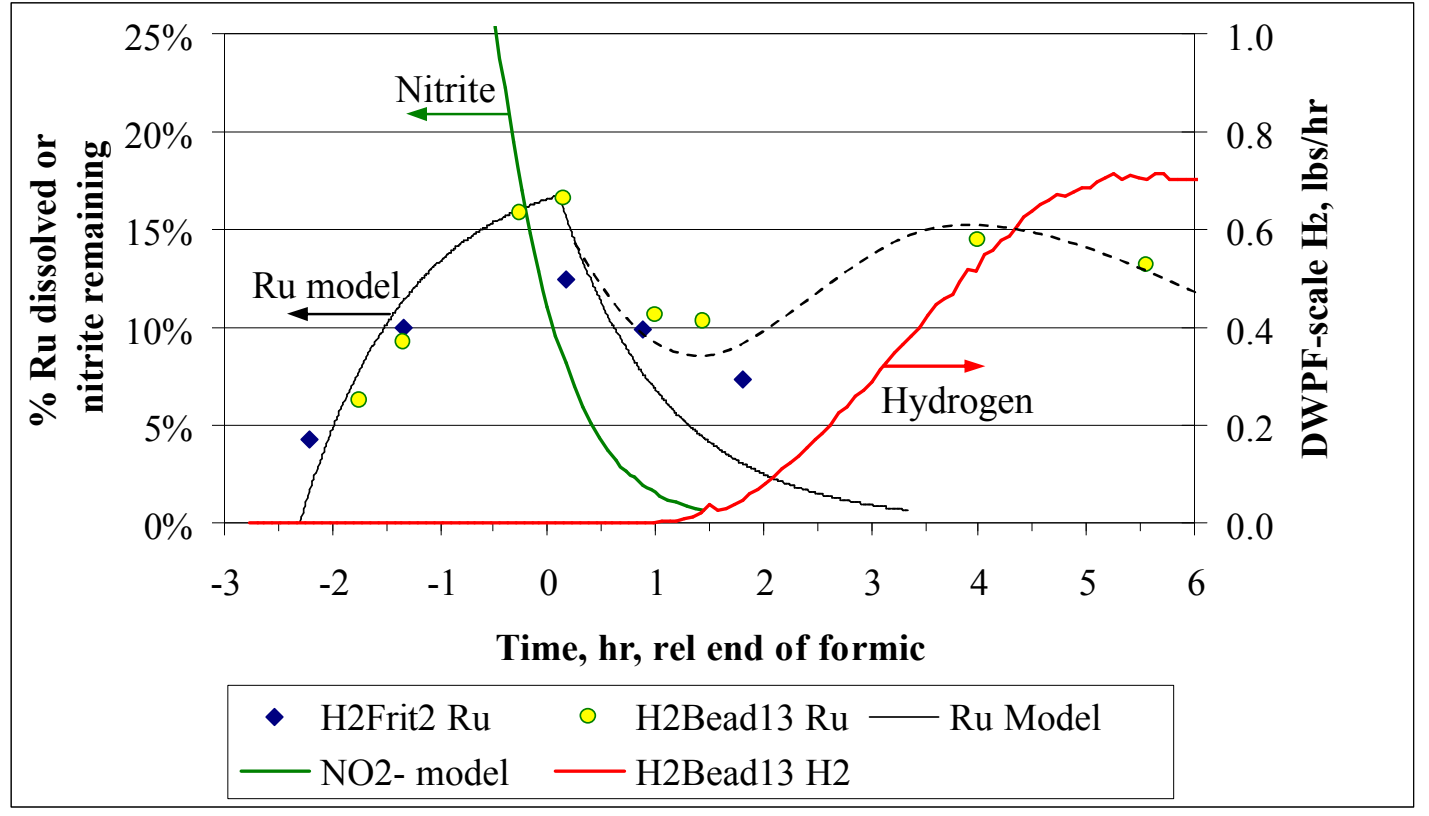

Figure 41. Nitrite and Ru versus hydrogen

The onset of hydrogen in the $\mathrm{Ru}$ only system at +1 hour seems to be fairly closely correlated with the time that nitrite fell below the detection limit of the instrument, i.e. Ru became a good catalyst for hydrogen generation after nitrite was effectively destroyed, i.e. was smaller than $\mathrm{Ru}$ in concentration. This finding also appears to be consistent with the reported chemistry in the literature.

If these conclusions are both valid and generalize to more prototypical sludge systems, then the chances of the Rh-complex driven peak in hydrogen generation occurring simultaneously with the $\mathrm{Ru}$ driven peak in hydrogen generation appear small. $\mathrm{Rh}$ would require nitrite ion to be present, while $\mathrm{Ru}$ would require that nitrite be absent. There is still the issue of $\mathrm{Rh}$ catalytic activity after nitrite is destroyed to consider, which presumably combines with the Ru catalytic generation during reflux and the SME cycle. The Rh catalyst after nitrite ion is consumed must be something other than the nitro complex, since the nitrite is gone, but the form has yet to be determined.

King et al also found that nitrite and nitrate ions are both inhibitors for Pd-catalyzed hydrogen generation. ${ }^{12}$ Data from the bead-frit runs cannot be used to test this finding, since there were large concentrations of nitrate in all tests and no systematic variations to initial nitrite or nitrate concentrations. Pd was obviously less active for hydrogen generation than $\mathrm{Rh}$ and $\mathrm{Ru}$ at comparable loadings in the nitrite and nitrate rich bead-frit sludge feed system. This is at least 
consistent with King's result. For current DWPF concerns, species are expected to be present during CPC processing that essentially mitigate the catalytic ability of Pd to produce hydrogen. Pd was not entirely inactive catalytically in general, however, as the parallel report on SRAT chemistry found a doubling of $\mathrm{N}_{2} \mathrm{O}$ production in the presence of $\mathrm{Pd}$ compared to the baseline test with no noble metals. ${ }^{6}$ Neither Rh nor Ru produced as large an enhancement in the set of comparable runs at $0.2 \mathrm{wt} \%$ noble metal.

It was observed in the second phase of form of noble metal testing that the decline in hydrogen generation following the peak was linearly correlated with both the $\mathrm{Rh}$ and $\mathrm{Ru}$ concentrations measured in the centrifuged supernate by ICP-MS. ${ }^{14}$ Such correlations were not apparent in the data from the two all noble metal runs, H2Frit8 and H2Bead14, though this may have been due to the large formate losses in these two runs. The reason for decreasing hydrogen generation may have shifted from loss of active noble metal species to loss of the main reactant under these extreme conditions. Normally about $75-85 \%$ of the formate added to the SRAT survives to the end of the cycle, but only about $20 \%$ survived in the two all noble metal runs. The Rh-only runs generally had such an abrupt peak that it was difficult to obtain samples from the SRAT during the decline from the peak. Very little Rh remained in the supernate in samples taken an hour or more after the hydrogen peak.

The sampling situation was different for $\mathrm{Ru}$. The hydrogen generation rate peaks came later and lasted longer. In particular, there was a good data set from the two runs at $0.2 \mathrm{wt} \% \mathrm{Ru}, \mathrm{H} 2 \mathrm{Frit} 2$ and $\mathrm{H} 2 \mathrm{Bead13}$. $\mathrm{Ru}$ data from these two tests were plotted versus hydrogen, since seven samples fell in the period of declining rates, Figure 42.

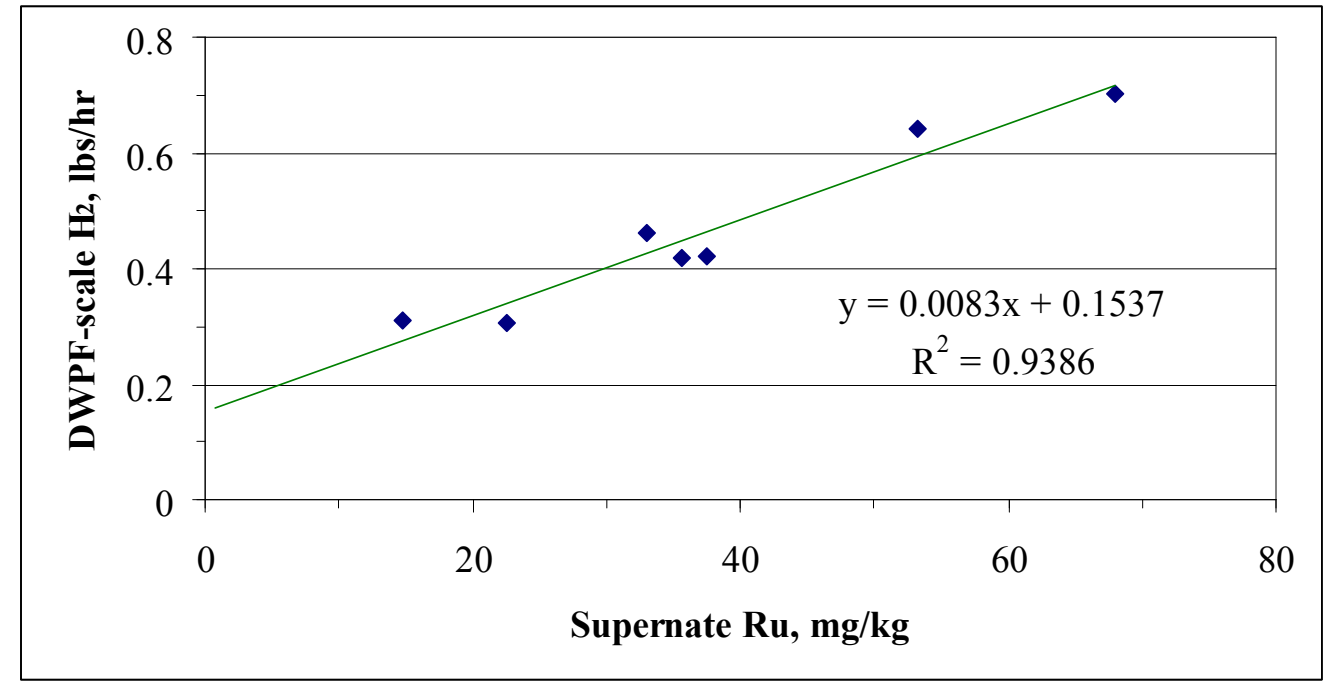

Figure 42. Hydrogen decline as Ru precipitates $(0.2 \mathrm{wt} \%)$

An approximate correlation $\left(\mathrm{R}^{2}=0.94\right)$ was observed between declining $\mathrm{Ru}$ supernate concentration and the falling hydrogen generation rate after the peak. The peak occurred at about +5 hours after formic acid addition. (In the context of the graph above, SRAT processing time increases from right to left, not from left to right. The point at $68 \mathrm{mg} / \mathrm{kg}$ came about 35 minutes after hydrogen generation had peaked.) Neither the trend line above, nor the one for $\mathrm{Ru}$ 
in the form of noble metal testing, came particularly close to the origin. The bead-frit data above, however, are free of the influence of the other noble metals, unlike the data in the form of noble metal study. Limited data were also available from the pair of runs at $0.375 \mathrm{wt} \% \mathrm{Ru}$, and these are shown in Figure 43.

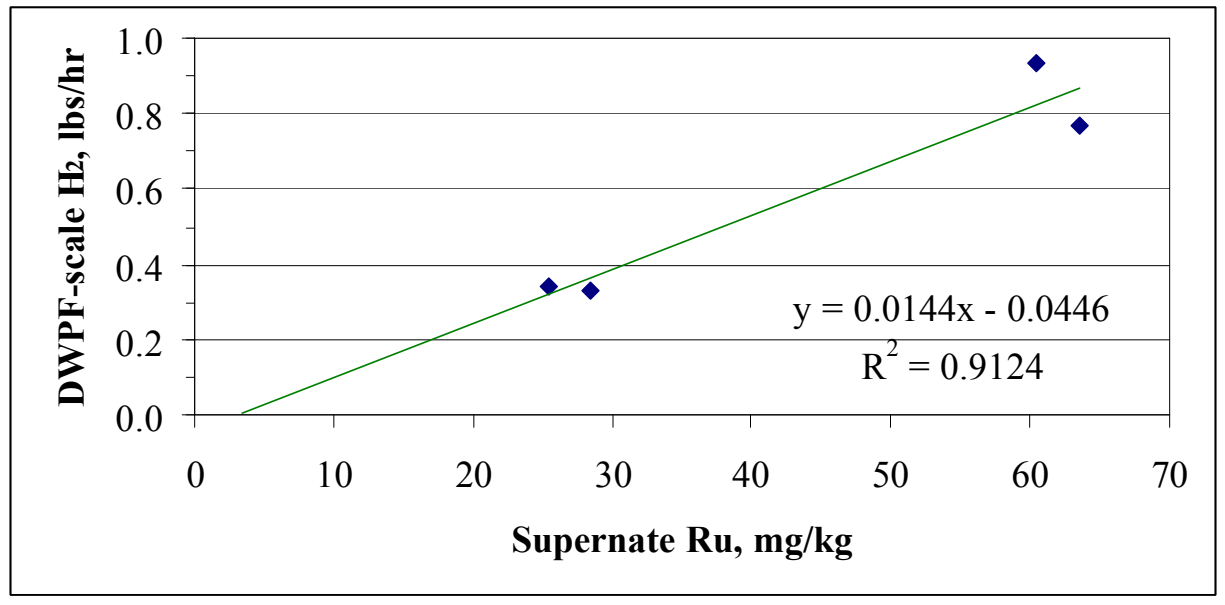

Figure 43. Hydrogen decline as Ru precipitates $(0.375$ wt\%)

Three of the four data points come from H2Frit5. The quality of the linear correlation was not particularly strong, but the same trend was repeated of falling hydrogen generation with falling $\mathrm{Ru}$ concentration detected in the supernate phase. Therefore, the new bead-frit Ru data supports the conclusion in the form of noble metal testing that there is some correlation between postpeak hydrogen generation rate and the $\mathrm{Ru}$ concentration detected in centrifuged supernate samples (dissolved or dispersed very fine colloidal particles remains an open question).

There have been hints in the noble metal data that these linear fits are being made on the transition between two different active forms of $\mathrm{Ru}$. The bead-frit tests allowed the timeline to be extended into the SME cycle (the form of noble metal tests were SRAT cycle only tests). Two SME cycle samples were evaluated in H2Frit2 and in H2Frit5. One sample was taken in between the two frit dewaterings prior to the addition of the second frit-water-formic acid slurry, and the second sample was taken of the SME product slurry. The addition of significant insoluble frit caused the bulk concentration of soluble $\mathrm{Ru}$ to differ by progressively more from the supernate concentration, so an increasing supernate concentration of Ru does not necessarily translate into an increasing slurry concentration of soluble $\mathrm{Ru}$. The numbers below are supernate concentrations. Data exist that could convert the SME product supernate concentrations to slurry concentrations, but the supporting data were not obtained to convert the between frit addition supernate concentrations to slurry concentrations (no density or wt $\%$ soluble and insoluble data were obtained at the time of the mid-SME sample).

In $\mathrm{H} 2 \mathrm{Frit} 2(0.2 \mathrm{wt} \% \mathrm{Ru})$, the SME results were 25 (before second frit addition) and $28 \mathrm{mg} \mathrm{Ru} / \mathrm{kg}$ supernate (in SME product) with peaks during dewatering of 0.34 and $0.42 \mathrm{lbs} \mathrm{H}_{2} / \mathrm{hr}$. In H2Frit5 there were 20 and $31 \mathrm{mg} \mathrm{Ru} / \mathrm{kg}$ supernate in the intermediate SME and SME product samples respectively. Peaks of 0.49 and $0.61 \mathrm{lbs}_{2}$ per hour were associated with the two dewaterings 
before and between the two samples. While the two trend lines in Figure 42 and Figure 43 show falling $\mathrm{H}_{2}$ with falling $\mathrm{Ru}$ concentration until one or the other hits zero, the actual decline in $\mathrm{Ru}$ concentration stopped near the end of the SRAT cycle, and consequently the hydrogen generation rate at boiling also stopped falling. 
WSRC-STI-2008-00002

Revision 0

This page intentionally left blank. 


\subsection{CONCLUSIONS}

The results covered in this report confirm many previous hypotheses and include new findings with respect to the noble metal interaction with hydrogen. Most, if not all, of these are expected to apply to normal DWPF sludge batches. The SRAT/SME simulations in this study, however, were intentionally conducted at noble metal concentrations above what is expected for normal sludge batches in order to produce suitable samples for x-ray absorption spectroscopy to better understand hydrogen/noble metal interactions. The higher noble metal concentrations also facilitated analytical accuracy by providing relatively stronger noble metal signals. The majority of the testing did not include mercury, so its potential impact is absent from most of the conclusions. It is possible that some of the chemical and processing results may not translate to more typical noble metal concentrations. For example, equilibrium limited dissolution may have occurred for a noble metal in a test pair, when this might never happen at the lower concentrations of normal sludge batches.

Certain hypotheses and findings from previous studies were supported or confirmed by the beaded frit melter feed preparation tests. Timing of hydrogen generation events was reproduced very well within the pairs of runs, e.g. the onset of hydrogen, peak in hydrogen, etc. seemed to occur at nearly identical times. Peak generation rates and total SRAT masses for hydrogen were approximately reproduced within each of the eight cases. Comparable results for other off-gas species data were reproduced much better than hydrogen. The extent of the reproducibility of the results validates the conclusions that were drawn from the data. Supported and confirmed hypotheses include:

- Sludge without $\mathrm{Rh}, \mathrm{Ru}$, and $\mathrm{Pd}$ produced no catalytic activity for hydrogen generation. This confirms the results of a limited set of prior tests without noble metals.

- During single noble metal tests at $0.2 \mathrm{wt} \%$, rhodium produced the maximum SRAT hydrogen generation rate, while ruthenium was responsible for forming the largest total hydrogen mass. Palladium and silver made comparatively minimal amounts of hydrogen.

- Doubling Rh led to a decrease in the peak hydrogen generation rate in two pairs of the new runs. This was the first confirmation of a single result from the 2005 form of noble metal testing.

- Increasing Ru by $87 \%$ increased the SRAT peak hydrogen generation rate about $100 \%$ and the total mass of hydrogen produced by $30-50 \%$. It was expected that more Ru would produce more $\mathrm{H}_{2}$ everything else being equal.

- Historically, nitrite destruction was believed to be a prerequisite for all noble metal catalyzed hydrogen generation. In this testing, nitrite destruction appeared to be a prerequisite for the initiation of Ru-catalyzed hydrogen generation.

- Nitrite destruction data and hydrogen data from the testing with $\mathrm{Rh}$ suggested that sufficient nitrite remained for a nitro-Rh complex to be present at the time of the peak hydrogen generation rate, i.e. $\mathrm{Rh}$ appeared to activate while the nitrite concentration was still comparable to the Rh concentration. Supernate concentration data indicated that most of the $\mathrm{Rh}$ was no longer in the supernate. Nitro-Rh complexes were proposed as the most active catalyst for hydrogen generation in the University of Georgia study in 1991-1992. 
- The hydrogen generation rate declined nearly linearly as the supernate Ru concentration declined following the peak. The $\mathrm{Rh}$ peak and decline occurred too rapidly to obtain comparable data. Similar behavior was observed for both $\mathrm{Rh}$ and $\mathrm{Ru}$ in the 2005 form of noble metal testing.

- SME cycle hydrogen results depended greatly on SRAT cycle behavior. Generally, the SME cycle began slightly higher than where the SRAT cycle ended in terms of hydrogen generation rate due to the formic acid added with the first frit addition.

Major new noble metal dissolution and hydrogen generation correlations and findings from these tests include:

- Insoluble Rh dissolved during SRAT acid addition and was precipitating about the time of the maximum hydrogen generation rate.

- Nitrite was apparently present in small quantities during the period of peak hydrogen generation with $\mathrm{Rh}$. Circumstantial evidence supported a nitro-Rh complex catalyst that activated toward the end of nitrite destruction and deactivated via destruction of the nitrite groups that sustained the complex.

- Palladium dissolved before $\mathrm{Rh}$ and $\mathrm{Ru}$ during SRAT acid addition, and then began precipitating before significant hydrogen generation. Pd-induced hydrogen generation was about 20 times less than $\mathrm{Rh}$ or Ru at the same noble metal mass loading.

- $\mathrm{Ru}$ began dissolving about the same time as $\mathrm{Rh}$ and then also began precipitating. Data indicate that $\mathrm{Ru}$ underwent a second dissolution-precipitation sequence during the SRAT cycle. The second sequence generally corresponded with the onset, peak, and decline of hydrogen generation during Ru testing and occurred after nitrite destruction.

- Silver did not appear to dissolve. The Ag tests produced more hydrogen than the no noble metal tests indicating that Ag was a weak catalyst for hydrogen generation.

- Combining all four noble metals led to a smaller SRAT peak hydrogen generation rate than in the corresponding runs with matching concentrations of either $\mathrm{Rh}$ or $\mathrm{Ru}$ alone. The four noble metal combination, however, destroyed the most formate.

- Mercury, initially at $1.5 \mathrm{wt} \%$ in the total solids, did not inhibit hydrogen generation at 0.2 $\mathrm{wt} \% \mathrm{Ru}$. Hydrogen generation seemed to begin sooner when mercury was present, however, and nitrite appeared to be destroyed sooner as well.

The rhodium and palladium data strongly suggest that a change in the precipitated form of these noble metals was occurring during acid addition. The new forms began to appear prior to hydrogen generation. One hypothesis is that the freshly precipitated forms were the active catalyst species based on the alignment of the hydrogen generation curves with the extent of dissolution curves. Under this hypothesis, nitro-complexes are not needed to explain hydrogen generation. Ruthenium dissolution behavior was more complex than expected. It appeared that a freshly precipitated form of $\mathrm{Ru}$ was formed during formic acid addition from the dissolving $\mathrm{Ru}$ in the starting sludge. This precipitated $\mathrm{Ru}$ compound subsequently began to dissolve and precipitate into a second new insoluble form. It was during this latter process that hydrogen was observed when the other noble metals were absent. The formation of the second insoluble Ru form took more time than the formation of the $\mathrm{Pd}$ and $\mathrm{Rh}$ forms, which may explain the delay in the onset and peak times for the $\mathrm{Ru}$ runs relative to the $\mathrm{Pd}$ and $\mathrm{Rh}$ runs. The formation of the second $\mathrm{Ru}$ species also seemed to coincide with the elimination of nitrite from the system. It was 
also likely that the concentration of the catalytically active second form of $\mathrm{Ru}$ may never approach $100 \%$ of the total $\mathrm{Ru}$ in the system, since it was formed so slowly. This in turn may explain why the peak generation rates with $\mathrm{Ru}$ are lower than for an equivalent quantity of Rh.

The value of the bead-frit runs to the hydrogen generation program was considerable. Generally, single noble metal tests are not performed as part of flowsheet studies, qualification studies, etc. Many past results that were in the "one of a kind" category were reproduced here. This in turn will help with the critique of historical hydrogen generation data phase of the program. The parallel task of examining SRAT chemistry and acid consumption as a function of time provided data related to nitrite ion concentration as a function of time that could be compared to the noble metal dissolution and hydrogen generation rate data. The nitrite data suggest that the magnitude of the Rh-driven peak generation rate could be limited by catalyzed destruction of nitrite ion. This mechanism could explain why doubling the $\mathrm{Rh}$, or combining $\mathrm{Rh}$ with other noble metals, led to smaller peak hydrogen generation rates. It was accelerated destruction of nitrite by $\mathrm{Rh}$ and/or other noble metals that helped to extinguish the primary catalytic hydrogen generation reaction due to a nitro-Rh complex. This block of data on $\mathrm{Rh}$ and nitrite ion concentration provides the strongest circumstantial evidence yet obtained to justify a mechanism for both activation and deactivation of the catalyst producing the peak hydrogen generation rate. 
WSRC-STI-2008-00002

Revision 0

This page left blank. 


\subsection{PATH FORWARD}

A separate study is already underway to evaluate the statistical significance of interaction effects between $\mathrm{Rh}, \mathrm{Ru}$, and $\mathrm{Hg}$ using 4-L scale SRAT simulations at more typical concentration ranges for the noble metals. The data reported here support the hypothesis that this interaction study is needed to better understand how these three species impact hydrogen generation and that the focus should be on $\mathrm{Rh}$ and $\mathrm{Ru}$ of the four noble metals.

A separate study into catalytic deactivation mechanisms is part of the TTQAP scope of work. These experiments have been designed to screen potential deactivation mechanisms by spiking selected hydrogen promoting chemicals into the SRAT following the peak in hydrogen generation. The extent to which the hydrogen generation reaction(s) are accelerated would be observed. The goal is to identify the species controlling the decline in hydrogen generation by a process of elimination. This test series includes mercury.

Some additional experimental and sample work remains to be completed that is related to the single noble metal testing at high concentrations for x-ray absorption spectroscopy. Current plans include two more SRAT simulations to generate samples containing one or more noble metals plus mercury. The planned tests will be at 4-L scale like the one run completed so far with $\mathrm{Ru}$ and $\mathrm{Hg}$. The bead-frit SRAT/SME processing data indicate that the focus should be on $\mathrm{Rh}, \mathrm{Ru}$, and $\mathrm{Hg}$. One run will include $\mathrm{Rh}$ and $\mathrm{Hg}$ with no other noble metals, and the other run will be all four noble metals plus $\mathrm{Hg}$ (the second run might omit Ag and $\mathrm{Pd}$ ). The final choices will depend on the findings and recommendations in the initial XAS report.

The resolution of two analytical issues is still pending. SRNL has scope from the prior hydrogen TTQAP to duplicate a Shielded Cells run using simulant with coprecipitated noble metals. Various titration approaches of slurry samples to $\mathrm{pH}$ seven and the measurement of total inorganic carbon in the slurry are the two issues being worked. The duplication of a Cells SRAT/SME run with coprecipitated noble metal simulants will not be pursued until these issues are satisfactorily resolved or a suitable work around has been identified. The form of noble metal testing phase of the hydrogen program in 2004-2005 demonstrated that coprecipitated noble metals activated differently from trimmed noble metals. Data in this report indicate that the timing of nitrite destruction relative to rhodium activation could be a critical aspect of catalytic hydrogen generation.

The current TTQAP includes a critical review of past hydrogen generation data, hypotheses, etc. with the goal of issuing a position paper on what data appears to be relevant to current process operations. This task is a paper study. Data from the sixteen bead-frit runs, however, have helped clarify some of the issues.

Other issues remaining to be investigated include:

- Effect of Pd and Ag on Rh and Ru catalyzed hydrogen generation. The data here show that these two species are not significant hydrogen generators on their own, but they may impact $\mathrm{Rh}$ and $\mathrm{Ru}$ catalyzed hydrogen generation, for example by changing the rate of nitrite destruction. 
- A SRAT heel impact study was proposed. DWPF starts the SRAT with formate ion in the receipt sample, while lab-scale tests lack any by-products of the SRAT cycle such as reduced $\mathrm{Mn}$, reduced $\mathrm{Hg}$, deactivated noble metals, etc. DWPF seems to produce less hydrogen than the qualification sample testing would indicate.

- Studies were also proposed to study particle morphology effects, to study nitrite ion effects, and to study process flowsheet improvements such as eliminating formic acid from the frit slurry.

- The effect of the bulk sludge species on hydrogen generation and noble metal catalysis will be investigated following completion of the sludge simulant matrix study with some additional SRAT runs using the simulant matrix feedstocks.

- Porous substrates containing metal binding ligands have been proposed as a means of trapping the noble metals in a non-catalytically active form during SRAT processing. This approach needs to be investigated with a simple scoping SRAT run as a minimum.

- Finally, it has been recognized that too much excess acid is the reason that the DWPF hydrogen limit would be exceeded. Work on refining the DWPF stoichiometric acid equation to reduce uncertainty and limit excess acid remains a sound strategy for controlling hydrogen generation. 


\subsection{REFERENCES}

\footnotetext{
${ }^{1}$ Plodinec, M. J., Report of the Hydrogen Generation Review Panel - Review of Hydrogen Generation in the DWPF. March 15, 2007.

${ }^{2}$ Koopman, D. C., Task Technical and Quality Assurance Plan - Catalytic Hydrogen Generation Program. WSRC-RP-2007-00338, SRNL, Aiken, SC 29808 (April 2007).

${ }^{3}$ Koopman, D. C., Analytical Study Plan for Catalytic Hydrogen Generation Program. SRNL-PSE2007-00154, August 9, 2007.

${ }^{4}$ Fox, E. B. and B. R. Pickenheim, Speciation of Ru and Hg during Simulated Nuclear Waste Processing, WSRC-STI-2008-00xxx, SRNL, Aiken, SC 29808 (May 2008).

${ }^{5}$ Pickenheim, B. R., Task Technical and Quality Assurance Plan - Use of Beads to Replace Frit in DWPF. WSRC-RP-2007-00199, SRNL, Aiken, SC 29808 (March 2007).

${ }^{6}$ Koopman, D. C., SRAT Chemistry and Acid Consumption during Simulated DWPF Melter Feed Preparation, WSRC-STI-2008-00131, SRNL, Aiken, SC, 29808 (May 2008).

${ }^{7}$ Koopman, D. C., Preparation, Characterization, and Preliminary SRAT/SME Testing of a Simulant for the Hydrogen and Rheology Modifiers Program. SRNL-PSE-2007-00191, September 11, 2007.

${ }^{8}$ Koopman, D. C. and M. A. Baich, Review of Catalytic Hydrogen Generation in the DWPF Chemical Processing Cell, Part II, WSRC-TR-2005-00206, SRNL, Aiken, SC, 29808 (August 2005).

${ }^{9}$ Koopman, D. C., Review of Catalytic Hydrogen Generation in the Defense Waste Processing Facility (DWPF) Chemical Processing Cell, WSRC-TR-2002-00034, SRNL, Aiken, SC, 29808 (December 2004).

${ }^{10}$ Hsu, C. S. and J. A. Ritter, Study on Hydrogen Generation During Treatment of SRS High Level Radioactive Sludge Simulant with Formic Acid, WSRC-MS-92-270, WSRC, Aiken, SC, 29808 (August 1992).

${ }^{11}$ King, R.B. and N. K. Bhattacharrya, Catalytic reactions of formate 4. A nitrite-promoted rhodium(III) catalyst for hydrogen generation from formic acid in aqueous solution. Inorganica Chimica Acta 237 (1995) 65-69.

${ }^{12}$ King, R. B., N. K. Bhattacharrya, and K. D. Wiemers, Noble Metal Catalyzed Hydrogen Generation from Formic Acid in Nitrite-Containing Simulated Nuclear Waste Media, Environ. Sci. Technol. 30 (1996) 1292-1299.

${ }^{13}$ Koopman, D. C., DWPF Hydrogen Generation Study - Form of Noble Metal Testing, WSRC-TR2005-00286, SRNL, Aiken, SC, 29808 (July 2005).

${ }^{14}$ Koopman, D. C., DWPF Hydrogen Generation Study: Phase II - Form of Noble Metal Testing, WSRC-TR-2005-00420, SRNL, Aiken, SC, 29808 (December 2005).
} 
WSRC-STI-2008-00002

Revision 0

This page intentionally left blank. 


\subsection{ACKNOWLEDGEMENTS}

The author wishes to acknowledge the contributions of a number of people. One key element of this report was the noble metal sample data. Obtaining the samples during the process simulations added a considerable burden to the work load of the ACTL laboratory technicians. The efforts of J. W. DuVall, V. J. Williams, I. A. Reamer, R. J. (Phyllis) Workman, T. O. Burckhalter, and D. M. Marsh are especially appreciated in this regard. Various researchers assisted the technicians with data logging during the busier periods. Consequently thanks are also due to B. R. Pickenheim, M. E. Stone, E. B. Fox, and J. Abramczyk. Once the samples were pulled, they were mostly sent to Analytical Development. The high quality of the bulk of the ICP-MS data from L. C. Johnson was critical to developing some of the conclusions in this report, and his efforts were greatly appreciated. Additional analytical support was provided by the Process Science Analytical Lab, including D. R. Best, W. A. Thomas, and P. T. Simmons. Finally, a report on hydrogen requires gas composition data. Developing and validating the GC gas composition data was made more difficult by some anomalous behavior that developed in the instruments during processing. This was a relatively major issue during the eight frit runs. Thanks are due to J. M. Pareizs and M. F. Williams who maintained the GCs during the testing and reprocessed the GC data after the runs were over. 


\section{Distribution:}

J. C. Griffin, 773-A

D. A. Crowley, 999-W

C. C. Herman, 773-42A

A. B. Barnes, 999-W

B. J. Giddings, 786-5A

S. D. Fink, 773-A

N. E. Bibler, 773-A

J. E. Occhipinti, 704-S

R. T. McNew, 704-27S

J. F. Iaukea, 704-30S

J. W. Ray, 704-S

T. L. Fellinger, 704-26S

H. B. Shah, 766-H

J. M. Gillam, 766-H

B. A. Hamm, 766-H

B. A. Davis, 704-27S

E. B. Fox, 999-2W

B. R. Pickenheim, 999-W

M. E. Stone, 999-W

R. E. Eibling, 999-W

D. P. Lambert, 999-W

J. M. Pareizs, 773-A

S. H. Reboul, 773-42A

C. J. Bannochie, 773-42A

J. D. Newell, 999-W

M. F. Williams, 999-1W

D. R. Best, 786-A 